\title{
Cholinergic Modulation of Glial Function During Aging and Chronic Neuroinflammation
}

\author{
Rashmi Gamage ${ }^{1 \dagger}$, Ingrid Wagnon ${ }^{1 \dagger}$, Ilaria Rossetti ${ }^{1}$, Ryan Childs ${ }^{1}$, Garry Niedermayer ${ }^{2}$, \\ Rose Chesworth ${ }^{3}$ and Erika Gyengesi ${ }^{1 *}$
}

${ }^{1}$ Department of Pharmacology, School of Medicine, Western Sydney University, Penrith, NSW, Australia, ${ }^{2}$ School of Science, Western Sydney University, Penrith, NSW, Australia, ${ }^{3}$ School of Medicine, Western Sydney University, Penrith, NSW, Australia

\section{OPEN ACCESS}

Edited by:

Diego Gomez-Nicola, University of Southampton,

United Kingdom

Reviewed by:

Martin Gerbert Frasch,

University of Washington,

United States

Andrew David Greenhalgh, INRA UMR1286 Laboratoire

NutriNeuro, France

*Correspondence:

Erika Gyengesi

e.gyengesi@westernsydney.edu.au

tThese authors have contributed equally to this work

Specialty section: This article was submitted to Non-Neuronal Cells,

a section of the journal

Frontiers in Cellular Neuroscience

Received: 30 June 2020 Accepted: 07 September 2020

Published: 15 October 2020

Citation:

Gamage R, Wagnon I, Rossetti I, Childs $R$, Niedermayer $G$

Chesworth $R$ and Gyengesi $E$ (2020) Cholinergic Modulation of Glial Function During Aging and Chronic Neuroinflammation. Front. Cell. Neurosci. 14:577912. doi: 10.3389/fncel.2020.577912
Aging is a complex biological process that increases the risk of age-related cognitive degenerative diseases such as dementia, including Alzheimer's disease (AD), Lewy Body Dementia (LBD), and mild cognitive impairment (MCl). Even non-pathological aging of the brain can involve chronic oxidative and inflammatory stress, which disrupts the communication and balance between the brain and the immune system. There has been an increasingly strong connection found between chronic neuroinflammation and impaired memory, especially in AD. While microglia and astrocytes, the resident immune cells of the central nervous system (CNS), exerting beneficial effects during the acute inflammatory phase, during chronic neuroinflammation they can become more detrimental. Central cholinergic circuits are involved in maintaining normal cognitive function and regulating signaling within the entire cerebral cortex. While neuronal-glial cholinergic signaling is anti-inflammatory and anti-oxidative, central cholinergic neuronal degeneration is implicated in impaired learning, memory sleep regulation, and attention. Although there is evidence of cholinergic involvement in memory, fewer studies have linked the cholinergic anti-inflammatory and anti-oxidant pathways to memory processes during development, normal aging, and disease states. This review will summarize the current knowledge of cholinergic effects on microglia and astroglia, and their role in both anti-inflammatory and anti-oxidant mechanisms, concerning normal aging and chronic neuroinflammation.

\footnotetext{
Abbreviations: $\mathrm{ACh}$, acetylcholine; $\mathrm{AChE}$, acetylcholine esterase; $\mathrm{AD}$, Alzheimer's disease; ANS, autonomic nervous system; APOE4, apolipoprotein E4; ATP, adenosine tri-phosphate; A $\beta$, Amyloid $\beta$; BBB, the blood-brain barrier; BDNF, brain-derived neurotrophic factor; BF, basal forebrain; BS, Brainstem; CCR, CC chemokine receptor; ChAT, choline acetyltransferase; CNS, central nervous system; COX-2, cyclooxygenase-2; CSF, cerebrospinal fluid; CXCL, CXC motif ligand; DMXBA, 3-[(2, 4-dimethoxy)benzylidene]-anabaseine dihydrochloride; GABA, $\gamma$-aminobutyric acid; GDNF, glial cell line-derived neurotrophic factor; GFAP, glial fibrillary acidic protein; HO1, heme oxygenase; IL, interleukin; INF, interferon; IP, inducible protein; IP3, inositol-3-phosphate; IкB, an inhibitor of nuclear factor $\kappa B$; JAK, Janus kinase; JNK, c-jun N-terminal kinase; LBD, Lewy body dementia; LPS, lipopolysaccharide; mAChR, muscarinic acetylcholine receptor; MAPK, mitogen-activated protein kinase; MHC, major histocompatibility complex; MLA, methyllycaconitine; MPTP, 1-methyl-4-phenyl-1,2,3,6-tetrahydropyridine; nAChR, nicotinic acetylcholine receptor; NADPH, nicotinamide adenine dinucleotide phosphate; NF-кB, nuclear factor-кB; NO, nitric oxide; Nrf2, nuclear factor erythroid 2-related factor 2; ORM2, orosomucoid 2; PAM, positive allosteric modulator; PD, Parkinson's disease; PFC, the pre-frontal cortex; PI3K, phosphatidylinositol-3-kinase; PLC, Phospholipase C; PNS, peripheral nervous system; ROS, reactive oxygen species; STAT, signal transducer and activator of transcription; TGF, transforming growth factor; TNF, tumor necrosis factor: TQS, 3a,4,5,9b-Tetrahydro-4-(1-naphthalenyl)-3H-cyclopentan[c]quinoline-8-sulfonamide; VTA, a ventral tegmental area $\alpha 7 \mathrm{nAChR}, \alpha 7$ nicotinic acetylcholine receptor.
} 
We provided details on how stimulation of $\alpha 7$ nicotinic acetylcholine ( $\alpha 7 \mathrm{nACh}$ ) receptors can be neuroprotective by increasing amyloid- $\beta$ phagocytosis, decreasing inflammation and reducing oxidative stress by promoting the nuclear factor erythroid 2-related factor 2 (Nrf2) pathways and decreasing the release of pro-inflammatory cytokines. There is also evidence for astroglial $\alpha 7 \mathrm{nACh}$ receptor stimulation mediating anti-inflammatory and

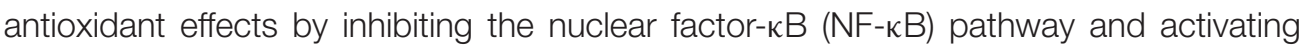
the Nrf2 pathway respectively. We conclude that targeting cholinergic glial interactions between neurons and glial cells via $\alpha 7 n A C h$ receptors could regulate neuroinflammation and oxidative stress, relevant to the treatment of several neurodegenerative diseases.

Keywords: cholinergic

system,

microglia,

astrocytes,

basal

forebrain,

neuroinflammation aging, neurodegeneration

\section{INTRODUCTION}

\section{Acetylcholine Receptors in the CNS}

Acetylcholine (ACh) was one of the first identified neurotransmitters (Valenstein, 2002) and has been shown to modulate many physiological functions within the peripheral nervous system (PNS), the autonomic nervous system (ANS), and the central nervous system (CNS). In the CNS, ACh plays a crucial role in modulating diverse functions including cognition, attention, and arousal (English and Jones, 2012). This neurotransmitter is synthesized by choline acetyltransferase (ChAT) along with choline and acetyl coenzyme A as substrates. Signal transmission by this neurotransmitter is terminated through rapid hydrolysis of $\mathrm{ACh}$ into choline and acetic acid by acetylcholinesterase (AChE; English and Jones, 2012). ACh receptors are classified according to binding affinity to their ligands and can be divided into muscarinic (mAChR) or nicotinic receptors ( $\mathrm{nAChR}$ ).

Muscarinic receptors, named from M1 to M5, are metabotropic $G$ protein-coupled receptors which are further subdivided according to the sub-type of associated $\mathrm{G}_{\alpha}$ subunit. The M1, M3, and M5 receptors are coupled through $G_{q / 11}$ proteins to upregulate phospholipase C (PLC), inositol triphosphate, and intracellular calcium. M2 and M4 receptors deactivate adenylate cyclase and activate $\mathrm{K}^{+}$channels through actions involving $G_{i}$ (Akaike and Izumi, 2018). Muscarinic receptors are involved in cholinergic signal transduction in the CNS, autonomic ganglia, smooth muscles, and other parasympathetic end organs (Liu et al., 2007). They are also widely expressed in non-neuronal cells, such as epithelial, endothelial, muscle fibers, and CNS glial cells (microglia and astrocytes; Liu et al., 2007, 2016; Guizzetti et al., 2008).

Nicotinic acetylcholine receptors, which are the focus of this review, are ionotropic cation channels permeable to $\mathrm{Na}^{+}$and $\mathrm{K}^{+}$ and are abundantly expressed in skeletal muscle and the CNS. These receptors belong to the cysteine-loop (Cys-loop) receptor ligand-gated ion channel superfamily and are extensively involved in cognitive and locomotive processes (Lester et al., 2004). Neuronal nAChRs are cation channels which can either be homopentamers formed of $\alpha 7-\alpha 9$ subunits, or heteropentamers formed of $\alpha \beta$ subunits combinations including $\alpha 2-\alpha 6$ and $\beta 2-\beta 4$, or combinations of $\alpha 9 / \alpha 10$ subunits (Dani and Bertrand, 2007). The most abundant and widely distributed nAChR subtypes in the human CNS are $\alpha 4 \beta 2$ and $\alpha 3 \beta 4$ heteromers, and $\alpha 7$ homomers ( $\alpha 7 \mathrm{nAChR}$; Pym et al., 2005). $\alpha 7 \mathrm{nAChR}$ is expressed in both neurons in the cortex and hippocampus, two structures related to cognition, attention, and memory tasks (Foucault-Fruchard and Antier, 2017) and non-neuronal cells, including microglia, astrocytes, oligodendrocytes, and brain endothelial cells (Dani and Bertrand, 2007; Cortes et al., 2017a,b; Morioka et al., 2018; Cao S. et al., 2019). Neuronal nAChRs have been studied extensively as potential drug targets for neurological disorders such as Alzheimer's disease (AD) and Parkinson's disease (PD; O'Neill et al., 2002; Lester et al., 2004). Recently, expression of these receptors in peripheral immune cells and CNS glial cells have attracted attention due to their involvement in neuroinflammation and neurodegenerative disease via the "cholinergic anti-inflammatory pathway," as introduced later (De Jonge and Ulloa, 2007; Fujii et al., 2017; Takata et al., 2018).

\section{Structure and Function of the Cholinergic System}

Cholinergic circuits in the CNS are involved in maintaining normal cognitive function and regulating signaling within the entire cerebral cortex. The four main mammalian brain regions with the highest expression of cholinergic neurons are: (1) the brainstem pedunculopontine and lateral dorsal tegmental nuclei projecting to the thalamus; (2) a subset of the thalamic nuclei; (3) the striatum interneurons, which are involved in suppressing dopamine release; and (4) the basal forebrain (BF) nuclei (Ballinger et al., 2016). The mammalian BF is a heterogeneous aggregate of subcortical structures including the medial septum, ventral pallidum, vertical and horizontal diagonal band nuclei, substantia innominata/extended amygdala, and peripallidal regions (Zaborszky et al., 2012; Agostinelli et al., 2019). Collectively, the BF serves as the major source of cholinergic projection neurons to the olfactory bulb, neocortex, hippocampus, and amygdala. The central cholinergic system helps regulate the vascularization of the brain (Sato and Sato, 1995; Van Beek and Claassen, 2011), and modulates cognition, specifically executive functions, attention, and memory (Levin and Simon, 1998; Ballinger et al., 2016; Prado et al., 2017; 
Solari and Hangya, 2018). The cholinergic neurons in the medial septum and the ventral diagonal band of the BF project to the hippocampus and are implicated in attention, short-term memory, and spatial learning (Boskovic et al., 2019). The cholinergic neurons of the brain stem (BS) project to the BF, the thalamus, and the ventral tegmental area (VTA), and are involved in regulating the waking state, behavioral responses as well as ocular saccades (Kobayashi and Isa, 2002; Newman et al., 2012; Mena-Segovia, 2016). Interestingly, cholinergic neurons appear to have a higher demand for energy production which may reflect a higher sensitivity to aging-related energy (glucose) deprivation (Szutowicz et al., 2013).

The cholinergic system modulates memory and hippocampal plasticity not only via neuronal cells but also via interactions with non-neuronal cells (e.g., microglia and astrocytes; Maurer and Williams, 2017). This suggests that microglia and astrocytes can respond directly to Ach via $\alpha 7 \mathrm{nAChRs}$ and influence both short-term and long-term synaptic function and plasticity, contributing to cognition (Ben Achour and Pascual, 2010). $\mathrm{BF}$ cholinergic neurons release $\mathrm{ACh}$ in all regions of the hippocampus, which exhibit a high density of microglia and astrocytes, as well as nAChRs expressed in many hippocampal cell types (Maurer and Williams, 2017). It has been hypothesized that $\mathrm{ACh}$ acts as the decider between encoding and retrieval in memory-processing and thus, is implicated in suppressing old associations and inhibiting proactive interference (Easton et al., 2012; Maurer and Williams, 2017). Thus, rats with BF cholinergic lesions can perform equally to controls in a water maze if the location of the platform is not changed daily (Baxter et al., 2013). The rats with the intact cholinergic system can form new associations inhibiting previous associations, while rats with a lesioned $\mathrm{BF}$ tend to express a previously encoded association (the previous location of the platform), due to the lack of ACh in the hippocampus. The underlying neural events can be explained as follows: inputs to the CA1 region of the hippocampus come from two brain regions: entorhinal cortex layer 3 (associated with sensory perception/ "extrinsic input") and the CA3 region of the hippocampus (associated with previously formed associations/ "intrinsic input"; Hasselmo, 2006; Easton et al., 2012). ACh reduces the recurrent pathway in the CA3 region via mAChRs activation on interneurons, and allow sensory inputs to be encoded, thus prioritizing encoding in novel contexts and allows working memory to be more efficient (Haam and Yakel, 2017; Maurer and Williams, 2017). Interestingly, a slow inhibition of dentate granule cells by septo-hippocampal release of $\mathrm{ACh}$ is not by a direct action on neurons but occurs rather by actions on both microglia and astrocytes via $\alpha 7 n$ AChRs. A proposed mechanism for neuronal-glial interactions via $\mathrm{ACh}$ and its impact on the hippocampus is that $\mathrm{BF}$ cholinergic projections release $\mathrm{ACh}$ and decrease cytokine release from microglia, as well as activate hilar astrocytes by activating the $\alpha 7 \mathrm{nAChRs}$ (Hasselmo, 2006; Pabst et al., 2016). These activated astrocytes release glutamate, activating inhibitory interneurons, which in turn decrease firing from granule cells, leading to the decreased firing of CA3 pyramidal cells (Bezzi et al., 2004; Volterra and Meldolesi,
2005). Overall, this prevents interference of past associations on encoding, facilitating the formation of new memories (Pabst et al., 2016; Maurer and Williams, 2017).

In summary, it is established that the $\mathrm{BF}$ provides multiple inputs to the hippocampus and that these modulatory cholinergic inputs play an important role in cognitive functions. A substantial body of evidence suggests that the direct activation of neuronal nAChRs, and more specifically the $\alpha 7$ subtype, reverses cognitive deficits that arise due to disruption of the BF-hippocampal pathway (O'Neill et al., 2002). However, it is not only neurons that respond to ACh via nAChRs. Indeed, both hippocampal microglia and astrocytes express nAChRs, suggesting that ACh also affects the hippocampus through glial cell activation (Foucault-Fruchard and Antier, 2017). Hence, this review will primarily focus on the cholinergic anti-inflammatory and anti-oxidant pathways to memory processes during development, normal aging, and disease states, specifically via activation of glial $\alpha 7 \mathrm{nAChRs}$.

\section{THE FUNCTIONAL ROLE OF GLIAL CELLS IN THE IMMUNE RESPONSE OF THE CNS AND THEIR INTERACTION DURING NEUROINFLAMMATION}

As highlighted in a review from Herculano-Houzel (2014), after the discovery of glia cells, it was commonly thought that they massively outnumbered neurons and that their number was directly correlated with brain size. But in fact, it seems that the glia/neuron ratio increases as neuronal density decreases (Herculano-Houzel, 2014). A decrease in neuronal density is related to an increase in neuronal cell mass which is highly variable among species and brain structures in mammals, while the average glial cell mass is relatively conserved (Mota and Herculano-Houzel, 2014). Thus, the glia/neuron ratio varies among species and brain structures. For example, overall in the brain, this ratio is about 1 in humans and 0.54 in mice, and when looking at different brain structures in humans, it is about 0.23 in the cerebellum but is 1.48 in the gray matter of the cerebral cortex (Herculano-Houzel, 2014). The composition of the glial cells can also vary depending on the brain region considered, the sex and the age of the subject (Pelvig et al., 2008; Herculano-Houzel, 2014). This is important to keep in mind when considering the limitations from research conducted in vivo (with animal models) or in vitro (with cell culture) when translating these findings to humans.

This review will focus on two of the major glial cell types in the mammalian CNS: astrocytes and microglia, and their crosstalk, which is extremely important for neuronal development, regulation of synaptic transmission as well as protection of the CNS and maintenance of its homeostasis (Vainchtein and Molofsky, 2020). Glial cell activation physiologically occurs during CNS insults, such as inflammation, infection, or lesion, to facilitate neuroprotection. However, this activation can be dysregulated and promote chronic neuroinflammation and/or neurodegeneration. 
Microglia are the innate immune resident cells of the CNS. In both developing and adult brains, these cells are critical for the maintenance of CNS homeostasis and perform several physiological functions, including regulation of neurogenesis, synaptic pruning, and production of trophic factors in both developing and adult brains (Ransohoff and El Khoury, 2016). In the presence of external stimuli that could negatively affect CNS homeostasis, microglia can acquire an activated phenotype to mediate a glial immune response that contributes to the development of pathological processes (Frank-Cannon et al., 2009; Kierdorf and Prinz, 2013). Possible causes for microglia activation include trauma, brain injury, stroke, apoptotic debris from dying neurons, aggregates of neurotoxic proteins, and pro-inflammatory cytokines. Microglia can transit from a resting or ramified state to an activated or primed amoeboid state, this transition is tightly regulated by molecular factors (e.g., CD200, CX3CR1 and TREM2) and minor changes in this signaling can potentially cause dysregulation of microglia homeostasis and pathology (Butovsky et al., 2014; Wolf et al., 2017; Deczkowska et al., 2018).

While the classical macrophage activation nomenclature (three functional states of polarized microglia phenotypes are postulated, M0, M1, and M2) has been adopted to define functional states of microglia, transcriptome analysis of microglia from animal models of neurodegeneration and aging suggests this classification is over-simplified (Chiu et al., 2013; Khakh and Sofroniew, 2015; Grabert et al., 2016; Ransohoff, 2016; Wes et al., 2016). Recent research suggests that microglia display phenotypes specific to changes in their microenvironment and surrounding CNS structures rather than showing only a distinct M1/M2 phenotype (Chiu et al., 2013; Khakh and Sofroniew, 2015; Grabert et al., 2016; Ransohoff, 2016; Wes et al., 2016). Historically, gene profiling data revealed that the molecular signature of the M0 phenotype was related to nervous system development and resembled adult microglia crucial in maintaining homeostasis (Butovsky et al., 2014; Sarlus and Heneka, 2017). The M1 phenotype appeared to express relatively high levels of inflammatoryrelated transcripts ( $\mathrm{Ccl} 2, \mathrm{Ccl} 3$, and $\mathrm{Ccl} 5$ ), and upregulate cytokines like tumor necrosis factor (TNF), interleukin-1 $\beta$ (IL$1 \beta)$, as well as nitric oxide (NO) and reactive oxygen species (ROS). The M2 phenotype expressed genes (e.g., Insulin-like growth factor 1) that promoted tissue development, neural cell renewal, and upregulated anti-inflammatory cytokines like IL-4 and IL10.

Microglia-mediated inflammation is essential to the primary acute CNS immune response; however, this acute response must be resolved to prevent chronic activation. To this end, microglia can release anti-inflammatory cytokines and tissue-repairing factors (Colton, 2009), and to reduce oxidative and nitrogeninduced stress by downregulating free radicals that accumulate in the interstitial space after trauma or in neurodegenerative diseases (Wagner et al., 2003; Moestrup and Møller, 2004). Dysregulation of this mechanism can be a breeding ground for the development of pathologies. A recent review summarizes how microglia priming renders aged microglia more responsive to proinflammatory stimuli, thus enhancing and prolonging their response to homeostatic disturbance and increased risk of neuronal loss and progression toward neurodegenerative disease (Wolf et al., 2017). Moreover, mouse models for aging and neurodegeneration account for senescent proinflammatory microglia that display morphological features and signaling pathways distinct from those microglia activated by the acute inflammation induced by lipopolysaccharides (LPS) in young mice (Holtman et al., 2015; Ransohoff and El Khoury, 2016). We have summarized the principal intracellular pathways involved in the regulation of microglial activity by highlighting their protective and detrimental roles in Table 1.

Astrocytes are responsible for the maintenance and support of neurons. They are crucial in regulating oxidative stress thanks to the production of glutathione (GSH) and, according to the astrocyte-neuron lactate shuttle hypothesis, by glucose transformation into lactate which ensures energetic support of neurons (Sidoryk-Wegrzynowicz et al., 2011). Astrocytes can also regulate innate and adaptive immune responses in the CNS by controlling the activation and immune cell trafficking and are immune-competent cells able to detect danger signals and respond via secretion of cytokines and chemokines and activate adaptive immune defenses (Farina et al., 2007). In reaction to harmful stimuli to the CNS, astrocytes can respond with proliferation, migration, hypertrophy, and increased production of glial fibrillary acidic protein (GFAP). Indeed, inflammatory stimuli from the microenvironment can shift the role of astrocytes from a protective "neuronal-focused" state to an inflammatory-focused state, also called "neuronalneglecting." Activated astrocytes were originally divided into two groups-A1 and A2. A1 astrocytes promote inflammation, lose the ability to protect neurons and control synaptogenesis, become phagocytic, and lead to neuronal loss through the NF-kB pathway. A2 astrocytes upregulate neurotrophic factors promoting neuronal survival via Janus Kinase/Signal Transducer and Activator of Transcription 3 (JAK-STAT3) signaling, which leads to the production of neurotrophic factors like brainderived neurotrophic factor (BDNF; Li K. et al., 2019). However, as with microglia, the A1/A2 astrocytic phenotypes do not exactly account for the in vivo complexity of astrocyte activation. Rather, there appears a continuous spectrum of astrocytic activation (or astrogliosis) with a gradient in morphological as well as functional changes based on the nature and severity of the stimuli (Sofroniew, 2015). Also, heterogeneity in astrocyte morphology and physiology (Matyash and Kettenmann, 2010) may affect glial responses to specific inflammatory stimuli (e.g., an early or late activation of astrocytes can modulate a disease onset and progression). A summary of both pro- and anti-inflammatory astroglia intercellular pathways is provided in Table 2.

The maintenance of CNS integrity depends on glial cells and their well-orchestrated interactions. As the balance between protective vs. detrimental function of glial cells is regulated by surface and cytoplasmic proteins, transcription factors, and released mediators, it is crucial to highlight the crosstalk between distinct neuroinflammatory pathways and identify 
TABLE 1 | Summary of protective and detrimental pathways of microglial signaling.

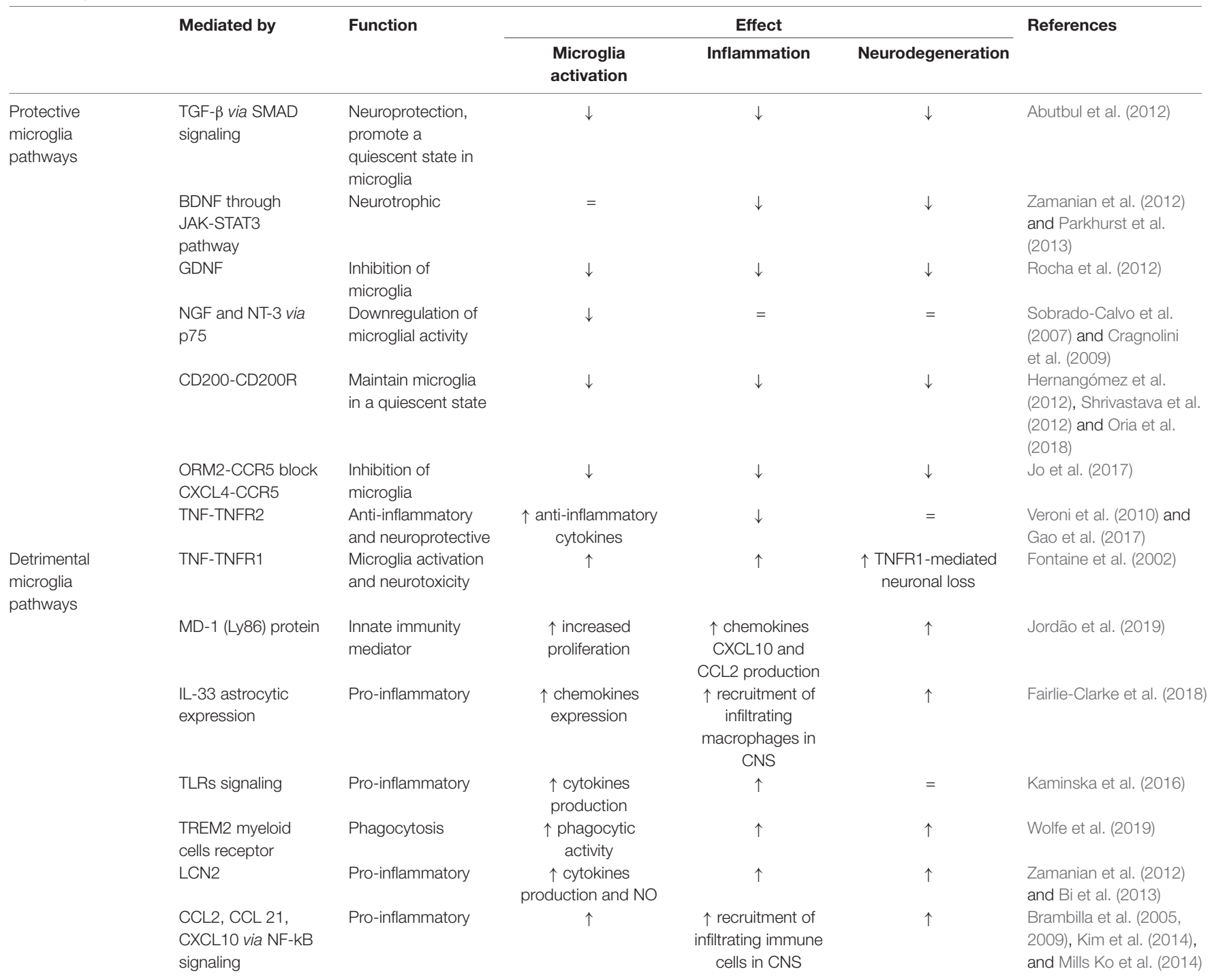

Principal intracellular pathways involved in the regulation of microglial activity, according to the protective and detrimental roles of microglia. This table highlights the main function of microglia, followed by the specific effect on cellular activation and the effect on the inflammatory and neurodegenerative condition. $\uparrow$ and $\downarrow$ represent upregulation and downregulation, respectively, = means that the pathway does not affect that condition.

their shared effector mechanisms (Colombo and Farina, 2016). There is evidence supporting a faster response by microglia to stimuli, showing a higher phagocytic activity after IFN- $\gamma$ stimulation compared to astrocytes (Magnus et al., 2002). During CNS injury there is a rapid release of cytokines by microglia, while the astrocytic response seems to be delayed (Zhang et al., 2009, 2010). These findings are supported by the high dynamicity of microglia typical of their resting state; indeed, microglia appear to be the dynamic surveillants of CNS (Nimmerjahn et al., 2005; Ransohoff and Cardona, 2010; Gomez-Nicola and Perry, 2015) and their activation can trigger and modulate the different responses of surrounding glial cells. Microglial dynamics can be stimulated by factors like ATP and other nucleotides or reduced by factors including fractalkine, also known as chemokine CX3CL1 (Liang et al.,
2009). Recent evidence supporting the role of microglia in regulating the astrocytic response (Jha et al., 2019) indicates a reactive astrocytic phenotype through the release of IL- $1 \alpha$, TNF- $\alpha$, and complement component 1 (C1q; Liddelow et al., 2017). However, microglia-astrocyte interactions via purinergic signaling are crucial to switch astrocytes toward a neuroprotective phenotype (Shinozaki et al., 2017). In return, astrocytes can also regulate microglial phenotypes and functions through numerous astrocyte-derived factors, such as cytokines, chemokines, complement proteins, $\mathrm{Ca}^{2+}$, and other inflammatory mediators (Tanuma et al., 2006; Jha et al., 2019). Moreover, microglial activation can also be modulated by astrocyte- released glial cell line-derived neurotrophic factor (GDNF), cerebral dopamine neurotrophic factor (CDNF), and BDNF. Astrocyte-derived GDNF in particular has been 
TABLE 2 | Summary of protective and detrimental pathways of astroglial signaling.

\begin{tabular}{|c|c|c|c|c|c|c|}
\hline & \multirow[t]{2}{*}{ Mediated by } & \multirow[t]{2}{*}{ Function } & \multicolumn{3}{|c|}{ Effect } & \multirow[t]{2}{*}{ References } \\
\hline & & & $\begin{array}{l}\text { Microglia } \\
\text { activation }\end{array}$ & Inflammation & Neurodegeneration & \\
\hline \multirow[t]{4}{*}{$\begin{array}{l}\text { Protective microglia } \\
\text { pathways }\end{array}$} & $\begin{array}{l}\text { Glycoprotein } \\
\text { gp130 Signal } \\
\text { transducer for IL-6 } \\
\text { cytokine family }\end{array}$ & Astrocyte's survival & $\begin{array}{l}\uparrow \text { astrocytes- } \\
\text { mediated } \\
\text { apoptosis }\end{array}$ & $=$ & $\downarrow$ & Haroon et al. (2011) \\
\hline & TGF $\beta$ signaling & $\begin{array}{l}\text { Immuno- } \\
\text { suppressive }\end{array}$ & $\downarrow$ proliferation & $\begin{array}{c}\downarrow \text { inhibition of } \\
\text { NF-kB signaling }\end{array}$ & $\downarrow$ & $\begin{array}{l}\text { Cekanaviciute et al. } \\
\text { (2014) }\end{array}$ \\
\hline & NrF2 pathway & $\begin{array}{l}\text { Anti-inflammatory } \\
\text { and antioxidant }\end{array}$ & $\begin{array}{c}\uparrow \text { expression of } \\
\text { antioxidant genes }\end{array}$ & $\begin{array}{l}\downarrow \text { suppression of } \\
\text { cytokines }\end{array}$ & $\downarrow$ & Patel et al. (2017) \\
\hline & $\begin{array}{l}\text { BDNF through } \\
\text { JAK-STAT3 } \\
\text { pathway }\end{array}$ & $\begin{array}{l}\text { Anti-inflammatory } \\
\text { and neurotrophic }\end{array}$ & $\downarrow$ & $\begin{array}{l}\downarrow \text { suppression of } \\
\text { cytokines }\end{array}$ & $\downarrow$ & O'Callaghan et al. (2014) \\
\hline \multirow{4}{*}{$\begin{array}{l}\text { Detrimental } \\
\text { astrocyte pathways }\end{array}$} & $\begin{array}{l}\text { NFkB recruitment } \\
\text { after IL-17 binding } \\
\text { to its receptor }\end{array}$ & $\begin{array}{l}\text { Release of } \\
\text { pro-inflammatory } \\
\text { cytokines and } \\
\text { chemokines }\end{array}$ & $\uparrow$ & $\begin{array}{l}\uparrow \text { via astrocytic } \\
\mathrm{IL}-17 \text { pathway }\end{array}$ & $\uparrow$ & Brambilla et al. (2005) \\
\hline & $\begin{array}{l}\text { CCL2, CCL 21, } \\
\text { CXCL10 via NF-kB } \\
\text { signaling }\end{array}$ & Pro-inflammatory & $\uparrow$ & $\begin{array}{l}\uparrow \text { recruitment of } \\
\text { infiltrating immune } \\
\text { cells in CNS }\end{array}$ & $\uparrow$ & $\begin{array}{l}\text { Brambilla et al. (2005, } \\
\text { 2009), Kim et al. (2014), } \\
\text { and Mills Ko et al. (2014) }\end{array}$ \\
\hline & CXCL12 & Pro-inflammatory & $\uparrow$ & $\begin{array}{l}\uparrow \text { pro-inflammatory } \\
\text { cytokines } \\
\text { production }\end{array}$ & $=$ & Bezzi et al. (2001) \\
\hline & VEGF & $\begin{array}{l}\text { Control of vascular } \\
\text { permeability (BBB } \\
\text { integrity) }\end{array}$ & $=$ & $\begin{array}{l}\uparrow \text { recruitment of } \\
\text { infiltrating immune } \\
\text { cells in CNS }\end{array}$ & $\uparrow$ & Argaw et al. (2012) \\
\hline
\end{tabular}

The table reports the principal intracellular pathways involved in the regulation of astrocytes activity by dividing the protective and the detrimental role. It highlights the main function of astroglia, followed by the specific effect on cellular activation and the effect on the inflammatory and neurodegenerative condition. $\uparrow$ and $\downarrow$ represent upregulation and downregulation respectively, = means that the pathway does not affect that condition.

shown to control midbrain microglial activation and prevent neurodegeneration through inhibition of neuroinflammation (Rocha et al., 2012). Of particular interest is the role of two proteins belonging to the lipocalins family which astrocytes, observed in mouse and rat models, can mediate microglial activation: orosomucoid 2 (ORM2) binds CC chemokine receptor 5 (CCR5) on microglia and blocks the interaction between chemokine (C-X-C motif) ligand 4 (CXCL4)-CCR5, which is crucial for their activation (Jo et al., 2017). Lipocalin-2 opposes ORM2 function and enhances inflammatory activity (Lee et al., 2009) by the production of pro-inflammatory mediators including IL-1 $\beta$, IL-6, TNF- $\alpha$, and NO (Zamanian et al., 2012; Bi et al., 2013).

Considering that most cells in the brain, including astrocytes (Liddelow et al., 2017) and microglia (Füger et al., 2017), have a long lifespan, it is plausible that the accumulation and overstimulation of inflammation can trigger multiple cumulative molecular modifications (e.g., telomere shortening, DNA damage, epigenetic modifications, lysosomal dysregulation) that eventually contribute to cellular senescence and loss of function (Desplats et al., 2019).

\section{THE INTERACTION BETWEEN CHOLINERGIC NEURONS AND GLIAL CELLS-THE CHOLINERGIC ANTI-INFLAMMATORY PATHWAYS}

\section{Anatomical Evidence for the Connection Between Cholinergic Neurons and Glial Cells}

In the CNS, both microglia and astroglia express muscarinic and nicotinic AChRs, which can be composed of different sub-units depending upon the brain area and the species considered (André et al., 1994; Guizzetti et al., 1996; Xiu et al., 2005; Rock et al., 2008; Morioka et al., 2014; Pannell et al., 2016). This might raise the question of the validity of rodent models when studying the role of $\mathrm{nAChR}$ and mAChR on neuroinflammation. To our knowledge, more studies are still needed to fully characterize the expression profile of $\mathrm{mAChR}$ and $\mathrm{nAChR}$ subunits in both microglia and astrocytes. The currently known subunits expressed in humans, rats, and mice have been summarized in Table 3. 
TABLE 3 | Summary of known AChR subunits to be expressed in glial cells in human, rat, and mouse.

\begin{tabular}{|c|c|c|c|c|c|}
\hline & & \multicolumn{2}{|r|}{ Microglia } & \multicolumn{2}{|c|}{ Astrocytes } \\
\hline & & Subunits & Origin & Subunits & Origin \\
\hline \multirow[t]{2}{*}{ Human } & $n A C h R$ & $\alpha 3, \alpha 5, \alpha 7, \beta 4$ & Fetal brain (Rock et al., 2008) & $\alpha 7$ & $\begin{array}{l}\text { Hippocampus and entorhinal cortex } \\
\text { (Teaktong et al., 2003) }\end{array}$ \\
\hline & $m A C h R$ & M5 & Levey (1996) & M2, M3, M5 & Fetal brain (Guizzetti et al., 1996) \\
\hline \multirow[t]{2}{*}{ Rat } & $n A C h R$ & $\alpha 7, \alpha 4, \beta 2$ & $\begin{array}{l}\text { Neonatal Cortex (Morioka et al., 2014) } \\
\text { Adult brain (Martín et al., 2015) }\end{array}$ & $\alpha 4, \alpha 7, \beta 2, \beta 3$ & Neonatal brain (Xiu et al., 2005) \\
\hline & mAChR & M1 & $\begin{array}{l}\text { Adult cortex and hippocampus (Huang } \\
\text { et al., 2016) }\end{array}$ & M2, M3, M5 & Cell line 132 1N1 (Guizzetti et al., 1996) \\
\hline \multirow{2}{*}{ Mouse } & & & & $\beta 4$ & $\begin{array}{l}\text { The hippocampus of the adult brain } \\
\text { (Gahring et al., 2004) }\end{array}$ \\
\hline & mAChR & $\begin{array}{l}\text { M1, M2, M3, } \\
\text { M4, M5 }\end{array}$ & $\begin{array}{l}\text { Neonatal and adult whole brain (Pannell } \\
\text { et al., 2016) }\end{array}$ & M1, M3 & $\begin{array}{l}\text { Neonatal cerebral hemisphere, } \\
\text { mesencephalon, and medulla-pons } \\
\text { (André et al., 1994) }\end{array}$ \\
\hline
\end{tabular}

This table presents the different subunits of nAChR and mAChR that have been found until today (and to the best of our knowledge) in microglia and astrocytes in humans, rat, and mice.

Microglia express a variety of neurotransmitter receptors that help to intercede bidirectional communication with neurons, including glutamate, GABA, norepinephrine, cannabinoid, and ACh receptors (Liu et al., 2016). In humans, microglia express the $\alpha 3, \alpha 5, \alpha 7$, and $\beta 4$ subunits of $\mathrm{nAChR}$, while rat cortical microglia exclusively express $\alpha 7 \mathrm{nAChRs}$ (Morioka et al., 2018). A limited number of studies using electron microscopy indicate a close relationship between glia and cholinergic neurons. In the septal complex of the $\mathrm{BF}$, the dendrites, axon, and soma of cholinergic neurons are mostly surrounded by astrocytic processes (Milner, 1991). In the laterodorsal and pedunculopontine tegmental nuclei of the brainstem, cholinergic neurons receive a large amount of synaptic input, with approximately one-quarter of their somatic surface covered by astrocytic processes (Honda and Semba, 1995). Expression levels of $\alpha 7 \mathrm{nAChR}$ have been investigated in various inflammatory models. On one hand, an increase of $\alpha 7 \mathrm{nAChR}$ expression in both microglia and astrocytes was reported in cerebral ischemia in rats, leading to microglial activation and pro-inflammatory cytokine production (Niranjan et al., 2012; Wu L. et al., 2014; Colás et al., 2018). This was counteracted by nicotine treatment, which reduced pro-inflammatory cytokine production as well as microglial activation, and also prevented neuronal death in the CA1 region of the hippocampus in rats (Guan et al., 2015). Also, activation of $\alpha 7 \mathrm{nAChR}$ by a pre-treatment with a positive allosteric modulator (PAM) reduced LPS-induced expression of the pro-inflammatory markers IL- $1 \beta$, TNF- $\alpha$, and the microglial activation marker cluster of differentiation 11b (CD11b) in the hippocampus and prefrontal cortex (PFC) of mice, and even blocked LPS-induced anxiety-like behaviors (Abbas et al., 2017; Alzarea and Rahman, 2019). On the other hand, neuroinflammation induced by the intra-cerebroventricular injection of an inflammatory soup containing prostaglandin E2 $(0.2 \mathrm{mM})$, serotonin $(2 \mathrm{mM})$, bradykinin $(2 \mathrm{mM})$, and histamine $(2 \mathrm{mM})$, in a rat model can also be linked with a decrease in the expression level of $\alpha 7 \mathrm{nAChR}$ in the hippocampus, which can be reversed by the treatment with an $\alpha 7 \mathrm{nAChR}$ agonist (Liu et al., 2018).

\section{Functional Evidence for a Connection Between Cholinergic Neurons and Glial Cells}

Various electrophysiological studies have demonstrated how glial responses to cholinergic activation are the result of a balance between the hyperpolarizing action of $\mathrm{ACh}$ and the opponent modulation of glutamate and GABA from surrounding neurons. A study of rat hippocampal slices showed that cholinergic stimulation of glial cells increases intracellular $\mathrm{Ca}^{2+}$ mobilization (Araque et al., 2002). Understanding $\mathrm{Ca}^{2+}$ transmission in neuron and astrocyte interactions and effects on cholinergic activation is essential for pathologies characterized by dysfunctional cholinergic signaling (Parpura et al., 1994; Verkhratsky and Kettenmann, 1996; Bezzi et al., 1998; Perea and Araque, 2005; Verkhratsky, 2006). In vivo studies of cats have found that during activation states associated with ACh transmission, cortical glial cells are hyperpolarized through the interaction between membrane $\mathrm{ACh}$ and muscarinic AChRs (Seigneur et al., 2006). This interaction, observed in mice, causes neuronal depolarization that leads to the release of glutamate and GABA from neurons (Czarnecki et al., 2014; Takács et al., 2018), which can in turn cause depolarization of glial cells. Besides, glial cells can also be influenced by the release of $\mathrm{K}^{+}$provoked by the excitation of neighboring neurons, and this could be related to increased membrane resistance and decreased membrane capacitance in glial cells (Seigneur et al., 2006). In vivo cat and in vitro mouse models have observed decreased glial capacitance during cholinergic activation reflects several phenomena, such as osmotic changes and modifications of the gap junction permeability (Amzica and Neckelmann, 1999; Hernández-Balaguera et al., 2018), which drive glial shrinkage and the consequent expansion of extracellular space resulting in a decrease of the overall $\mathrm{K}^{+}$concentration. These studies illustrate a functional electrophysiological relationship between cholinergic neurons and astrocytes, highlighting the importance of this axis.

Microglial activation following LPS administration in the hippocampus decreases BDNF release by astrocytes in the 
CA1 region of rats (Tanaka et al., 2006). Chronic nicotine exposure activates nAChRs in the rat hippocampus and upregulates BDNF in this brain region (Kenny et al., 2000). Interestingly, cholinergic neuronal loss in the $\mathrm{BF}$ leads to a subsequent reduction of $\mathrm{BDNF}$ in the hippocampus of mice (Turnbull and Coulson, 2017). Furthermore, BDNF increases $\alpha 7 n A C h R$ density on hippocampal neurons, and activation of $\alpha 7 \mathrm{nAChRs}$ upregulates BDNF in the rat hippocampus (Freedman et al., 1993; Massey et al., 2006). However, there is no direct evidence linking microglial $\alpha 7 \mathrm{nAChR}$ activation and $\mathrm{BDNF}$ levels. It is also interesting that pharmacological activation of $\alpha 7 \mathrm{nAChRs}$ in the hippocampus (CA1 and CA3 regions) increases hippocampal long-term potentiation (LTP) through long-lasting increases in calcium activity in wild-type, but not in $\alpha 7 \mathrm{nAChR}$ knockout mice (Gu et al., 2012). The $\alpha 7 \mathrm{nAChR}$ is reported to be highly permeable to $\mathrm{Ca}^{2+}$ (Shen and Yakel, 2009), and microglial $\alpha 7 \mathrm{nAChR}$ stimulation also increases cytosolic $\mathrm{Ca}^{2+}$ (Takata et al., 2018). Together, this suggests activation of $\alpha 7 \mathrm{nAChR}$ on neurons as well as microglia can facilitate LTP.

After brain insult, ATP is released from injured cells and activates microglia which, thanks to the interaction with the purinergic P2X7 receptor, starts to release molecules to protect neurons of the neonatal rat brain in vitro (Suzuki et al., 2004). In particular, P2X7 receptor stimulation has a role in neuronal protection against glutamate toxicity mediated by small amounts of TNF- $\alpha$ released by microglia, while LPS treatment mediates TNF- $\alpha$ production that leads to neuroinflammation (Suzuki et al., 2006). Considering that ACh can elicit glutamate release through presynaptic $\alpha 7 \mathrm{nAChRs}$, and ATP is a co-transmitter of ACh, Patti et al. (2006) investigated the role of the $\mathrm{P} 2 \mathrm{X} 7$ receptor in this interaction in the rat neocortex. They found $\mathrm{P} 2 \mathrm{X} 7$ receptors and $\alpha 7 \mathrm{nAChRs}$ co-existed and interacted on glutamatergic terminals where P2X7 exerts a permissive role on the activation of $\alpha 7 \mathrm{nAChRs,}$ suggesting regulation of ATP-mediated signaling. A later work observed colocalization of the $\mathrm{P} 2 \mathrm{X} 7$ receptor with astrocytes and microglia, but not neurons, and proposed a role for these receptors in glial apoptotic and proliferative functions after ATP stimulation (Oliveira et al., 2011). Furthermore, it is generally recognized that healthy neurons and astrocytes can regulate microglia-mediated innate immune responses via activation of $\alpha 7 \mathrm{nAChR}$ and purinergic P2X7 receptors (Suzuki et al., 2006). Indeed, the hyperactivation of the $\mathrm{P} 2 \mathrm{X} 7$ receptor by ATP drives microglia toward a reactive phenotype and can increase pro- or anti-inflammatory microglia markers (Parisi et al., 2016). An example, observed in embryonic rat pups in vitro, is the increased formation of membrane vesicles in microglia containing IL-1 $\beta$ after ATP stimulation mediated by the $\mathrm{P} 2 \mathrm{X} 7$ receptor, which leads microglia to promote inflammation (Bianco et al., 2005).

The anatomical and electrophysiological evidence for a connection between the cholinergic system and glial cells supports further investigation into the role of aging and chronic microglial activation on their bidirectional relationship. Possibly, the loss of cholinergic connections, resulting from either damaged neurons or astrocytes may lead to hyperactive microglia, which then causes persistent neuroinflammation and augmentation of neurodegeneration.

\section{The Anti-inflammatory Role of the Cholinergic System}

The existence of a "cholinergic anti-inflammatory pathway" (CAP) in the CNS, mediated by the activation of $\alpha 7 \mathrm{nAChR}$ on microglia, was first proposed by Shytle et al. (2004). They demonstrated that pre-treatment of cultured murine-derived microglial cells with ACh and nicotine inhibited LPS-induced TNF- $\alpha$ release, which was attenuated by $\alpha 7$ selective nicotinic antagonist, $\alpha$-bungarotoxin (Shytle et al., 2004). Thus, the $\alpha 7 \mathrm{nAChR}$ subunit was confirmed as essential in the endogenous cholinergic anti-inflammatory pathway for inhibiting cytokine synthesis by macrophages. This was later confirmed by several other in vivo and in vitro studies demonstrating the existence of the cholinergic anti-inflammatory pathway in the CNS, which appears to mainly rely on the activity of nicotinic receptors and more specifically, $\alpha 7 \mathrm{nAChR}$ (De Jonge and Ulloa, 2007; Kalkman and Feuerbach, 2016; Hoover, 2017).

Neuroinflammation in utero, due to maternal infection during pregnancy, may contribute to fetal brain injury and life-long risk of neurodevelopmental defects (Al-Haddad et al., 2019). Glial cells, both microglia and astrocytes, play a pivotal role in the risk of neurodevelopmental defects but the exact mechanisms are poorly understood. However, recent studies have shed new light on the inflammatory phenotypes of fetal glia involved in life-long neurological disabilities ("second hit" hypothesis). Using an in vivo-in vitro model of developmental programming of neuroinflammation induced by LPS, Cao et al. (2015) demonstrated that the inflammatory microglial phenotype acquired by exposure to LPS in sheep fetus (in vivo) sustained and potentiated a pro-inflammatory phenotype in vitro upon re-exposure to LPS. They also confirmed the downregulation of heme oxygenase $(\mathrm{HO}) 1$ gene, a key gene of iron homeostasis, as well as an upregulation of gluconeogenesis (energy conserving) fructose-1,6-biphosphate (FBP) gene, in second hit microglia compared to single hit microglia (Cao et al., 2015). This suggests an interplay of inflammatory and metabolic pathways and immunological and metabolic memory of the prior-inflammatory insult relevant to neuronal development. A study expanding the work of Cao et al. (2015) used primary fetal sheep microglia cultures re-exposed to LPS in the presence of a selective $\alpha 7 \mathrm{nAChR}$ agonist (AR-R17779) or antagonist ( $\alpha$-bungarotoxin; Cao et al., 2015; Cortes et al., 2017b). The microglial $\alpha 7 \mathrm{nAChR}$ agonist reversed the pro-inflammatory microglial phenotype acquired in vitro by LPS stimulation while blocking $\alpha 7 \mathrm{nAChR}$ potentiated the pro-inflammatory microglial phenotype (Cortes et al., 2017b). In this study, a link between iron homeostasis and microglia $\alpha 7 \mathrm{nAChR}$ has also been proposed (Cortes et al., 2017b); iron accumulation and toxicity are related to oxidative stress, which is found in numerous neurodegenerative diseases (Gaasch et al., 2007).

A very recent study extended this investigation to examine the role of $\alpha 7 \mathrm{nAChR}$ in fetal sheep astrocytes (Cao M. et al., 2019) and showed that the pro-inflammatory transcriptome astrocyte phenotype acquired in vivo or in vitro by LPS stimulation 
was reversed by $\alpha 7 \mathrm{nAChR}$ agonist. Conversely, $\alpha 7 \mathrm{nAChR}$ inhibition potentiated the pro-inflammatory astrocytic phenotype and pro-inflammatory signaling pathways NF$\kappa \mathrm{B}$ and STAT3 (Cao M. et al., 2019). The exact mechanism by which activation of $\mathrm{nAChR}$ on astroglia or microglia can lead to an anti-inflammatory effect is still under investigation. A recent study applied $\mathrm{ACh}$ to rat hippocampal neuron-microglia co-cultures to confirm its anti-inflammatory properties in response to microglia-derived neuroinflammation (Li L. et al., 2019). A higher concentration of ACh markedly inhibited the LPS-induced microglial inflammatory response by decreasing pro-inflammatory factors and inhibiting hippocampal neuronal apoptosis, showing that $\mathrm{ACh}$ has concentration-dependent anti-inflammatory and neuroprotection properties in this model (Li L. et al., 2019). They also demonstrated, by genetic knockdown of $\alpha 7 \mathrm{nAChR}$, that both the anti-inflammatory and neuroprotective abilities of ACh depend on microglial $\alpha 7 n A C h R$ signaling (Li L. et al., 2019). In a model of oxaliplatininduced neurotoxicity in co-cultured neurons and astrocytes, the application of an $\alpha 7 \mathrm{nAChR}$ agonist increased neuron viability by preventing caspase- 3 activation, increased glutamine synthetase expression levels, and increased the production of the anti-inflammatory cytokine TGF- $\beta$ (Di Cesare Mannelli et al., 2015). Thus, the activation of cholinergic receptors could not only have an anti-inflammatory effect but also an antioxidant and neuroprotective role, as these three phenomena are highly interconnected. Indeed, ACh has been suggested to exert both anti-inflammatory and neuroprotective properties in several neurodegenerative disorders (Gallowitsch-Puerta and Pavlov, 2007; Martelli et al., 2014).

In astrocytes, activation of $\alpha 7 \mathrm{nAChRs}$ has an anti-inflammatory effect. This is mediated by the activation of nuclear factor erythroid 2-related factor 2 (Nrf2), which allows the expression of several antioxidant genes (HO1, thioredoxin reductase 1, glutamate-cysteine ligase catalytic subunit) and the inhibition of the NF- $\kappa \mathrm{B}$ pathway with a decrease of the expression of $\mathrm{p} 50$, of an inhibitor of $\kappa \mathrm{B} \alpha(\mathrm{I} \kappa \mathrm{B} \alpha)$ phosphorylation and NFкB nuclear translocation (Patel et al., 2017).

The anti-inflammatory action of $\alpha 7 \mathrm{nAChR}$ in microglia is also mediated via the Nrf2-HO1 pathway (Parada et al., 2013). Moreover, the activation of $\alpha 7 \mathrm{nAChR}$ in microglia decreases the phosphorylation, and therefore the activation, of the p38, p44/42 and c-jun N-terminal kinase (JNK) MAP kinases (Shytle et al., 2004; Suzuki et al., 2006), which are involved in neuroinflammation (Koistinaho and Koistinaho, 2002; You et al., 2018; Zhao et al., 2018). Interestingly, it also increases the expression of cyclooxygenase-2 (COX-2) and prostaglandin $\mathrm{E}_{2}$ (De Simone et al., 2005), but the latter has a complex role in neuroinflammation and can either be pro- or anti-inflammatory (Levi et al., 1998; Zhang and Rivest, 2001).

Some evidence suggests that $\alpha 7 \mathrm{nAChR}$ can function as a metabotropic receptor by activating the PLC-inositol-3phosphate (IP3) pathway, which triggers the release of $\mathrm{Ca}^{2+}$ from intracellular stores, and can reduce the release of TNF$\alpha$ triggered by LPS -induced neuroinflammation in microglia (Suzuki et al., 2006; Brawek and Garaschuk, 2013; Hua et al., 2014). Experiments in neuroblastoma support the hypothesis that $\alpha 7 \mathrm{nAChR}$ can also be a metabotropic receptor. $\alpha 7 \mathrm{nAChR}$ is physically connected with JAK2, phosphatidylinositol-3-kinase (PI3K), and Fyn, and its activation leads to neuroprotection against amyloid- $\beta(\mathrm{A} \beta)$-induced toxicity via the PI3K, leading to the upregulation of neuroprotective factors such as B-cell lymphoma 2 (Bcl-2; Kihara et al., 2001; Shaw et al., 2002). This neuroprotective effect is coherent with the decrease in LPS-induced caspase activation that has been shown in astrocytes after activation of $\alpha 7 \mathrm{nAChR}$ (Patel et al., 2017).

An important structure to discuss when considering the CAP is the vagus nerve. Peripherally, this nerve is involved in a neuroimmune reflex which can attenuate $\mathrm{TNF} \alpha$ production during endotoxemia, giving the vagus nerve promising clinical implications during sepsis (Bonaz et al., 2016). While the efferent arm of this reflex arc has been well described, the implication of a vagal-mediated central CAP has yet to be fully elucidated. Visceral afferents of the vagus nerve in the gut may be stimulated by cytokines, namely IL-1, to induce a neuroimmune reflex. This information is received by the nucleus of the solitary tract where a synaptic relay occurs with the dorsal motor nucleus of the vagus. Efferent vagal fibers will then communicate with splenic lymphocytes and macrophages to reduce the production of pro-inflammatory cytokines via the $\alpha 7 \mathrm{nACh}$ receptor (Bonaz et al., 2016). Recent evidence suggests that this neuroimmune signaling may go on to higher centers, including the $\mathrm{BF}$, to mediate a centralized CAP. Both afferent and efferent fibers of the vagus nerve have been shown to communicate with limbic structures, where afferents increase cholinergic signaling in the BF (Broncel et al., 2018; Suarez et al., 2018). This BF cholinergic signaling reduces pro-inflammatory cytokines both centrally and peripherally in an effect which requires an intact vagus nerve (Zhai et al., 2017). Vagal afferents may also influence cholinergic signaling through norepinephrine production from the locus coeruleus (LC), which in turn promotes ACh production from the Nucleus Basalis of Meynert (Kaczmarczyk et al., 2018). In light of these findings, the BF has been proposed as a higher integrative center for neuroimmune signaling by way of the vagus nerve. Recent studies have provided evidence for the anti-inflammatory role of vagal cholinergic signaling in the CNS. By using an in vivo model of near-term ovine fetuses, Frasch et al. (2016) described how microglial activation, induced by acidosis, was less prominent in animals with higher vagal afferent signaling and that this effect is likely mediated by the $\alpha 7 \mathrm{nACh}$ receptor. The higher vagal activity was associated with a higher count of $\alpha 7 \mathrm{nACh}$ receptors in neural tissue, suggesting a relationship between vagal innervation and $\alpha 7 \mathrm{nACh}$ receptor expression. Reduced microglial activation and attenuation of pro-inflammatory cytokines were observed with vagal nerve stimulation (VNS) during peripheral LPS challenge in mice (Meneses et al., 2016). Morphological signs of microglial activation in a murine model of $\mathrm{AD}$ were reversed by VNS (Kaczmarczyk et al., 2018). Further, VNS used in a murine model of stroke provided a neuroprotective effect that was mitigated by $\alpha 7 \mathrm{nACh}$ receptor antagonists ( $\mathrm{Lu}$ et al., 2017). While future research is required to better understand the neuroimmune signaling pathways between the BF and afferent vagus nerve fibers, it appears vagal activity may have 
significant anti-inflammatory properties in the CNS by way of cholinergic signaling.

In summary, both astrocytes and microglia are involved in the cholinergic anti-inflammatory pathway, via $\alpha 7 \mathrm{nAChR}$ expression, resulting in anti-inflammatory, antioxidant, and neuroprotective effects. We hypothesize that the loss of cholinergic profiles resulting in decreased $\alpha 7 \mathrm{nAChR}$ activation on glial cells has a significant impact during aging and contributes to the development of the neurodegenerative disease.

\section{IMPLICATIONS OF CHOLINERGIC-GLIAL INTERACTIONS IN AGING AND NEURODEGENERATIVE DISORDERS}

\section{Physiological Aging}

Aging is a physiological process accompanied by a decline in brain function, reduction in synaptic plasticity, and changes in neurotransmission and receptor availability in the CNS which may affect cognitive performance (Li et al., 2001; Mahncke et al., 2006). Hallmarks of brain aging include increased oxidative stress and inflammation (Lee et al., 1999; Godbout et al., 2005), due to the accumulation of free radicals and enhanced expression of pro-inflammatory cytokines, including IL-1 $\beta$ and IL-6 (Sierra et al., 2007; Kuzumaki et al., 2010), combined with decreased in anti-inflammatory cytokines such as IL-10 and IL-4 (Ye and Johnson, 2001; Nolan et al., 2005). Resident glial cells are key contributors to the age-related shift in the inflammatory profile of CNS. Histological examination of postmortem brain samples reveals microglial de-ramification and the shortening of cellular processes that are related to the activated state of microglia (Streit et al., 2004). Furthermore, microglia exhibit a "primed" phenotype, indicating an enhanced inflammatory response to an immune stimulus (Perry and Holmes, 2014). This can be accompanied by upregulation of genes associated with antigen presentation, like major histocompatibility complex (MHC) II and CD68 (Frank et al., 2006; VanGuilder et al., 2011), suppression of anti-inflammatory proteins, such as IL-10 and CD200 (Frank et al., 2006), and rise of pro-inflammatory cytokines as IL-1 $\beta$ (Henry et al., 2009). Microglia also decrease their mobility with age, becoming less reactive in surveying the CNS microenvironment, and reducing the resolution of an established inflammatory state (Damani et al., 2011). Astrocytes move from a resting/flat morphology towards a stellate state (VanGuilder et al., 2011), and acquire an activated profile indicated by increased expression of GFAP (Zamanian et al., 2012; Liddelow et al., 2017). Reactive astrocytes also exhibit upregulated MHCI (Mangold et al., 2017), and chemoattractants for infiltrating immune cells such as CXCL10 and CXCL5 (Boisvert et al., 2018; Sorensen et al., 2018). Interestingly, the receptor for CXCL10 is CXCR3 which is a microglial marker, suggesting communication between astrocytes and microglia that affects aging (Rothhammer et al., 2018).

Glial inflammatory profiles are regulated by ACh through $\alpha 7 \mathrm{nAChRs}$ on astrocytes and microglia, to control the production of inflammatory cytokines (Niranjan et al., 2012;
Kalashnyk et al., 2014). Thus, cholinergic transmission appears crucial in regulating glial cell inflammatory profiles during aging. During development and aging, there are changes to the profiles of nicotinic and muscarinic receptors. In a study using human brain tissue from 24 weeks of gestation to 100 years, Court et al. (1997) found the highest level of nAChR expression in the late fetal stage in the hippocampus, entorhinal cortex, and presubiculum. In the hippocampus, this is followed by a considerable decrease within the first 6 months of life and a slight decrease during aging (Court et al., 1997). Muscarinic ACh receptor expression slightly decreased with age in the hippocampus and the subicular complex (Court et al., 1997). This age-related decrease in cholinergic receptor expression may contribute to age-related cognitive impairment (Dumas and Newhouse, 2011). Indeed, a reduction in cholinergic transmission appears to affect the protective and supportive role of glial cells to neurons, and this is mediated by ACh. An example is the expression of GDNF stimulated by the activation of astrocytic $\alpha 4 \beta 2$ and $\alpha 7 \mathrm{nAChRs,} \mathrm{whereby} \mathrm{astrocyte-derived}$ GDNF promotes the inhibition of microglia activation and neuronal protection (Rocha et al., 2012; Konishi et al., 2014). The neuroprotective effect of $\mathrm{nAChR}$ can be mediated by different subunits in different brain regions, for instance, $\alpha 4 \beta 2$-type $\mathrm{nAChRs}$ are involved in nicotine-mediated protection in the cortex and striatum (Ryan et al., 2001; Laudenbach et al., 2002) while $\alpha 7$ subunits are involved in hippocampal nAChRs (Messi et al., 1997; Dajas-Bailador et al., 2000). Studies on aged $\beta_{2}$ subunit knockout mice show neocortical hypotrophy, loss of pyramidal neurons in the CA3 field, and Astro- and microgliosis in neocortex and CA1-3 hippocampal fields, suggesting that chronic loss of $\beta_{2}$ subunit removes the protective role of glial cells against neurodegenerative processes during aging in the mouse brain. The same mice also showed impaired spatial learning (Zoli et al., 1999; Caldarone et al., 2000), implying that nAChRs contribute to both neuronal survival and maintenance of cognitive performance during aging (Picciotto and Zoli, 2002).

A SPECT imaging human study involving 47 healthy female and male volunteers from 18 to 85 years old, revealed an inverse correlation between age and regional $\beta 2 \mathrm{nAChR}$ availability in several brain regions including the thalamus, frontal, parietal, and anterior cingulate cortices (Mitsis et al., 2007). These results confirmed what was observed in postmortem human samples using RT-PCR, where mRNA expression of $\alpha 4$ and $\beta 2$ subunit $\mathrm{nAChRs}$ decreased with age in the frontal cortex, while in the hippocampus, only $\beta 2$ significantly decreased with age (Tohgi et al., 1998). The age-related changes also affect the $\alpha 7 \mathrm{nAChR}$ : binding experiments with $\left[{ }^{125} \mathrm{I}\right] \alpha$-bungarotoxin, the specific marker of this $\mathrm{nAChR}$ subtype, showed a higher expression of the $\alpha 7$ subunit in several brain areas in the human fetal sample (9-11 weeks of gestation) compared to middle-aged (28-51 years) and aged (68-94 years) samples (Falk et al., 2003). However, opposing evidence has been reported: a PET imaging study with 25 healthy volunteers aged from 21 to 86 years showed a positive correlation between $\alpha 7 \mathrm{nAChRs}$ distribution and age in all the brain regions investigated, including the thalamus, striatum, hippocampus, cerebellar cortex, temporal cortex, occipital cortex, cingulate cortex, frontal cortex, and 
parietal cortex, suggesting an increase in cerebral $\alpha 7 n$ AChRs during healthy aging (Coughlin et al., 2018). Rodent data may shed light on these seemingly contradictory results, as not all nAChR subunits appear equally affected by age. Adult (12-14 months) and aged (24-28 month) mice from two strains $(\mathrm{C} 57 \mathrm{BL} / 6$ and $\mathrm{CBA} / \mathrm{J})$ showed different trajectories of $\alpha 4$ and $\alpha 7$ expression with age (Gahring et al., 2005; Utkin, 2019). CBA/J mice demonstrated a considerable decrease in $\alpha 4$ and $\alpha 7$ expression with age, while C57BL/6 mice showed a slight decrease in $\alpha 4$ and a reduction in $\beta 4 \mathrm{nAChR}$ with age, suggesting that the interpretation of age-related AChR changes should be done very carefully, preferentially using a large group of individuals (Gahring et al., 2005; Utkin, 2019). Moreover, electrophysiological studies using whole-cell patchclamp recordings in mouse brain slices highlighted differences in the contribution of $\mathrm{nAChR}$ subunits to ACh-induced inward currents across aging (Christensen and Kohlmeier, 2016). In younger animals, this was predominantly mediated by the $\mathrm{nAChR}$ containing $\beta 2$ and/or $\beta 4$ subunits, however, in neurons from older animals, the currents conducting by nAChRs containing the $\beta 2$ and/or $\beta 4$ and the $\alpha 7$ subunits were similar (Christensen and Kohlmeier, 2016).

All these findings support the cholinergic hypothesis of age-related cognitive dysfunction and underline the importance of a better characterization of the contribution of $\mathrm{nAChR}$ subunits during aging (Dumas and Newhouse, 2011; Utkin, 2019). One of the possible future directions in the field of studying normal aging could be to find a specific correlation between the loss of different cholinergic receptor subunits and resulting cognitive impairment. Eventual findings could be very helpful in understanding not only physiological aging but also the pathogenesis of the age-related neurodegenerative disease. Physiological aging is also associated with active clearance of accumulated neurotoxic proteins, like amyloid and tau, from and around neurons by microglia (Clayton et al., 2017). The failure of this process leads to the formation of aggregates, typical of $\mathrm{AD}$ and other forms of dementia, and dysfunction of the neuron to glia communication. Indeed, there is the age-related loss of cholinergic function driven by dendritic, synaptic, and axonal degeneration, a decrease in neurotrophic support, and impairment in glial intracellular signaling (Clayton et al., 2017). The aging process alters the expression of muscarinic and nicotinic receptors for $\mathrm{ACh}$, contributing to impaired crosstalk between neurons and surrounding glial cells, which may be responsible for dysfunction leading to neurodegenerative processes instead of normal brain aging (De Keyser et al., 2008; Sofroniew, 2009).

\section{Pathological Aging and Neurodegenerative Disorders}

Inflammation and aging appear closely linked and microglial activation has been shown to increase with age (Bachiller et al., 2018). While low levels of inflammation correlate with healthy brain function (Walker et al., 2017) and longevity (Arai et al., 2015), high levels of inflammation during aging are likely to disrupt brain homeostasis and the physiological equilibrium between the pro- and the anti-inflammatory response of microglia and astrocytes.

Basic signaling between astrocytes and neurons is preserved in the early stages of aging; however, in a mouse model of $\mathrm{AD}$, this communication mechanism is dysfunctional, affecting astrocyte $\mathrm{Ca}^{2+}$ signaling, which is crucial for normal brain activity (Gómez-Gonzalo et al., 2017). This confirms what was previously observed regarding astrocytic $\mathrm{Ca}^{2+}$ signaling during age-related neurodegeneration: mouse cortical astrocytes near $\mathrm{A} \beta$ plaques demonstrate enhanced $\mathrm{Ca}^{2+}$ excitability (Kuchibhotla et al., 2009). Moreover, $\mathrm{Ca}^{2+}$ levels are increased in hippocampal slices acutely treated with $\mathrm{A} \beta$ oligomers (Pirttimaki et al., 2013; Talantova et al., 2013). While both microglia and astrocytes respond to perturbations that lead to an activated state, this mechanism needs to be tightly regulated to avoid glial cell overstimulation, which could result in a failure to return to a resting basal state and leading to cellular dysfunction (Van Rossum and Hanisch, 2004; Biber et al., 2007). Physiological aging leads to activated microglia and increased glial neuroinflammatory markers. However, there are differences between aging and aging with the presence of an inflammatory stimulus, like LPS, which causes a prolonged and exaggerated immune response (Xie et al., 2003). Microglia and astrocytes of aged mice are prone to exhibit an uncontrolled LPS-induced inflammatory response (Nava Catorce and Gevorkian, 2016). Thus, the combination of aging and an inflammatory stimulus can cause an overdrive of normal physiological aging mechanisms, leading to severe anatomical degeneration in the CNS and subsequent neurological deficits (Rosczyk et al., 2008; Norden and Godbout, 2013; Wong, 2013).

Cholinergic neurons in the $\mathrm{BF}$ show a lower excitability profile compared to their neighboring non-cholinergic neurons, and their basic properties do not significantly change between adolescence and young adulthood in mice (López-Hernández et al., 2017). However, older animals have a lower excitability profile in cholinergic neurons than younger animals, and there is an age-dependent bi-phasic profile of cholinergic neurons during physiological aging, whereby excitability increases in adult mice (9-12 months old), but excitability decreases in aged mice (>18 months; Kékesi et al., 2019). Together, this suggests age-dependent susceptibility of BF neurons to changes in excitability. Interestingly, the number of cholinergic neurons also decreases with age in humans (Schliebs and Arendt, 2011).

Some research groups have assessed the susceptibility of cholinergic neurons to neuroinflammation throughout aging. In these studies, LPS injections were used to induce glial cell activation, which leads to a release of pro-inflammatory cytokines and ROS (Goossens et al., 1995; Minghetti and Levi, 1995). A study on 3 months old rats observed a significant loss of cholinergic neurons and extensive inflammation, including astrocyte and microglia activation, after direct BF LPS injections (Wenk et al., 2000). LPS can also be administrated via peripheral injections to induce a milder inflammatory response in the brain and allow for the investigation of glial activation at different ages. Kékesi et al. (2019) noticed that LPS peripheral injections slightly affect electrophysiological properties of cholinergic neurons in younger mice (3-6 months), but drive hyperexcitability in 
older mice (9-12 months). Surprisingly, they did not report LPS-induced excitability differences in aged mice ( $>18$ months). The mechanism underlying the altered excitability of cholinergic neurons and neuroinflammation is yet to be resolved, although the authors proposed a connection between the bi-phasic pattern and LPS injections. The pattern is abolished due to dysregulation of calcium homeostasis and changes in membrane resistance of cholinergic neurons, which is caused by glial activation subsequent LPS-induced neuroinflammation (Kékesi et al., 2019).

Neurodegenerative diseases including Alzheimer's and Lewy Body Dementia (LBD) share two characteristics in common: a prevalence that increases with age and is associated with elevated neuroinflammatory markers. This relationship has led to the hypothesis that pathogenic mechanisms underlying age-related neurodegenerative disease involve changes in the CNS cells responsible for the immune response during aging (Wong, 2013).

\section{Alzheimer's Disease}

$\mathrm{AD}$ is the most common cause of age-related dementia, and its pathological hallmarks include senile plaques and neurofibrillary tangles along with extensive neurodegeneration, characterized by progressive cognitive impairment (Francis et al., 1999). Several environmental and genetic factors increase the risk for AD development (Armstrong, 2019). Aging is one of the strongest risk factors for $\mathrm{AD}$, and mechanisms for this include an age-related increase in microglial activation (Schuitemaker et al., 2012), degradation of the blood-brain barrier, and a decrease of glucose influx (Mooradian, 1988; Mooradian et al., 1991; Shah and Mooradian, 1997). Other risk factors associated with $\mathrm{AD}$ include several genes associated with the formation of $A \beta$ aggregates or tau neurofibrils, as well as genes involved in the modulation of the immune system (Giri et al., 2016). Some environmental factors are also associated with AD include stress (Baglietto-Vargas et al., 2015; Caruso et al., 2018, 2019) or systemic inflammation (Holmes et al., 2009; Holmes, 2013; Takeda et al., 2014; Lim et al., 2015). One hypothesis suggests that in $\mathrm{AD}$ (and other neurodegenerative diseases), microglia can be "primed" which later leads to a disproportionated response towards a pro-inflammatory stimulus (Dilger and Johnson, 2008; Lue et al., 2010; Cunningham, 2013; Niraula et al., 2017; Sfera et al., 2018). Several factors can induce this priming. During systemic inflammation, pro-inflammatory cytokines are expressed in response to a pathogen invasion or tissue injury, and they can reach the CNS. This can prime microglia which, combined with other risk factors e.g., genetic mutations associated with $\mathrm{AD}$, leads to chronic neuroinflammation and neurodegeneration. Microglia can also be primed by exposure to $A \beta$ aggregates or other abnormal proteins, to glucocorticoids, or by the loss of their inhibition because of a genetic predisposition (which could also be favorited by aging). Subsequent systemic inflammation then leads to chronic neuroinflammation and neurodegeneration (Cunningham, 2013). It is relevant to mention that the vagus nerve, which uses ACh as the main neurotransmitter, is involved in the regulation of the innate immune response during systemic inflammation. The vagus nerve is thought to be an important component for the bidirectional exchange between the CNS and the peripheral immune system (Thayer and Sternberg, 2010; Kox and Pickkers, 2015) and is involved in the cholinergic anti-inflammatory pathway (Zila et al., 2017).

\section{Alzheimer's Disease and the Basal Forebrain Cholinergic System}

The early establishment of the "cholinergic hypothesis" of $\mathrm{AD}$ was based on deficits in cholinergic function in $\mathrm{AD}$ (Bartus et al., 1982; Francis et al., 1999; Hampel et al., 2019). Indeed, interest in the cholinergic hypothesis of $\mathrm{AD}$ has attracted recent attention, as virtually all older adults over the age of 70 show progressive accumulation of misfolded extracellular amyloid and intracellular over-phosphorylated tau proteins, but progressive neurodegeneration that accounts for $\mathrm{AD}$-related cognitive impairment occurs only in $\sim 10 \%$ of this population (Kok et al., 2009; Deture and Dickson, 2019). These findings suggest that "proteinopathies" alone are not a sufficient driving force to lead to progressive neurodegeneration and cognitive loss. Recent evidence indicates microglia may play a key role in neurodegenerative processes. Indeed, microglial $\mathrm{A} \beta$ phagocytosis is identified as one of the mechanisms to reduce $A \beta$ burden and has been proposed as a therapeutic target for $\mathrm{AD}$ (Bard et al., 2000). As opposed to the "amyloid hypothesis" to explain $\mathrm{AD}$ etiology, the "inverse Warburg hypothesis" is a theory centered on metabolic mechanisms and more particularly on the cooperation between neurons and astrocytes, the latter playing a fundamental role in energy supply and glutamate-glutamine cycle, that could have critical implications for neurodegeneration (Bélanger et al., 2011; Demetrius et al., 2015). Thus, astrogliosis might have major metabolic consequences on neurons.

Cholinergic neurons are amongst the most energy-consuming neurons as they require the production of supplementary acetyl-CoA by mitochondria which makes them highly sensitive to toxicity from excess microglial activation (Wenk et al., 2000) and oxidative stress (Wurtman, 1992; Fass et al., 2000; McKinney, 2005; Szutowicz et al., 2013). These neurons have also been shown to be vulnerable to the activation of the hypothalamic-pituitary-adrenal axis early in life (Aisa et al., 2009). As mentioned earlier, the central cholinergic system is involved in cognitive processes such as executive function, attention, and memory (Levin and Simon, 1998; Ballinger et al., 2016; Prado et al., 2017; Solari and Hangya, 2018) but also in the regulation of the vascularization of the brain (Sato and Sato, 1995; Van Beek and Claassen, 2011). In AD, amongst the two main cholinergic nuclei of the brain, the cholinergic neurons of the BF appear to be the ones to degenerate compared to the cholinergic neurons of the BS which seem to be relatively spared (Woolf et al., 1989; Lehéricy et al., 1993; Kotagal et al., 2012; Schmitz and Nathan Spreng, 2016; Schmitz et al., 2018). Nonetheless, cholinergic neurons of the BS are still affected and exhibit neurofibrillary tangles or/and amyloid plaques (Parvizi et al., 2001). Interestingly, the cholinergic neurons of the BS are involved in ocular saccades (Kobayashi and Isa, 2002). This may raise the question of a link between impairment of the BS cholinergic neurons and its involvement in visual complaints of some $\mathrm{AD}$ patients, which is sometimes their 
primary reason for a consult (Kobayashi and Isa, 2002). The degeneration of $\mathrm{BF}$ cholinergic neurons appears to coincide with cognitive decline exhibited by $\mathrm{AD}$ patients (Grothe et al., 2014; Ballinger et al., 2016; Schmitz and Nathan Spreng, 2016). Thus, the loss of cholinergic inputs to the hippocampus from the $\mathrm{BF}$ could contribute to $\mathrm{AD}$ memory impairment, as the hippocampus is a key structure in learning and memory (Bartsch and Wulff, 2015). The loss of cholinergic input to the frontal cortex also affects executive function and cognitive flexibility (Prado et al., 2017), which also impairs memory as patients can no longer develop efficient memorization strategies. In $\mathrm{AD}$ patients, there is a hypometabolism of the temporoparietal area, the frontal cortex, and the posterior cingulate cortex (Mosconi, 2005; McMurtray et al., 2008). This hypometabolism is likely due to the loss of cholinergic inputs from the BF, which in turn leads to functional impairment in downstream temporoparietal regions (Grothe et al., 2016). This may coincide with hypoperfusion due to the death of cholinergic neurons, as the $\mathrm{BF}$ is involved in brain blood flow regulation (Sarter and Bruno, 2004; Van Beek and Claassen, 2011). In return, this hypoperfusion could lead to the death of even more cholinergic neurons as the cholinergic neurons are energy-deprived. In rats, cholinergic inputs from the $\mathrm{BF}$ are responsible for increasing cerebral blood flow in the hippocampus (Nishimura et al., 1992; Sato et al., 2004); this can be impaired by limited NO production via a decrease of neuronal NO-synthase catalytic activity (Hartlage-Rübsamen and Schliebs, 2001). In humans, it has been shown that greater blood flow into the hippocampus is correlated with a better performance in spatial memory in older adults (Heo et al., 2010) and a greater hippocampal vascular reserve might be a protective factor against cognitive loss (Perosa et al., 2020).

The relationship between central cholinergic degeneration and $\mathrm{AD}$ proposed in this review is summarized in Figure 1.

As mentioned earlier, microglia can function by displaying persistent chronic inflammation which can lead to neurodegeneration (Zamanian et al., 2012; Sochocka et al., 2017; Tohidpour et al., 2017). One of the mechanisms involved in the establishment of neurodegeneration is increased phagocytosis and upregulation of an innate immune receptor protein on the cell membrane, TREM2, which aids in the phagocytosis of accumulated amyloid and tau debris (Klinkenberg et al., 2011). During phagocytosis of the accumulated debris, membrane TREM2 is released into the cerebrospinal fluid (CSF) as soluble (s)TREM2, with little apparent inflammation (Ewers et al., 2019; Parhizkar et al., 2019). This process may be neuroprotective during the earliest stages of amyloid pathology, but with the subsequent occurrence of tau pathology associated with a larger increase in CSF STREM2, may reflect the transition of microglia to a detrimental phenotype (Leyns et al., 2017; Schmitz et al., 2020). Activated microglia upregulate multiple proinflammatory cytokines in response to neuronal amyloid and tau accumulation (Sarlus and Heneka, 2017). Activated microglia are also linked to the proliferation of neurotoxic reactive astrocytes via the complement component $\mathrm{C} 3$, which is the activating gene of the complement cascade, highly upregulated in the cross-talk between activated microglia and reactive astrocytes (Liddelow et al., 2017). Dysregulation of cholinergic modulation, possibly due to early age-related BF cholinergic neuronal loss, may remove an important check on the proliferation of pro-inflammatory activated microglia. Indeed, the loss of cholinergic inputs to the hippocampus from the $\mathrm{BF}$ might favor neuroinflammation in the hippocampus as the anti-inflammatory effect of the ACh is impaired. This view was supported by a recent study by Schmitz et al. (2020) which shows that an increased magnitude of BF degeneration in preclinical adults was associated with abnormally elevated levels of sTREM2 in the CSF and increased levels of peripheral blood C3. The authors hypothesized that damage to cholinergic neurons in the aging brain might result from a disruption to lipid metabolism, possibly due to an apolipoprotein E4 (APOE4) genetic background (Schmitz et al., 2020). Interestingly, they showed that increased BF degeneration and C3 expression were most pronounced in preclinical APOE $\varepsilon 4$ carriers, despite equivalent levels of CSF A $\beta$ and pTau (Schmitz et al., 2020). Previous studies validate these results, as APOE4 glia secrete less lapidated cholesterol and fatty acids which are unable to be transported into neurons, and deprived neurons of energy to build, repair, and maintain synapses and axons (Kanekiyo et al., 2014; Hu et al., 2015). The larger size of the cholinergic axon arbors presents biological challenges such as a large expenditure of resources for growth, maintenance, repair, and axonal transport, making these cells susceptible to age-related changes ( $\mathrm{Wu} \mathrm{H}$. et al., 2014). Overall, the data presented suggest that the loss of afferent cholinergic BF input in $\mathrm{AD}$ may disrupt anti-inflammatory cholinergic signaling and exacerbate microglial proinflammatory responses in the presence of other age-related "proteinopathies," leading to further neurodegeneration and cognitive loss in the later stages of the disease.

\section{Reduced Cholinergic Transmission and the Therapeutic Effect of $\alpha$ 7nAChR in AD}

Decreased expression of nicotinic receptors can be found in the brain of $\mathrm{AD}$ patients. This decrease is not uniform depending on the sub-unit or the brain area considered. In a study using human brain homogenates, a significant decrease in protein levels of $\alpha 7 \mathrm{nAChR}$ (about 17\%) and $\alpha 4 \mathrm{nAChR}$ (about $40 \%$ ) was found in the superior temporal gyrus in $\mathrm{AD}$ patients compared to controls (Burghaus et al., 2000). Similarly, a different study detected a decrease in protein levels of $35 \%$ for the $\alpha 4$ subunit, $25 \%$ for the $\alpha 3$ subunit, and $36 \% \alpha 7$ subunit was found in the hippocampus, and in the temporal cortex, there was a decrease of $47 \%$ for the $\alpha 4$ subunit and $29 \%$ for the $\alpha 3$ subunit, with no change for the $\alpha 7$ subunit (Guan et al., $2000)$. There was no change in the $\beta 2$ subunit in these areas (Guan et al., 2000). When looking specifically at the expression of $\alpha 7 \mathrm{nAChR}$ in the astrocytes, Teaktong et al. (2003) found more $\alpha 7$-immunoreactive astrocytes in the hippocampus and entorhinal cortex of $\mathrm{AD}$ patients compared to controls. Also, in human post mortem $\mathrm{AD}$ brain tissue, microglia accumulates on $\mathrm{A} \beta$ deposits and expressed $\alpha 7 n$ AChRs (Takata et al., 2010). Together, this suggests a reduction in glial $\alpha 7 \mathrm{nAChR}$ is evident in several brain regions in $\mathrm{AD}$. 


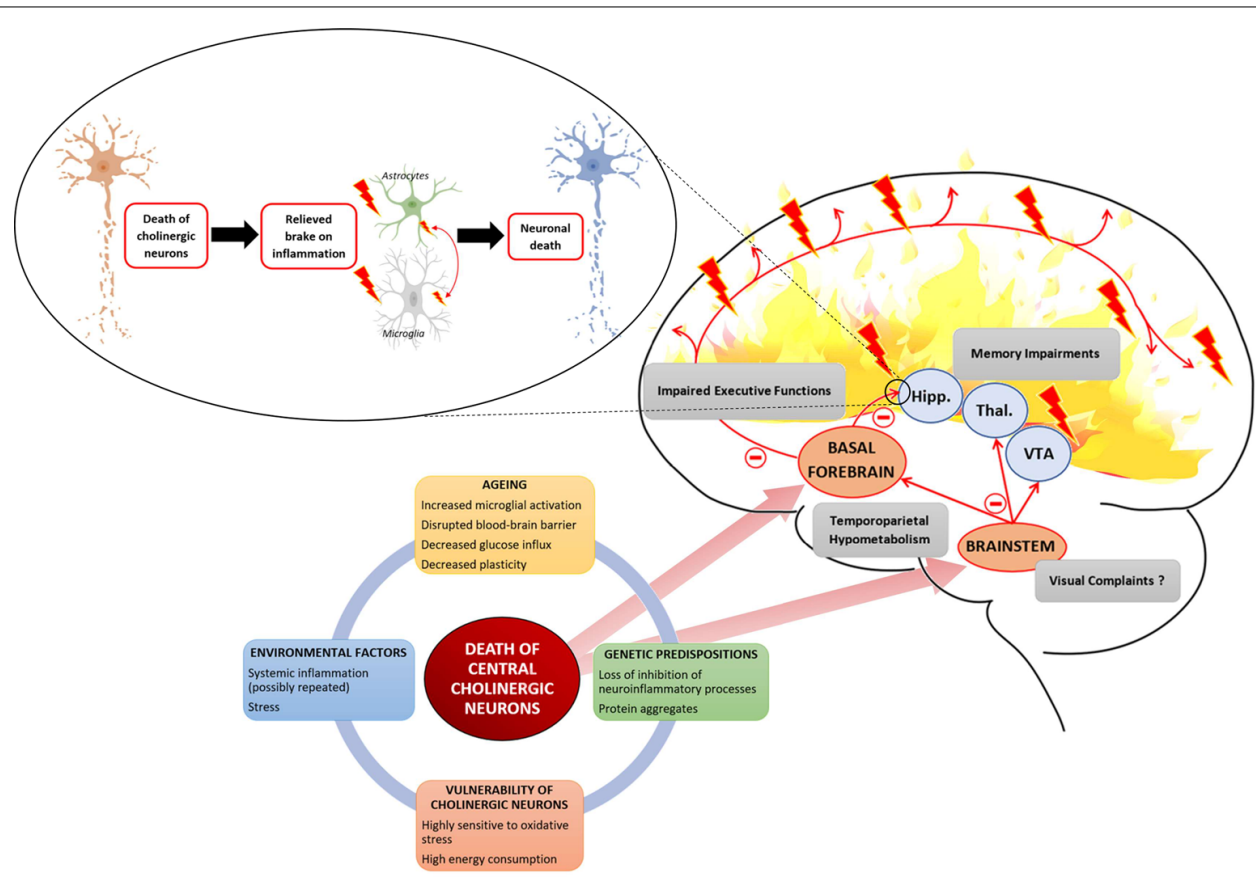

FIGURE 1 | Several interacting factors can lead to the death of central cholinergic neurons. Aging with an increased microglial activation disrupted the blood-brain barrier and decreased neuronal plasticity provides a breeding ground to which environmental factors, such as stress or systemic inflammation, and genetic factors, such as loss of inhibition of neuroinflammatory process or abnormal protein leading to aggregates, are added. Cholinergic neurons are highly demanding in energy and highly sensitive to oxidative stress. The two main cholinergic populations of the central nervous system (CNS) are located to the brainstem (BS) and the basal forebrain (BF). The cholinergic neurons of the BF are projecting to the hippocampus (Hipp.) and throughout the neocortex. The cholinergic neurons of the BS are projecting to the thalamus (Thal.), the ventral tegmental area (VTA), and the BF. Death of BF cholinergic cells leads to a loss of acetylcholine (Ach) influx in the hippocampus which is involved in memory impairment but also relieves a brake on neuroinflammation. The loss of cholinergic input to the PFC leads to impaired executive function. Concerning cholinergic death in the BS, it raises the question of its association with the inaugural visual complaints expressed by Alzheimer patients as it controls ocular saccades. Finally, the death of central cholinergic neurons is associated with a temporoparietal hypometabolism.

Preclinical data suggest that increasing the expression and function of glial $\alpha 7 \mathrm{nAChR}$ may be protective in AD. In primary cultured rat microglia, the positive modulation of nAChRs by galantamine or stimulation of nAChRs by nicotine increases $\mathrm{A} \beta$ phagocytosis (Takata et al., 2010). Moreover, these changes were closely associated with reduced $A \beta$ burden in the brain and enhancement of memory in the APdE9 transgenic mouse model of $\mathrm{AD}$ (Takata et al., 2010). A recent study published by the same group confirmed the subtype of nAChR involved in these beneficial effects as $\alpha 7$, and $\alpha 7 \mathrm{nAChR}$ selective agonist 3-[(2, 4dimethoxy)benzylidene]-anabaseine dihydrochloride (DMXBA) promoted $A \beta$ phagocytosis in primary cultures of rat microglia (Takata et al., 2018). They also reported the administration of DMXBA to ApdE9 mice attenuated brain $A \beta$ burden and memory dysfunction (Takata et al., 2018). Moreover, DMXBA also repressed $\gamma$-secretase activity in human neuroblastoma cells and in transgenic mouse brains (Takata et al., 2018). In another study, long-term treatment of aged 3xTg-AD mice with the selective $\alpha 7 \mathrm{nAChR}$ agonist, A-582941 (12 mg/kg/day, for 3 months, from 15 to 18 months of age), completely restored cognition in 3xTg-AD mice to the level of that in age-matched non-transgenic controls (Medeiros et al., 2014). Overall, this suggests that selective activation of microglial and neuronal $\alpha 7 \mathrm{nAChRs}$ promotes $\mathrm{A} \beta$ phagocytosis and suppresses neuronal $\gamma$-secretase activity respectively, lessening $A \beta$ burden and cognitive impairment.

Stimulation of $\alpha 7 \mathrm{nAChRs}$ on microglia and neurons ameliorates brain $\mathrm{A} \beta$ burden and cognitive impairment via two distinct mechanisms (Takata et al., 2010, 2018). In microglia, stimulation of $\alpha 7 n A C h R$ increases cytosolic $\mathrm{Ca}^{2+}$ and consecutively activates calcium-dependent pathways for actin reorganization through $\mathrm{CaM}-\mathrm{CaMKII}\left(\mathrm{Ca}^{2+} /\right.$ calmodulindependent protein kinase II) and CaM-Racl-WAVE (CaMRas-related C3 botulinum toxin substrate 1-Wiskott-Aldrich syndrome protein family verprolin-homologous protein) signaling pathways and subsequently may promote microglial $\mathrm{A} \beta$ phagocytosis. In neurons, $\alpha \mathrm{nnAChR}$ stimulation may downregulate presenilin 1 (PS1) expression and subsequent suppression of $\gamma$-secretase activity.

One of the proposed mechanisms explaining $A \beta$-related neurotoxicity is microglia-related oxidative stress and neuroinflammation via nicotinamide adenine dinucleotide phosphate (NADPH) activation (Kim et al., 2007). The neuroprotective function of nicotine may be mediated by suppressing $A \beta$-induced ROS production in microglia. Nicotine suppresses ATP release and thus inhibits NADPH oxidase activation, completely blocking $\mathrm{Ca}^{2+}$ influx in $\mathrm{A} \beta$-stimulated microglia (Della Bianca et al., 1999; Moon et al., 2008). Taken 
together, these findings suggest that reduced expression or inactivation of microglial and neuronal $\alpha 7 \mathrm{nAChRs}$ receptors may contribute to some pathological changes and cognitive impairment observed in $\mathrm{AD}$.

A therapeutic approach that targets $\alpha 7 \mathrm{nAChRs}$ is already being explored by pharmaceutical companies not only for $\mathrm{AD}$ but also for disorders such as PD, schizophrenia, or attention deficit hyperactivity disorder (Yang et al., 2017).

\section{Lewy Body Dementia}

Neurodegenerative diseases characterized by the presence of intraneuronal Lewy bodies (constituted primarily of $\alpha$ - synuclein) and Lewy neurites are termed Lewy body diseases and are considered the hallmark of dementia with Lewy bodies and PD (Duda, 2004). The principal Lewy body diseases are PD, Parkinson's disease dementia, and LBD (Barrett et al., 2020). LBD is recognized as a common cause of cognitive deterioration in the elderly and is the second most common cause of neurodegenerative dementia after AD (Tiraboschi et al., 2002; Ferman and Boeve, 2007). It is well-established that cholinergic input from the nucleus basalis of Meynert in the $\mathrm{BF}$ is required for cognitive function, and degeneration of the nucleus basalis of Meynert in LBD contributes to the weakening of cognitive function observed in LBD patients. LBD is also characterized by neuropsychiatric symptoms such as psychosis with visual hallucinations and depressive symptoms associated with BF cholinergic degeneration. More compelling evidence of cholinergic BF degeneration in LBD comes from cholinesterase inhibitor trials (Barrett et al., 2020). One such early clinical trial using rivastigmine, a cholinesterase inhibitor, improved hallucinations, delusions, apathy, and anxiety in patients with LBD (Mckeith et al., 2000). In LBD, ACh downregulation is generally thought to be more severe than that in $\mathrm{AD}$ (Kitajima et al., 2015) and autoradiographic studies on postmortem brains showed reduced $\mathrm{nAChR}$ in the cortex and hippocampus in PD (Rinne et al., 1991; Lange et al., 1993; Barrett et al., 2020). Rinne et al. (1991) showed that a reduction in nicotinic receptor binding in the frontal cortex correlated with the severity of dementia in PD and AD (Rinne et al., 1991). While there was a reduction in both $\alpha 7$ and non- $\alpha 7 \mathrm{nAChRs}$ in LBD, only the decrease in $\alpha 7$ receptors correlated with cholinergic denervation as measured by ChAT activity (Reid et al., 2000). Moreover, Court et al. (2001) reported a loss of $\alpha 7 n A C h R s$ in the temporal cortex of dementia with Lewy Bodies (DLB) patients associated with visual hallucinations and delusional misidentification (Court et al., 2001). Together, this indicates a role for cortical and hippocampal nAChRs, and in particular $\alpha 7 \mathrm{nAChRs}$ in $\mathrm{LBD}$, which may be linked to behaviors such as hallucinations, delusions, apathy, and anxiety in LBD patients. All the abovementioned studies focused on $\alpha 7 \mathrm{nAChRs}$ as a whole, without differentiating them into neuronal or glial subtypes. However, direct evidence of inflammation in LBD is growing, with augmented microglial activation identified at post-mortem (Togo et al., 2001), as well as a recent study reporting microglial activation in key brain regions associated with disease pathology (Surendranathan et al., 2018). Immunohistochemical studies carried out on post-mortem brains of $\mathrm{AD}$ and $\mathrm{LBD}$ patients reported an increase in the number of astrocytes double-labeled with $\alpha 7 \mathrm{nAChR}$ and GFAP antibodies, in most areas of the hippocampus and entorhinal cortex in $\mathrm{AD}$, but not in $\mathrm{LBD}$ (Teaktong et al., 2003, 2004). Thus, further pre-clinical and clinical evidence is required to support the direct involvement of glial $\alpha 7 \mathrm{nAChRs}$ in LBD to establish an association with neurodegenerative pathology in this disease.

\section{Parkinson's Disease}

$\mathrm{PD}$ is a common neurodegenerative disease in the elderly and is pathologically characterized by the loss of dopaminergic neurons in the substantia nigra $(\mathrm{SN})$. However, the origin of PD and mechanisms of neuronal degeneration are not fully understood. Compelling evidence indicates that CNS glia has an initiating role in PD pathophysiology. While $\mathrm{PD}$ patients show significant loss of dopaminergic neurons in the $\mathrm{SN}$, the degeneration of the $\mathrm{BF}$ cholinergic system is a factor in dementia associated with PD (Maurer and Williams, 2017). There is some evidence for the contribution of the $\mathrm{BF}$ function to dementia in PD. Administration of the neurotoxin 1-methyl-4-phenyl-1,2,3,6-tetrahydropyridine (MPTP) is used to model PD in rodents. A metabolite of MPTP in astrocytes, 1-methyl-4-phenylpyridinium ion (MPP+), can block mitochondrial complex I, leading to selective dopaminergic neurodegeneration, similar to that present in PD (Jakowec and Petzinger, 2004). LPS administration is also used to model PD in animals, as it activates glial cells and induces inflammatory changes and dopaminergic neurodegeneration (Dutta et al., 2008). In a study using in vivo and in vitro murine models of $\mathrm{PD}$, microglia and astrocytes in the $\mathrm{SN}$ increased in number and displayed more activation-associated morphology compared to controls, due to neuroinflammation triggered by MPTP/MPP+ or LPS (Liu et al., 2012). Systemic administration of nicotine alleviated MPTP-induced perturbed behavioral symptoms (by improving motor coordination) and protected against dopaminergic neuron loss, as well as microglia and astrocyte activation in the SN (Liu et al., 2012). Protective effects of nicotine were abolished by the administration of the $\alpha 7 \mathrm{nAChR}$-selective antagonist methyllycaconitine (MLA), indicating $\alpha 7 n$ AChRs mediate neuroinflammation and PD-like behaviors in these models (Liu et al., 2012). Interestingly, in primary cultured mouse microglia and astrocytes, pre-treatment with nicotine suppressed MPP+-induced or LPS-induced glial activation and number, evidenced by decreased production of TNF- $\alpha$ and inhibition of extracellular regulated kinase1/2 (Erk1/2) and p38 activation in glia (Liu et al., 2012). These effects were also reversed by MLA, suggesting a role for microglial and astrocyte $\alpha 7 \mathrm{nAChR}$ in inflammatory responses relevant to $\mathrm{PD}$. A recent study assessed the anti-apoptotic effects of an $\alpha 7 \mathrm{nAChR}$ agonist PNU-282987 in primary cultured astrocytes treated with MPP+ (Hua et al., 2019). They showed that PNU-282987 promoted the viability of astrocytes, alleviated MPP+ induced apoptosis by upregulating the expression of the antiapoptotic protein $\mathrm{Bcl}$ 2 , and downregulated the expression of the apoptotic protein Bax and cleaved-caspase-3 (Hua et al., 2019). This suggests that PNU-282987 may be a potential drug for restoring astroglial 
function in the treatment of PD via astroglial $\alpha 7 \mathrm{nAChR}-J N K-$ p53 signaling.

Recent literature has described how the vagus nerve may play an important role in the pathogenesis of PD. Reflecting our previous discussion on the function of the vagus in the CAP, disruption in vagal cholinergic signaling could promote a neuroinflammatory state. Studies using murine models have shown that in advanced age, vagal visceral sensory innervation of the gastrointestinal tract is reduced (Phillips and Powley, 2001; West et al., 2019). Additionally, in aging the vagus nerve is found to reduce in size (Walter et al., 2018) and afferent fibers are found to regress and undergo dystrophic changes (Phillips et al., 2010). Further research is required to understand how changes to vagal afferent fibers might impact neuroimmune signaling and the CAP. Recent literature discussing the vagus nerve during aging focuses on its role in the gut-brain axis and PD. It has been suggested that truncal vagotomy could reduce the risk of PD development (Liu et al., 2017). Prodromal gut dysfunction and inflammation have been found to precede motor symptoms of PD by decades (Nair et al., 2018). The vagus nerve acts as the main link between the gut-brain axis and inflammation or a prion-like cascade of $\alpha$-synuclein may be propagated to the CNS via the vagus nerve (Liddle, 2018). Even throughout life, gut infections by vagal signaling could influence an endophenotype of microglial cells that promotes neurodegeneration in later decades (Desplats et al., 2019). A better understanding of vagal neuroimmune signaling could provide insight into the progression of $\mathrm{PD}$.

\section{Dementias Associated With Chronic Pain}

Chronic pain occurs due to altered neuronal plasticity, and this includes altered sensitization of peripheral primary sensory neurons in the dorsal root ganglia and trigeminal ganglia, as well as the sensitization of central nociceptive neurons in the spinal cord, trigeminal nucleus, BS, and cortex (Ji et al., 2014). Clinically, chronic pain is defined as pain lasting more than 3 months and is typically characterized by hyperalgesia (an increased response to noxious thermal and mechanical stimuli) and allodynia (nociceptive responses to normally innocuous stimuli such as light touch; Ji et al., 2014).

Neuroinflammation plays an important role in the induction and maintenance of chronic pain (Ji et al., 2014). Unlike acute inflammation that produces transient central sensitization, chronic pain is associated with producing a long-lasting or permanent central sensitization that persists even after the acute inflammation has been resolved (Ji et al., 2014). Chronic pain affects up to $30 \%$ of older adults worldwide (Larsson et al., 2017). Generally, it is associated with abnormalities in sensory processes, but it is highly associated with cognitive, emotional, and social dysfunction (Malfliet et al., 2017). The Einstein Aging Study showed that chronic pain is associated with dementia, and $10 \%$ of the 1114 elderly participants in the study developed dementia over 4.4 years (Katz et al., 2012; Ezzati et al., 2019). Moreover, a recent review summarized evidence for a possible mechanism of chronic pain-induced $\mathrm{AD}$ pathogenesis through LC-noradrenaline (NE) system dysfunction and microglial neuroinflammation (Cao M. et al., 2019). They suggested that chronic pain may induce pathological activation of the LC-NE system and lead to an increased NE release in brain areas such as the PFC and hippocampus, which could then result in chronic pain-induced microglial pro-inflammatory activation. Thus, this microglial pro-inflammatory activation may aggravate $\mathrm{AD}$ pathogenesis via decreased $A \beta$ phagocytosis, increased tau seeding, loss of synaptic function, and cytokine-induced neuron death in these brain regions (Cao S. et al., 2019).

While the hippocampus appears to play a vital role in pain perception and processing, this limbic structure shows high expression of microglial cells (Soleimannejad et al., 2007; Tan et al., 2020). As mentioned previously, while microglia contribute to the early development of chronic pain, dysregulation of astrocyte function is required to sustain developed chronic pain (Jha et al., 2012). Furthermore, hippocampal $\mathrm{ACh}$ is an important mediator in regulating chronic pain-induced behavioral deficits and studies have demonstrated antinociceptive effects of cholinergic compounds (Jiao et al., 2009; Chen et al., 2016). The compound 3a,4,5,9bTetrahydro-4-(1-naphthalenyl)-3H-cyclopentan[c] quinoline-8sulfonamide (TQS) is a $\alpha 7 \mathrm{nAChR}$ PAM. A study using a mouse model of LPS-induced neuroinflammatory pain demonstrated that TQS reduced hippocampal microglial activation and hyperalgesia and allodynia, an effect that was reversed by pre-treatment with the $\alpha 7 \mathrm{nAChR}$ antagonist MLA (Abbas and Rahman, 2016). Microglia regulate the transcription of various pain mediating genes, including the inhibitor of $\kappa \mathrm{B}$ (IкB) mRNA (Abbas et al., 2017). Within the cytoplasm of resting-state microglia, I $\mathrm{KB}$ is bound to NF- $\kappa \mathrm{B}$, preventing inflammatory signaling (Abbas et al., 2017). When stimulated, IкB becomes phosphorylated and unmasks NF-кB from an inactive to an active state (Abbas et al., 2017). Activated NF- $\kappa B$ then translocates to the nucleus and positively regulates the transcription of various pain mediating genes ( $\mathrm{Li}$ and Verma, 2002; Abbas et al., 2017). Increased IкB mRNA and CD11b mRNA, which is a microglial activation marker in the brain, are expressed simultaneously during hyperalgesia and allodynia (Loram et al., 2010; Abbas et al., 2017). Recently, Abbas and Rahman, demonstrated the $\alpha 7 \mathrm{nAChR}$ PAM decreases IкB and $\mathrm{CD} 11 \mathrm{~b}$ gene expression and microglial activation associated with hyperalgesia and allodynia, by targeting microglial $\alpha 7 \mathrm{nAChR}$ in the hippocampus (Abbas et al., 2017). Thus, targeting excessive neuroinflammation could offer new therapeutic approaches when managing chronic pain related neurological and cognitive disorders. In addition, these findings suggest that a $\alpha 7 \mathrm{nAChR}$ PAM may represent a new treatment approach for allodynia and hyperalgesia associated with microglial activation during chronic pain (Abbas and Rahman, 2016; Abbas et al., 2017).

\section{CONCLUSIONS}

This review has summarized research on the cholinergic modulation on glial function, with a particular focus upon aging and chronic neuroinflammation in the CNS. The BF provides cholinergic inputs into various brain regions including 
the hippocampus and the cortical areas, regions with important higher cognitive functions. It has been shown that nicotinic receptor $\alpha 7 \mathrm{nAChR}$ is expressed on hippocampal neurons, and is involved in neuroprotective processes. This is evidenced by the direct activation of neuronal $\alpha 7 \mathrm{nAChR}$ reversing cholinergic pathway-dependent cognitive deficits. The nicotinic $\mathrm{BF}$ inputs to hippocampal regions not only modulate neuronal $\alpha 7 \mathrm{nAChR}$ receptors but also have a substantial influence upon hippocampal glia. Both astrocytes and microglia are involved in the cholinergic anti-inflammatory pathway via $\alpha 7 \mathrm{nAChR}$ expression. This has been demonstrated by modulation of microglial and astrocytic nicotinic receptor activity, which results in $\mathrm{A} \beta$ phagocytosis and cognitive improvement in neurodegenerative disease states. Expression of GDNF is stimulated by the activation of $\alpha 7 \mathrm{nAChRs}$ which inhibit microglial activation, leading to neuronal protection. Wider and more extensive studies on microglial $\alpha 7 n A C h R$ may lead to the use of microglial function in the diagnostic screening of dementias.

The effects of the cholinergic BF projections on anti-inflammatory and anti-oxidant processes is not a simple unilateral interaction between $\mathrm{BF}$ projections and neurons, microglia, and astrocytes, but a multilateral integration of these components. This is evident in the extensive cellular relationship between microglia and astrocytes. Hence, the disruption of

\section{REFERENCES}

Abutbul, S., Shapiro, J., Szaingurten-Solodkin, I., Levy, N., Carmy, Y., Baron, R., et al. (2012). TGF- $\beta$ signaling through SMAD2/3 induces the quiescent microglial phenotype within the CNS environment. Glia 60, 1160-1171. doi: 10.1002/glia.22343

Armstrong, R. A. (2019). Risk factors for Alzheimer's disease. Folia Neuropathol. 57, 87-105. doi: 10.5114/fn.2019.85929

Abbas, M., Alzarea, S., Papke, R. L., and Rahman, S. (2017). The $\alpha 7$ nicotinic acetylcholine receptor positive allosteric modulator attenuates lipopolysaccharide-induced activation of hippocampal IкB and CD11b gene expression in mice. Drug Discov. Ther. 11, 206-211. doi: 10.5582/ddt.2017. 01038

Abbas, M., and Rahman, S. (2016). Effects of $\alpha-7$ nicotinic acetylcholine receptor positive allosteric modulator on lipopolysaccharide-induced neuroinflammatory pain in mice. Eur. J. Pharmacol. 783, 85-91. doi: 10.1016/j. ejphar.2016.05.003

Agostinelli, L. J., Geerling, J. C., and Scammell, T. E. (2019). Basal forebrain subcortical projections. Brain Struct. Funct. 224, 1097-1117. doi: 10.1007/s00429-018-01820-6

Aisa, B., Gil-Bea, F. J., Marcos, B., Tordera, R., Lasheras, B., Del Río, J., et al. (2009). Neonatal stress affects vulnerability of cholinergic neurons and cognition in the rat: involvement of the HPA axis. Psychoneuroendocrinology 34, 1495-1505. doi: 10.1016/j.psyneuen.2009.05.003

Akaike, A., and Izumi, Y. (2018). "Overview," in Nicotinic Acetylcholine Receptor Signaling in Neuroprotection, eds A. Akaike, S. Shimohama and Y. Misu (Singapore: Springer). doi: 10.1007/978-981-10-8488-1_1

Al-Haddad, B. J. S., Jacobsson, B., Chabra, S., Modzelewska, D., Olson, E. M., Bernier, R., et al. (2019). Long-term risk of neuropsychiatric disease after exposure to infection in utero. JAMA Psychiatry 76, 594-602. doi: 10.1001/jamapsychiatry.2019.0029

Alzarea, S., and Rahman, S. (2019). $\alpha-7$ nicotinic receptor allosteric modulator PNU120596 prevents lipopolysaccharide-induced anxiety, cognitive deficit and depression-like behaviors in mice. Behav. Brain Res. 366, 19-28. doi: 10.1016/j. bbr.2019.03.019 the cholinergic BF system, via neurodegeneration, energy loss, infection, or aging, may play a significant role in the development of neurodegenerative diseases.

\section{AUTHOR CONTRIBUTIONS}

All authors have contributed to conceiving the idea of this review, reviewed the literature, and contributed to the writing and editing of this manuscript. All authors have approved this manuscript. RG and IW have contributed equally to this manuscript as the first authors. All authors contributed to the article and approved the submitted version.

\section{FUNDING}

This work was supported by the Ainsworth Medical Research Innovation Fund (MRIF) award to EG. The PhD scholarships held by IR and IW were supported by the Ainsworth WRIF, Western Sydney University Graduate Research School, and Indena SpA, Italy combined scholarship program. RG was supported by a Western Sydney University Graduate Research School scholarship award. RC was supported by the Ainsworth Medical Research Innovation Fund (Project Grant 2019) and the Rebecca Cooper Medical Research Foundation (Project Grant 2020).

Amzica, F., and Neckelmann, D. (1999). Membrane capacitance of cortical neurons and glia during sleep oscillations and spike-wave seizures. J. Neurophysiol. 82, 2731-2746. doi: 10.1152/jn.1999.82.5.2731

André, C., Santos, G. D., and Koulakoff, A. (1994). Muscarinic receptor profiles of mouse brain astrocytes in culture vary with their tissue of origin but differ from those of neurons. Eur. J. Neurosci. 6, 1702-1709. doi: 10.1111/j.1460-9568.1994. tb00562.x

Arai, Y., Martin-Ruiz, C. M., Takayama, M., Abe, Y., Takebayashi, T., Koyasu, S. et al. (2015). Inflammation, but not telomere length, predicts successful ageing at extreme old age: a longitudinal study of semi-supercentenarians. EBioMedicine 2, 1549-1558. doi: 10.1016/j.ebiom.2015.07.029

Araque, A., Martín, E. D., Perea, G., Arellano, J. I., and Buño, W. (2002). Synaptically released acetylcholine evokes $\mathrm{Ca}^{2+}$ elevations in astrocytes in hippocampal slices. J. Neurosci. 22, 2443-2450. doi: 10.1523/jneurosci.22-0702443.2002

Argaw, A. T., Asp, L., Zhang, J., Navrazhina, K., Pham, T., Mariani, J. N., et al. (2012). Astrocyte-derived VEGF-A drives blood-brain barrier disruption in CNS inflammatory disease. J. Clin. Invest. 122, 2454-2468. doi: 10.1172/JCI60842

Bachiller, S., Jiménez-Ferrer, I., Paulus, A., Yang, Y., Swanberg, M., Deierborg, T., et al. (2018). Microglia in neurological diseases: a road map to braindisease dependent-inflammatory response. Front. Cell. Neurosci. 12:488. doi: $10.3389 /$ fncel.2018.00488

Baglietto-Vargas, D., Chen, Y., Suh, D., Ager, R. R., Rodriguez-Ortiz, C. J., Medeiros, R., et al. (2015). Short-term modern life-like stress exacerbates A $\beta$ pathology and synapse loss in 3xTg-AD mice. J. Neurochem. 134, 915-926. doi: 10.1111/jnc.13195

Ballinger, E. C., Ananth, M., Talmage, D. A., and Role, L. W. (2016). Basal forebrain cholinergic circuits and signaling in cognition and cognitive decline. Neuron 91, 1199-1218. doi: 10.1016/j.neuron.2016.09.006

Bard, F., Cannon, C., Barbour, R., Burke, R. L., Games, D., Grajeda, H., et al. (2000). Peripherally administered antibodies against amyloid $\beta$-peptide enter the central nervous system and reduce pathology in a mouse model of Alzheimer disease. Nat. Med. 6, 916-919. doi: 10.1038/ 78682 
Barrett, M. J., Cloud, L. J., Shah, H., and Holloway, K. L. (2020). Therapeutic approaches to cholinergic deficiency in Lewy body diseases. Expert Rev. Neurother. 20, 41-53. doi: 10.1080/14737175.2020.1676152

Bartsch, T., and Wulff, P. (2015). The hippocampus in aging and disease: From plasticity to vulnerability. Neuroscience 309, 1-16. doi: 10.1016/j.neuroscience. 2015.07.084

Bartus, R. T. III., D, R., B, B., and AS, L. (1982). The cholinergic hypothesis of geriatric memory dysfunction. Science $217,408-417$. doi: 10.1126/science. 7046051

Baxter, M. G., Bucci, D. J., Gorman, L. K., Wiley, R. G., and Gallagher, M. (2013). Selective immunotoxic lesions of basal forebrain cholinergic cells: Effects on learning and memory in rats. Behav. Neurosci. 127, 619-627. doi: 10.1037/a0033939

Bélanger, M., Allaman, I., and Magistretti, P. J. (2011). Brain energy metabolism: focus on astrocyte-neuron metabolic cooperation. Cell Metab. 14, 724-738. doi: 10.1016/j.cmet.2011.08.016

Ben Achour, S., and Pascual, O. (2010). Glia: the many ways to modulate synaptic plasticity. Neurochem. Int. 57, 440-445. doi: 10.1016/j.neuint.2010.02.013

Bezzi, P., Carmignoto, G., Pasti, L., Vesce, S., Rossi, D., Rizzini, B. L., et al. (1998). Prostaglandins stimulate calcium-dependent glutamate release in astrocytes. Nature 391, 281-285. doi: 10.1038/34651

Bezzi, P., Domercq, M., Brambilla, L., Galli, R., Schols, D., De Clercq, E., et al. (2001). CXCR4-activated astrocyte glutamate release via TNFa: Amplification by microglia triggers neurotoxicity. Nat. Neurosci. 4, 702-710. doi: $10.1038 / 89490$

Bezzi, P., Gundersen, V., Galbete, J. L., Seifert, G., Steinhäuser, C., Pilati, E., et al. (2004). Astrocytes contain a vesicular compartment that is competent for regulated exocytosis of glutamate. Nat. Neurosci. 7, 613-620. doi: $10.1038 / \mathrm{nn} 1246$

Bi, F., Huang, C., Tong, J., Qiu, G., Huang, B., Wu, Q., et al. (2013). Reactive astrocytes secrete $\mathrm{lcn} 2$ to promote neuron death. Proc. Natl. Acad. Sci. U S A 110, 4069-4074. doi: 10.1073/pnas.1218497110

Bianco, F., Pravettoni, E., Colombo, A., Schenk, U., Möller, T., Matteoli, M., et al. (2005). Astrocyte-derived ATP induces vesicle shedding and IL-1 $1 \beta$ release from microglia. J. Immunol. 174, 7268-7277. doi: 10.4049/jimmunol.174. 11.7268

Biber, K., Neumann, H., Inoue, K., and Boddeke, H. W. G. M. (2007). Neuronal "On" and "Off" signals control microglia. Trends Neurosci. 30, 596-602. doi: $10.1016 /$ j.tins.2007.08.007

Bonaz, B., Sinniger, V., and Pellissier, S. (2016). Anti-inflammatory properties of the vagus nerve: potential therapeutic implications of vagus nerve stimulation. J. Physiol. 594, 5781-5790. doi: 10.1113/jp271539

Boisvert, M. M., Erikson, G. A., Shokhirev, M. N., and Allen, N. J. (2018). The aging astrocyte transcriptome from multiple regions of the mouse brain. Cell Rep. 22, 269-285. doi: 10.1016/j.celrep.2017.12.039

Boskovic, Z., Meier, S., Wang, Y., Milne, M. R., Onraet, T., Tedoldi, A., et al. (2019). Regulation of cholinergic basal forebrain development, connectivity and function by neurotrophin receptors. Neuronal Signal. 3:NS20180066. doi: $10.1042 / \mathrm{ns} 20180066$

Brambilla, R., Bracchi-Ricard, V., Hu, W. H., Frydel, B., Bramwell, A., Karmally, S., et al. (2005). Inhibition of astroglial nuclear factor- $\mathrm{KB}$ reduces inflammation and improves functional recovery after spinal cord injury. J. Exp. Med. 202, 145-156. doi: 10.1084/jem.20041918

Brambilla, R., Persaud, T., Hu, X., Karmally, S., Shestopalov, V. I., Dvoriantchikova, G., et al. (2009). Transgenic inhibition of astroglial NF- $\mathrm{kB}$ improves functional outcome in experimental autoimmune encephalomyelitis by suppressing chronic central nervous system inflammation. J. Immunol. 182, 2628-2640. doi: 10.4049/jimmunol.0802954

Brawek, B., and Garaschuk, O. (2013). Microglial calcium signaling in the adult, aged and diseased brain. Cell Calcium 53, 159-169. doi: 10.1016/j.ceca.2012. 12.003

Broncel, A., Bocian, R., Kłos-Wojtczak, P., and Konopacki, J. (2018). Medial septal cholinergic mediation of hippocampal theta rhythm induced by vagal nerve stimulation. PLoS One 13:e0206532. doi: 10.1371/journal.pone.0206532

Burghaus, L., Schütz, U., Krempel, U., De Vos, R. A. I., Jansen Steur, E. N. H., Wevers, A., et al. (2000). Quantitative assessment of nicotinic acetylcholine receptor proteins in the cerebral cortex of Alzheimer patients. Mol. Brain Res. 76, 385-388. doi: 10.1016/s0169-328x(00)00031-0
Butovsky, O., Jedrychowski, M. P., Moore, C. S., Cialic, R., Lanser, A. J., Gabriely, G., et al. (2014). Identification of a unique TGF- $\beta$-dependent molecular and functional signature in microglia. Nat. Neurosci. 17, 131-143. doi: $10.1038 / \mathrm{nn} .3599$

Caldarone, B. J., Duman, C. H., and Picciotto, M. R. (2000). Fear conditioning and latent inhibition in mice lacking the high affinity subclass of nicotinic acetylcholine receptors in the brain. Neuropharmacology 39, 2779-2784. doi: 10.1016/s0028-3908(00)00137-4

Cao, M., Cortes, M., Moore, C. S., Leong, S. Y., Durosier, L. D., Burns, P., et al. (2015). Fetal microglial phenotype in vitro carries memory of prior in vivo exposure to inflammation. Front. Cell. Neurosci. 9:294. doi: 10.3389/fncel.2015. 00294

Cao, S., Fisher, D. W., Yu, T., and Dong, H. (2019). The link between chronic pain and Alzheimer's disease. J. Neuroinflammation 16, 1-11. doi: 10.1186/s12974019-1608-Z

Cao, M., Macdonald, J. W., Liu, H. L., Weaver, M., Cortes, M., Durosier, L. D., et al. (2019). $\alpha 7$ nicotinic acetylcholine receptor signaling modulates ovine fetal brain astrocytes transcriptome in response to endotoxin. Front. Immunol. 10:1063. doi: 10.3389/fimmu.2019.01063

Caruso, A., Nicoletti, F., Gaetano, A., and Scaccianoce, S. (2019). Risk factors for Alzheimer's disease: focus on stress. Front. Pharmacol. 10:976 doi: 10.3389/fphar.2019.00976

Caruso, A., Nicoletti, F., Mango, D., Saidi, A., Orlando, R., and Scaccianoce, S. (2018). Stress as risk factor for Alzheimer's disease. Pharmacol. Res. 132, 130-134. doi: 10.1016/j.phrs.2018.04.017

Cekanaviciute, E., Fathali, N., Doyle, K. P., Williams, A. M., Han, J., and Buckwalter, M. S. (2014). Astrocytic transforming growth factor- $\beta$ signaling reduces subacute neuroinflammation after stroke in mice. Glia 62, 1227-1240. doi: 10.1002/glia.22675

Chen, S. P., Kan, Y., Zhang, J. L., Wang, J. Y., Gao, Y. H., Qiao, L. N., et al. (2016). Involvement of hippocampal acetylcholinergic receptors in electroacupuncture analgesia in neuropathic pain rats. Behav. Brain Funct. 12:13. doi: 10.1186/s12993-016-0096-x

Chiu, I. M., Morimoto, E. T. A., Goodarzi, H., Liao, J. T., O'Keeffe, S., Phatnani, H. P., et al. (2013). A neurodegeneration-specific gene-expression signature of acutely isolated microglia from an amyotrophic lateral sclerosis mouse model. Cell Rep. 4, 385-401. doi: 10.1016/j.celrep.2013. 06.018

Christensen, M. H., and Kohlmeier, K. A. (2016). Age-related changes in functional postsynaptic nicotinic acetylcholine receptor subunits in neurons of the laterodorsal tegmental nucleus, a nucleus important in drug addiction. Addict. Biol. 21, 267-281. doi: 10.1111/adb.12194

Clayton, K. A., Van Enoo, A. A., and Ikezu, T. (2017). Alzheimer's disease: The role of microglia in brain homeostasis and proteopathy. Front. Neurosci. 11, 1-23. doi: $10.3389 /$ fnins. 2017.00680

Colás, L., Domercq, M., Ramos-Cabrer, P., Palma, A., Gómez-Vallejo, V., Padro, D., et al. (2018). In vivo imaging of A7 nicotinic receptors as a novel method to monitor neuroinflammation after cerebral ischemia. Glia 66, 1611-1624. doi: 10.1002/glia.23326

Colombo, E., Cordiglieri, C., Melli, G., Newcombe, J., Krumbholz, M., Parada, L. F., et al. (2012). Stimulation of the neurotrophin receptor TR $\beta B$ on astrocytes drives nitric oxide production and neurodegeneration. J. Exp. Med. 209, 521-535. doi: 10.1084/jem.20110698

Colombo, E., and Farina, C. (2016). Astrocytes: key regulators of neuroinflammation. Trends Immunol. 37, 608-620. doi: 10.1016/j.it.2016 06.006

Colton, C. A. (2009). Heterogeneity of microglial activation in the innate immune response in the brain. J. Neuroimmune Pharmacol. 4, 399-418. doi: 10.1007/s11481-009-9164-4

Cortes, M., Cao, M., Liu, H. L., Burns, P., Moore, C., Fecteau, G., et al. (2017a). RNAseq profiling of primary microglia and astrocyte cultures in near-term ovine fetus: A glial in vivo-in vitro multi-hit paradigm in large mammalian brain. J. Neurosci. Methods 276, 23-32. doi: 10.1016/j.jneumeth.2016.11.008

Cortes, M., Cao, M., Liu, H. L., Moore, C. S., Durosier, L. D., Burns, P., et al. (2017b). $\alpha 7$ nicotinic acetylcholine receptor signaling modulates the inflammatory phenotype of fetal brain microglia: First evidence of interference by iron homeostasis. Sci. Rep. 7:10645. doi: 10.1038/s41598-01709439-z 
Coughlin, J. M., Du, Y., Rosenthal, H. B., Slania, S., Min Koo, S., Park, A., et al. (2018). The distribution of the $\alpha 7$ nicotinic acetylcholine receptor in healthy aging: An in vivo positron emission tomography study with $\left[{ }^{18} \mathrm{~F}\right] \mathrm{ASEM}$. Neuroimage 165, 118-124. doi: 10.1016/j.neuroimage.2017.10.009

Court, J. A., Ballard, C. G., Piggott, M. A., Johnson, M., O’Brien, J. T., Holmes, C., et al. (2001). Visual hallucinations are associated with lower $\alpha$ bungarotoxin binding in dementia with Lewy bodies. Pharmacol. Biochem. Behav. 70, 571-579. doi: 10.1016/s0091-3057(01)00644-x

Court, J. A., Lloyd, S., Johnson, M., Griffiths, M., Birdsall, N. J. M., Piggott, M. A., et al. (1997). Nicotinic and muscarinic cholinergic receptor binding in the human hippocampal formation during development and aging. Dev. Brain Res. 101, 93-105. doi: 10.1016/s0165-3806(97)00052-7

Cragnolini, A. B., Huang, Y., Gokina, P., and Friedman, W. J. (2009). Nerve growth factor attenuates proliferation of astrocytes via the p75 neurotrophin receptor. Glia 57, 1386-1392. doi: 10.1002/glia.20857

Cunningham, C. (2013). Microglia and neurodegeneration: the role of systemic inflammation. Glia 61, 71-90. doi: 10.1002/glia.22350

Czarnecki, A., Le Corronc, H., Rigato, C., Le Bras, B., Couraud, F., Scain, A. L., et al. (2014). Acetylcholine controls GABA-, glutamate- and glycine- dependent giant depolarizing potentials that govern spontaneous motoneuron activity at the onset of synaptogenesis in the mouse embryonic spinal cord. J. Neurosci. 34, 6389-6404. doi: 10.1523/jneurosci.2664-13.2014

Dajas-Bailador, F. A., Lima, P. A., and Wonnacott, S. (2000). The $\alpha 7$ nicotinic acetylcholine receptor subtype mediates nicotine protection against NMDA excitotoxicity in primary hippocampal cultures through a $\mathrm{Ca}^{2+}$ dependent mechanism. Neuropharmacology 39, 2799-2807. doi: 10.1016/s00283908(00)00127-1

Damani, M. R., Zhao, L., Fontainhas, A. M., Amaral, J., Fariss, R. N., and Wong, W. T. (2011). Age-related alterations in the dynamic behavior of microglia. Aging Cell 10, 263-276. doi: 10.1111/j.1474-9726.2010.00660.x

Dani, J. A., and Bertrand, D. (2007). Nicotinic acetylcholine receptors and nicotinic cholinergic mechanisms of the central nervous system. Annu. Rev. Pharmacol. Toxicol. 47, 699-729. doi: 10.1146/annurev.pharmtox.47.120505. 105214

De Jonge, W. J., and Ulloa, L. (2007). The $\alpha 7$ nicotinic acetylcholine receptor as a pharmacological target for inflammation. Br. J. Pharmacol. 151, 915-929. doi: 10.1038/sj.bjp.0707264

De Keyser, J., Mostert, J. P., and Koch, M. W. (2008). Dysfunctional astrocytes as key players in the pathogenesis of central nervous system disorders. J. Neurol. Sci. 267, 3-16. doi: 10.1016/j.jns.2007.08.044

De Simone, R., Ajmone-Cat, M. A., Carnevale, D., and Minghetti, L. (2005). Activation of $\alpha 7$ nicotinic acetylcholine receptor by nicotine selectively up-regulates cyclooxygenase- 2 and prostaglandin E2 in rat microglial cultures. J. Neuroinflammation 2:4. doi: 10.1186/1742-2094-2-4

Deczkowska, A., Keren-Shaul, H., Weiner, A., Colonna, M., Schwartz, M., and Amit, I. (2018). Disease-associated microglia: a universal immune sensor of neurodegeneration. Cell 173, 1073-1081. doi: 10.1016/j.cell.2018.05.003

Della Bianca, V., Dusi, S., Bianchini, E., Dal Prà, I., and Rossi, F. (1999). $\beta$-amyloid activates the O-2 forming NADPH oxidase in microglia, monocytes and neutrophils. A possible inflammatory mechanism of neuronal damage in Alzheimer's disease. J. Biol. Chem. 274, 15493-15499. doi: 10.1074/jbc.274.22. 15493

Demetrius, L. A., Magistretti, P. J., and Pellerin, L. (2015). Alzheimer's disease: The amyloid hypothesis and the Inverse Warburg effect. Front. Physiol. 5:522. doi: 10.3389/fphys.2014.00522

Desplats, P., Gutierrez, A. M., Antonelli, M. C., and Frasch, M. G. (2019). Microglial memory of early life stress and inflammation: susceptibility to neurodegeneration in adulthood. Neurosci. Biobehav. Rev. doi: 10.1016/j. neubiorev.2019.10.013 [Epub ahead of print].

Deture, M. A., and Dickson, D. W. (2019). The neuropathological diagnosis of Alzheimer's disease. Mol. Neurodegener. 14:32. doi: 10.1186/s13024-0190333-5

Di Cesare Mannelli, L., Tenci, B., Zanardelli, M., Failli, P., and Ghelardini, C. (2015). A7 nicotinic receptor promotes the neuroprotective functions of astrocytes against oxaliplatin neurotoxicity. Neural Plast. 2015:396908. doi: $10.1155 / 2015 / 396908$

Dilger, R. N., and Johnson, R. W. (2008). Aging, microglial cell priming and the discordant central inflammatory response to signals from the peripheral immune system. J. Leukoc. Biol. 84, 932-939. doi: 10.1189/jlb.02 08108

Duda, J. E. (2004). Pathology and neurotransmitter abnormalities of dementia with Lewy bodies. Dement. Geriatr. Cogn. Disord. 17, 3-14. doi: 10.1159/000074677

Dumas, J. A., and Newhouse, P. A. (2011). The cholinergic hypothesis of cognitive aging revisited again: cholinergic functional compensation. Pharmacol. Biochem. Behav. 99, 254-261. doi: 10.1016/j.pbb.2011.02.022

Dutta, G., Zhang, P., and Liu, B. (2008). The lipopolysaccharide Parkinson's disease animal model: Mechanistic studies and drug discovery. Fundam. Clin. Pharmacol. 22, 453-464. doi: 10.1111/j.1472-8206.2008.00616.x

Easton, A., Douchamps, V., Eacott, M., and Lever, C. (2012). A specific role for septohippocampal acetylcholine in memory? Neuropsychologia 50, 3156-3168. doi: 10.1016/j.neuropsychologia.2012.07.022

English, B. A., and Jones, C. K. (2012). "Cholinergic neurotransmission," Primer on the Autonomic Nervous System, in D. Robertson, I. Biaggioni, G. Burnstock, P. A. Low and J. F. R. Paton (Cambridge, MA: Academic Press), 71-74

Ewers, M., Franzmeier, N., Suárez-Calvet, M., Morenas-Rodriguez, E., Angel, M., and Caballero, A. (2019). Increased soluble TREM2 in cerebrospinal fluid is associated with reduced cognitive and clinical decline in Alzheimer's disease for the Alzheimer's Disease Neuroimaging Initiative. Sci. Transl. Med. 11:eaav6221. doi: 10.1126/scitranslmed.aav6221

Ezzati, A., Wang, C., Katz, M. J., Derby, C. A., Zammit, A. R., Zimmerman, M. E., et al. (2019). The temporal relationship between pain intensity and pain interference and incident dementia. Curr. Alzheimer Res. 16, 109-115. doi: 10.2174/1567205016666181212162424

Fairlie-Clarke, K., Barbour, M., Wilson, C., Hridi, S. U., Allan, D., and Jiang, H. R. (2018). Expression and function of IL-33/ST2 axis in the central nervous system under normal and diseased conditions. Front. Immunol. 9:2596 doi: 10.3389/fimmu.2018.02596

Falk, L., Nordberg, A., Seiger, Å., Kjældgaard, A., and Hellström-Lindahl, E. (2003). Higher expression of $\alpha 7$ nicotinic acetylcholine receptors in human fetal compared to adult brain. Dev. Brain Res. 142, 151-160. doi: 10.1016/s01653806(03)00063-4

Farina, C., Aloisi, F., and Meinl, E. (2007). Astrocytes are active players in cerebral innate immunity. Trends Immunol. 28, 138-145. doi: 10.1016/j.it.2007.01.005

Fass, U., Panickar, K., Personett, D., Bryan, D., Williams, K., Gonzales, J., et al. (2000). Differential vulnerability of primary cultured cholinergic neurons to nitric oxide excess. Neuroreport 11, 931-936. doi: 10.1097/00001756200004070-00007

Ferman, T. J., and Boeve, B. F. (2007). Dementia with Lewy bodies. Neurol. Clin. 25, 741-760. doi: 10.1016/j.ncl.2007.03.001

Fontaine, V., Mohand-Said, S., Hanoteau, N., Fuchs, C., Pfizenmaier, K., and Eisel, U. (2002). Neurodegenerative and neuroprotective effects of tumor necrosis factor (TNF) in retinal ischemia: opposite roles of TNF receptor 1 and TNF receptor 2. J. Neurosci. 22:RC216. doi: 10.1523/jneurosci.22-07-j0001. 2002

Foucault-Fruchard, L., and Antier, D. (2017). Therapeutic potential of $\alpha 7$ nicotinic receptor agonists to regulate neuroinflammation in neurodegenerative diseases. Neural Regen. Res. 12, 1418-1421. doi: 10.4103/1673-5374.215244

Francis, P. T., Palmer, A. M., Snape, M., and Wilcock, G. K. (1999). The cholinergic hypothesis of Alzheimer's disease: a review of progress. J. Neurol. Neurosurg. Psychiatry 66, 137-147. doi: 10.1001/jama.281.15.1433

Frank, M. G., Barrientos, R. M., Biedenkapp, J. C., Rudy, J. W., Watkins, L. R., and Maier, S. F. (2006). mRNA up-regulation of MHC II and pivotal pro-inflammatory genes in normal brain aging. Neurobiol. Aging 27, 717-722. doi: 10.1016/j.neurobiolaging.2005.03.013

Frank-Cannon, T. C., Alto, L. T., McAlpine, F. E., and Tansey, M. G. (2009). Does neuroinflammation fan the flame in neurodegenerative diseases? Mol. Neurodegener. 4:47. doi: 10.1186/1750-1326-4-47

Frasch, M. G., Szynkaruk, M., Prout, A. P., Nygard, K., Cao, M., Veldhuizen, R., et al. (2016). Decreased neuroinflammation correlates to higher vagus nerve activity fluctuations in near-term ovine fetuses: a case for the afferent cholinergic anti-inflammatory pathway? J. Neuroinflammation 13:103. doi: 10.1186/s12974-016-0567-x

Freedman, R., Wetmore, C., Stromberg, I., Leonard, S., and Olson, L. (1993). $\alpha$-bungarotoxin binding to hippocampal interneurons: immunocytochemical characterization and effects on growth factor expression. J. Neurosci. 13, 1965-1975. doi: 10.1523/jneurosci.13-05-01965.1993 
Füger, P., Hefendehl, J. K., Veeraraghavalu, K., Wendeln, A. C., Schlosser, C., Obermüller, U., et al. (2017). Microglia turnover with aging and in an Alzheimer's model via long-term in vivo single-cell imaging. Nat. Neurosci. 20, 1371-1376. doi: 10.1038/nn.4631

Fujii, T., Mashimo, M., Moriwaki, Y., Misawa, H., Ono, S., Horiguchi, K., et al. (2017). Expression and function of the cholinergic system in immune cells. Front. Immunol. 8:1085. doi: 10.3389/fimmu.2017.01085

Gaasch, J. A., Lockman, P. R., Geldenhuys, W. J., Allen, D. D., and Van Der Schyf, C. J. (2007). Brain iron toxicity: Differential responses of astrocytes, neurons and endothelial cells. Neurochem. Res. 32, 1196-1208. doi: 10.1007/s11064-007-9290-4

Gahring, L. C., Persiyanov, K., and Rogers, S. W. (2004). Neuronal and astrocyte expression of nicotinic receptor subunit $\beta 4$ in the adult mouse brain. J. Comp. Neurol. 468, 322-333. doi: 10.1002/cne.10942

Gahring, L. C., Persiyanov, K., and Rogers, S. W. (2005). Mouse strain-specific changes in nicotinic receptor expression with age. Neurobiol. Aging 26, 973-980. doi: 10.1016/j.neurobiolaging.2004.07.005

Gallowitsch-Puerta, M., and Pavlov, V. A. (2007). Neuro-immune interactions via the cholinergic anti-inflammatory pathway. Life Sci. 80, 2325-2329. doi: 10.1016/j.lfs.2007.01.002

Gao, H., Danzi, M. C., Choi, C. S., Taherian, M., Dalby-Hansen, C., Ellman, D. G., et al. (2017). Opposing functions of microglial and macrophagic TNFR2 in the pathogenesis of experimental autoimmune encephalomyelitis. Cell Rep. 18, 198-212. doi: 10.1016/j.celrep.2016.11.083

Giri, M., Zhang, M., and Lü, Y. (2016). Genes associated with Alzheimer's disease: An overview and current status. Clin. Interv. Aging 11, 665-681. doi: 10.2147/CIA.S105769

Godbout, J. P., Chen, J., Abraham, J., Richwine, A. F., Berg, B. M., Kelley, K. W., et al. (2005). Exaggerated neuroinflammation and sickness behavior in aged mice after activation of the peripheral innate immune system. FASEB J. 19, 1329-1331. doi: 10.1096/fj.05-3776fje

Gómez-Gonzalo, M., Martin-Fernandez, M., Martínez-Murillo, R., Mederos, S., Hernández-Vivanco, A., Jamison, S., et al. (2017). Neuron-astrocyte signaling is preserved in the aging brain. Glia $65,569-580$. doi: $10.1002 /$ glia. 23112

Gomez-Nicola, D., and Perry, V. H. (2015). Microglial dynamics and role in the healthy and diseased brain: a paradigm of functional plasticity. Neuroscientist 21, 169-184. doi: 10.1177/1073858414530512

Goossens, V., Grooten, J., De Vos, K., and Fiers, W. (1995). Direct evidence for tumor necrosis factor-induced mitochondrial reactive oxygen intermediates and their involvement in cytotoxicity. Proc. Natl. Acad. Sci. U S A 92, 8115-8119. doi: 10.1073/pnas.92.18.8115

Grabert, K., Michoel, T., Karavolos, M. H., Clohisey, S., Kenneth Baillie, J., Stevens, M. P., et al. (2016). Microglial brain region-dependent diversity and selective regional sensitivities to aging. Nat. Neurosci. 19, 504-516. doi: $10.1038 / \mathrm{nn} .4222$

Grothe, M. J., Heinsen, H., Amaro, E., Grinberg, L. T., and Teipel, S. J. (2016). Cognitive correlates of basal forebrain atrophy and associated cortical hypometabolism in mild cognitive impairment. Cereb. Cortex 26, 2411-2426. doi: 10.1093/cercor/bhv062

Grothe, M. J., Schuster, C., Bauer, F., Heinsen, H., Prudlo, J., and Teipel, S. J. (2014). Atrophy of the cholinergic basal forebrain in dementia with Lewy bodies and Alzheimer's disease dementia. J. Neurol. 261, 1939-1948. doi: 10.1007/s00415-014-7439-Z

Gu, Z., Lamb, P. W., and Yakel, J. L. (2012). Cholinergic coordination of presynaptic and postsynaptic activity induces timing-dependent hippocampal synaptic plasticity. J. Neurosci. 32, 12337-12348. doi: 10.1523/jneurosci.212912.2012

Guan, Y. Z., Jin, X. D., Guan, L. X., Yan, H. C., Wang, P., Gong, Z., et al. (2015). Nicotine inhibits microglial proliferation and is neuroprotective in global ischemia rats. Mol. Neurobiol. 51, 1480-1488. doi: 10.1007/s12035-0148825-3

Guan, Z. Z., Zhang, X., Ravid, R., and Nordberg, A. (2000). Decreased protein levels of nicotinic receptor subunits in the hippocampus and temporal cortex of patients with Alzheimer's disease. J. Neurochem. 74, 237-243. doi: 10.1046/j. 1471-4159.2000.0740237.x

Guizzetti, M., Costa, P., Peters, J., and Costa, L. G. (1996). Acetylcholine as a mitogen: Muscarinic receptor-mediated proliferation of rat astrocytes and human astrocytoma cells. Eur. J. Pharmacol. 297, 265-273. doi: 10.1016/00142999(95)00746-6

Guizzetti, M., Moore, N. H., Giordano, G., and Costa, L. G. (2008). Modulation of neuritogenesis by astrocyte muscarinic receptors. J. Biol. Chem. 283, 31884-31897. doi: 10.1074/jbc.m801316200

Haam, J., and Yakel, J. L. (2017). Cholinergic modulation of the hippocampal region and memory function. J. Neurochem. 142, 111-121. doi: 10.1111/jnc. 14052

Hampel, H., Mesulam, M. M., Cuello, A. C., Khachaturian, A. S., Vergallo, A., Farlow, M. R., et al. (2019). Revisiting the cholinergic hypothesis in Alzheimer's disease: emerging evidence from translational and clinical research. J. Prev. Alzheimers Dis. 6, 2-15. doi: 10.14283/jpad.2018.43

Haroon, F., Drögemüller, K., Händel, U., Brunn, A., Reinhold, D., Nishanth, G., et al. (2011). Gp130-dependent astrocytic survival is critical for the control of autoimmune central nervous system inflammation. J. Immunol. 186, 6521-6531. doi: 10.4049/jimmunol.1001135

Hartlage-Rübsamen, M., and Schliebs, R. (2001). Rat basal forebrain cholinergic lesion affects neuronal nitric oxide synthase activity in hippocampal and neocortical target regions. Brain Res. 889, 155-164. doi: 10.1016/s0006 8993(00)03128-0

Hasselmo, M. E. (2006). The role of acetylcholine in learning and memory. Curr. Opin. Neurobiol. 16, 710-715. doi: 10.1016/j.conb.2006.09.002

Henry, C. J., Huang, Y., Wynne, A. M., and Godbout, J. P. (2009). Peripheral lipopolysaccharide (LPS) challenge promotes microglial hyperactivity in aged mice that is associated with exaggerated induction of both pro-inflammatory IL-1 $\beta$ and anti-inflammatory IL-10 cytokines. Brain. Behav. Immun. 23, 309-317. doi: 10.1016/j.bbi.2008.09.002

Heo, S., Prakash, R. S., Voss, M. W., Erickson, K. I., Ouyang, C., Sutton, B. P., et al. (2010). Resting hippocampal blood flow, spatial memory and aging. Brain Res. 1315, 119-127. doi: 10.1016/j.brainres.2009.12.020

Herculano-Houzel, S. (2014). The glia/neuron ratio: How it varies uniformly across brain structures and species and what that means for brain physiology and evolution. Glia 62, 1377-1391. doi: 10.1002/glia.22683

Hernández-Balaguera, E., Vara, H., and Polo, J. L. (2018). Identification of capacitance distribution in neuronal membranes from a fractional-order electrical circuit and whole-cell patch-clamped cells. J. Electrochem. Soc. 165, G3104-G3111. doi: 10.1149/2.0161812jes

Hernangómez, M., Mestre, L., Correa, F. G., Loría, F., Mecha, M., Iñigo, P. M., et al. (2012). CD200-CD200R1 interaction contributes to neuroprotective effects of anandamide on experimentally induced inflammation. Glia 60, 1437-1450. doi: 10.1002/glia.22366

Hindinger, C., Bergmann, C. C., Hinton, D. R., Phares, T. W., Parra, G. I., Hussain, S., et al. (2012). IFN- $\gamma$ signaling to astrocytes protects from autoimmune mediated neurological disability. PLoS One 7:e42088. doi: 10.1371/journal.pone.0042088

Holmes, C. (2013). Review: systemic inflammation and Alzheimer's disease. Neuropathol. Appl. Neurobiol. 39, 51-68. doi: 10.1111/j.1365-2990.2012. 01307.x

Holmes, C., Cunningham, C., Zotova, E., Woolford, J., Dean, C., Kerr, S., et al. (2009). Systemic inflammation and disease progression in Alzheimer disease. Neurology 73, 768-774. doi: 10.1212/WNL.0b013e3181b6bb95

Holtman, I. R., Raj, D. D., Miller, J. A., Schaafsma, W., Yin, Z., Brouwer, N., et al. (2015). Induction of a common microglia gene expression signature by aging and neurodegenerative conditions: a co-expression meta-analysis. Acta Neuropathol. Commun. 3:31. doi: 10.1186/s40478-015-0203-5

Honda, T., and Semba, K. (1995). An ultrastructural study of cholinergic and non-cholinergic neurons in the laterodorsal and pedunculopontine tegmental nuclei in the rat. Neuroscience 68, 837-853. doi: 10.1016/0306-4522(95)00177-k

Hoover, D. B. (2017). Cholinergic modulation of the immune system presents new approaches for treating inflammation. Pharmacol. Ther. 179, 1-16. doi: 10.1016/j.pharmthera.2017.05.002

Hu, J., Liu, C. C., Chen, X. F., Zhang, Y. W., Xu, H., and Bu, G. (2015). Opposing effects of viral mediated brain expression of apolipoprotein E2 (ApoE2) and apoE4 on apoE lipidation and $\mathrm{A} \beta$ metabolism in apoE4-targeted replacement mice. Mol. Neurodegener. 10:6. doi: 10.1186/s13024-015-0001-3

Hua, S., Ek, C. J., Mallard, C., and Johansson, M. E. (2014). Perinatal hypoxiaischemia reduces $\alpha 7$ nicotinic receptor expression and selective $\alpha 7$ nicotinic 
receptor stimulation suppresses inflammation and promotes microglial Mox phenotype. Biomed Res. Int. 2014:718769. doi: 10.1155/2014/718769

Hua, Y., Yang, B., Chen, Q., Zhang, J., Hu, J., and Fan, Y. (2019). Activation of $\alpha 7$ nicotinic acetylcholine receptor protects against 1-methyl-4phenylpyridinium-induced astroglial apoptosis. Front. Cell. Neurosci. 13:507. doi: 10.3389/fncel.2019.00507

Huang, Y., Zhao, Z., Wei, X., Zheng, Y., Yu, J., Zheng, J., et al. (2016). Long-term trihexyphenidyl exposure alters neuroimmune response and inflammation in aging rat: relevance to age and Alzheimer's disease. J. Neuroinflammation 13:175. doi: 10.1186/s12974-016-0640-5

Jakowec, M. W., and Petzinger, G. M. (2004). 1-methyl-4-phenyl-1,2,3,6tetrahydropyridine-lesioned model of Parkinson's disease, with emphasis on mice and nonhuman primates. Comp. Med. 54, 497-513.

Jha, M. K., Jeon, S., and Suk, K. (2012). Glia as a link between neuroinflammation and neuropathic pain. Immune Netw. 12, 41-47. doi: 10.4110/in.2012. 12.2.41

Jha, M. K., Jo, M., Kim, J. H., and Suk, K. (2019). Microglia-astrocyte crosstalk: an intimate molecular conversation. Neuroscientist 25, 227-240. doi: $10.1177 / 1073858418783959$

Ji, R. R., Xu, Z. Z., and Gao, Y. J. (2014). Emerging targets in neuroinflammationdriven chronic pain. Nat. Rev. Drug Discov. 13, 533-548. doi: 10.1038/ $\operatorname{nrd} 4334$

Jiao, R., Yang, C., zhang, Y., Xu, M., and Yang, X. (2009). Cholinergic mechanism involved in the nociceptive modulation of dentate gyrus. Biochem. Biophys. Res. Commun. 379, 975-979. doi: 10.1016/j.bbrc.2008.12.184

Jo, M., Kim, J. H., Song, G. J., Seo, M., Hwang, E. M., and Suk, K. (2017). Astrocytic orosomucoid-2 modulates microglial activation and neuroinflammation. J. Neurosci. 37, 2878-2894. doi: 10.1523/jneurosci.2534-16.2017

Jordão, M. J. C., Sankowski, R., Brendecke, S. M., Sagar, ., Locatelli, G., Tai, Y. H., et al. (2019). Neuroimmunology: Single-cell profiling identifies myeloid cell subsets with distinct fates during neuroinflammation. Science 363:eaat7554. doi: $10.1126 /$ science.aat7554

Moon, J. H., Kim, S. Y., Lee, H. G., Kim, S. U., and Lee, Y. B. (2008). Activation of nicotinic acetylcholine receptor prevents the production of reactive oxygen species in fibrillar $\beta$ amyloid peptide (1-42)-stimulated microglia. Exp. Mol. Med. 40, 11-18. doi: 10.3858/emm.2008.40.1.11

Kaczmarczyk, R., Tejera, D., Simon, B. J., and Heneka, M. T. (2018). Microglia modulation through external vagus nerve stimulation in a murine model of Alzheimer's disease. J. Neurochem. 146, 76-85. doi: 10.1111/jnc. 14284

Kalashnyk, O., Lykhmus, O., Oliinyk, O., Komisarenko, S., and Skok, M. (2014). $\alpha 7$ Nicotinic acetylcholine receptor-specific antibody stimulates interleukin-6 production in human astrocytes through p38-dependent pathway. Int. Immunopharmacol. 23, 475-479. doi: 10.1016/j.intimp.2014.09.022

Kalkman, H. O., and Feuerbach, D. (2016). Modulatory effects of $\alpha 7 \mathrm{nAChRs}$ on the immune system and its relevance for CNS disorders. Cell. Mol. Life Sci. 73, 2511-2530. doi: 10.1007/s00018-016-2175-4

Kaminska, B., Mota, M., and Pizzi, M. (2016). Signal transduction and epigenetic mechanisms in the control of microglia activation during neuroinflammation. Biochim. Biophys. Acta 1862, 339-351. doi: 10.1016/j.bbadis.2015. 10.026

Kanekiyo, T., Xu, H., and Bu, G. (2014). ApoE and A $\beta$ in Alzheimer's disease: Accidental encounters or partners? Neuron $81,740-754$. doi: 10.1016/j.neuron. 2014.01.045

Katz, M. J., Lipton, R. B., Hall, C. B., Zimmerman, M. E., Sanders, A. E., Verghese, J., et al. (2012). Age-specific and sex-specific prevalence and incidence of mild cognitive impairment, dementia and Alzheimer dementia in blacks and whites. Alzheimer Dis. Assoc. Disord. 26, 335-343. doi: 10.1097/wad. 0b013e31823dbcfc

Kékesi, O., Liang, H., Münch, G., Morley, J. W., Gyengesi, E., and Buskila, Y. (2019). The differential impact of acute microglia activation on the excitability of cholinergic neurons in the mouse medial septum. Brain Struct. Funct. 224, 2297-2309. doi: 10.1007/s00429-019-01905-w

Kenny, P. J., File, S. E., and Rattray, M. (2000). Acute nicotine decreases and chronic nicotine increases the expression of brain-derived neurotrophic factor mRNA in rat hippocampus. Mol. Brain Res. 85, 234-238. doi: 10.1016/s0169$328 \mathrm{x}(00) 00246-1$
Khakh, B. S., and Sofroniew, M. V. (2015). Diversity of astrocyte functions and phenotypes in neural circuits. Nat. Neurosci. 18, 942-952. doi: 10.1038/ nn. 4043

Kierdorf, K., and Prinz, M. (2013). Factors regulating microglia activation. Front. Cell. Neurosci. 7:44. doi: 10.3389/fncel.2013.00044

Kihara, T., Shimohama, S., Sawada, H., Honda, K., Nakamizo, T., Shibasaki, H., et al. (2001). $\alpha 7$ nicotinic receptor transduces signals to phosphatidylinositol 3-kinase to block A $\beta$-amyloid-induced neurotoxicity. J. Biol. Chem. 276, 13541-13546. doi: 10.1074/jbc.M008035200

Kim, R. Y., Hoffman, A. S., Itoh, N., Ao, Y., Spence, R., Sofroniew, M. V., et al. (2014). Astrocyte CCL2 sustains immune cell infiltration in chronic experimental autoimmune encephalomyelitis. J. Neuroimmunol. 274, 53-61. doi: 10.1016/j.jneuroim.2014.06.009

Kim, Y. S., Morgan, M. J., Choksi, S., and Liu, Z. G. (2007). TNF-induced activation of the Nox1 NADPH oxidase and its role in the induction of necrotic cell death. Mol. Cell 26, 675-687. doi: 10.1016/j.molcel.2007.04.021

Kitajima, Y., Hori, K., Konishi, K., Tani, M., Tomioka, H., Akashi, N., et al. (2015). A review of the role of anticholinergic activity in lewy body disease and delirium. Neurodegener. Dis. 15, 162-167. doi: 10.1159/000381522

Klinkenberg, I., Sambeth, A., and Blokland, A. (2011). Acetylcholine and attention. Behav. Brain Res. 221, 430-442. doi: 10.1016/j.bbr.2010.11.033

Kobayashi, Y., and Isa, T. (2002). Sensory-motor gating and cognitive control by the brainstem cholinergic system. Neural Netw. 15, 731-741. doi: 10.1016/s0893-6080(02)00059-x

Koistinaho, M., and Koistinaho, J. (2002). Role of p38 and p44/42 mitogenactivated protein kinases in microglia. Glia 40, 175-183. doi: 10.1002/glia 10151

Kok, E., Haikonen, S., Luoto, T., Huhtala, H., Goebeler, S., Haapasalo, H., et al. (2009). Apolipoprotein E-dependent accumulation of alzheimer disease-related lesions begins in middle age. Ann. Neurol. 65, 650-657. doi: 10.1002/ana.21696

Konishi, Y., Yang, L. B., He, P., Lindholm, K., Lu, B., Li, R., et al. (2014). Deficiency of GDNF receptor GFR $\alpha 1$ in Alzheimer's neurons results in neuronal death. J. Neurosci. 275, 27505-27512. doi: 10.1074/jbc.m000306200

Kotagal, V., Müller, M. L. T. M., Kaufer, D. I., Koeppe, R. A., and Bohnen, N. I. (2012). Thalamic cholinergic innervation is spared in Alzheimer disease compared to parkinsonian disorders. Neurosci. Lett. 514, 169-172. doi: 10.1016/j.neulet.2012.02.083

Kox, M., and Pickkers, P. (2015). Modulation of the innate immune response through the vagus nerve. Nephron 131, 79-84. doi: 10.1159/000435843

Kuchibhotla, K. V., Lattarulo, C. R., Hyman, B. T., and Bacskai, B. J. (2009). Synchronous hyperactivity and intercellular calcium waves in astrocytes in Alzheimer mice. Science 323, 1211-1215. doi: 10.1126/science.1169096

Kuzumaki, N., Ikegami, D., Imai, S., Narita, M., Tamura, R., Yajima, M., et al. (2010). Enhanced IL-1 $\beta$ production in response to the activation of hippocampal glial cells impairs neurogenesis in aged mice. Synapse 64, 721-728. doi: 10.1002/syn.20800

Lange, K. W., Wells, F. R., Jenner, P., and Marsden, C. D. (1993). Altered muscarinic and nicotinic receptor densities in cortical and subcortical brain regions in Parkinson's disease. J. Neurochem. 60, 197-203. doi: 10.1111/j.14714159.1993.tb05838.x

Larsson, C., Hansson, E. E., Sundquist, K., and Jakobsson, U. (2017). Chronic pain in older adults: prevalence, incidence, and risk factors. Scand. J. Rheumatol. 46, 317-325. doi: 10.1080/03009742.2016.1218543

Laudenbach, V., Medja, F., Zoli, M., Rossi, F. M., Evrard, P., Changeux, J. P., et al. (2002). Selective activation of central subtypes of the nicotinic acetylcholine receptor has opposite effects on neonatal excitotoxic brain injuries. FASEB J. 16, 423-425. doi: 10.1096/fj.01-0532fje

Lee, C. K., Klopp, R. G., Weindruch, R., and Prolla, T. A. (1999). Gene expression profile of aging and its retardation by caloric restriction. Science 285, 1390-1393. doi: 10.1126/science.285.5432.1390

Lee, S., Park, J. Y., Lee, W. H., Kim, H., Park, H. C., Mori, K., et al. (2009). Lipocalin-2 is an autocrine mediator of reactive astrocytosis. J. Neurosci. 29, 234-249. doi: 10.1523/jneurosci.5273-08.2009

Lehéricy, S., Hirsch, É. C., Cervera-Piérot, P., Hersh, L. B., Bakchine, S., Piette, F., et al. (1993). Heterogeneity and selectivity of the degeneration of cholinergic neurons in the basal forebrain of patients with Alzheimer's disease. J. Comp. Neurol. 330, 15-31. doi: 10.1002/cne.903300103 
Lester, H. A., Dibas, M. I., Dahan, D. S., Leite, J. F., and Dougherty, D. A. (2004). Cys-loop receptors: new twists and turns. Trends Neurosci. 27, 329-336. doi: 10.1016/j.tins.2004.04.002

Levey, A. I. (1996). Muscarinic acetylcholine receptor expression in memory circuits: implications for treatment of Alzheimer disease. Proc. Natl. Acad. Sci. U S A 93, 13541-13546. doi: 10.1073/pnas.93.24.13541

Levi, G., Minghetti, L., and Aloisi, F. (1998). Regulation of prostanoid synthesis in microglial cells and effects of prostaglandin E2 on microglial functions. Biochimie 80, 899-904. doi: 10.1016/s0300-9084(00)88886-0

Levin, E. D., and Simon, B. B. (1998). Nicotinic acetylcholine involvement in cogitive function in animals. Psychopharmacology 138, 217-230. doi: $10.1007 /$ s002130050667

Leyns, C. E. G., Ulrich, J. D., Finn, M. B., Stewart, F. R., Koscal, L. J., Serrano, J. R., et al. (2017). TREM2 deficiency attenuates neuroinflammation and protects against neurodegeneration in a mouse model of tauopathy. Proc. Natl. Acad. Sci. US A 114, 11524-11529. doi: 10.1073/pnas.1710311114

Li, L., Liu, Z., Jiang, Y. Y., Shen, W. X., Peng, Y. P., and Qiu, Y. H. (2019). Acetylcholine suppresses microglial inflammatory response via $\alpha 7 \mathrm{nAChR}$ to protect hippocampal neurons. J. Integr. Neurosci. 18, 51-56. doi: 10.31083/j.jin. 2019.01.114

Li, K., Li, J., Zheng, J., and Qin, S. (2019). Reactive astrocytes in neurodegenerative diseases. Aging Dis. 10, 664-675. doi: 10.14336/ad.2018.0720

Li, S. C., Lindenberger, U., and Sikström, S. (2001). Aging cognition: from neuromodulation to representation. Trends Cogn. Sci. 5, 479-486. doi: 10.1016/s1364-6613(00)01769-1

Liang, K. J., Lee, J. E., Wang, Y. D., Ma, W., Fontainhas, A. M., Fariss, R. N., et al. (2009). Regulation of dynamic behavior of retinal microglia by CX3CR1 signaling. Investig. Ophthalmol. Vis. Sci. 50, 4444-4451. doi: 10.1167/ iovs.08-3357

Liddelow, S. A., Guttenplan, K. A., Clarke, L. E., Bennett, F. C., Bohlen, C. J., Schirmer, L., et al. (2017). Neurotoxic reactive astrocytes are induced by activated microglia. Nature 541, 481-487. doi: 10.1038/nature21029

Liddle, R. A. (2018). Parkinson's disease from the gut. Brain Res. 1693, 201-206. doi: 10.1016/j.brainres.2018.01.010

Lim, S. L., Rodriguez-Ortiz, C. J., and Kitazawa, M. (2015). Infection, systemic inflammation and Alzheimer's disease. Microbes Infect. 17, 549-556. doi: 10.1016/j.micinf.2015.04.004

Li, Q., and Verma, I. M. (2002). NF-кB regulation in the immune system. Nat. Rev. Immunol. 2, 725-734. doi: 10.1038/nri910

Liu, B., Fang, F., Pedersen, N. L., Tillander, A., Ludvigsson, J. F., Ekbom, A., et al. (2017). Vagotomy and Parkinson disease. Neurology 88, 1996-2002. doi: 10.1212/WNL.0000000000003961

Liu, H., Leak, R. K., and Hu, X. (2016). Neurotransmitter receptors on microglia. Stroke Vasc. Neurol. 1, 52-58. doi: 10.1016/j.tins.2007.07.007

Liu, Q., Liu, C., Jiang, L., Li, M., Long, T., He, W., et al. (2018). $\alpha 7$ nicotinic acetylcholine receptor-mediated anti-inflammatory effect in a chronic migraine rat model via the attenuation of Glial cell activation. J. Pain Res. 11, 1129-1140. doi: 10.2147/JPR.S159146

Liu, S., Li, J., Tan, D. T. H., and Beuerman, R. W. (2007). Expression and function of muscarinic receptor subtypes on human cornea and conjunctiva. Investig. Ophthalmol. Vis. Sci. 48, 2987-2996. doi: 10.1167/iovs. 06-0880

Liu, Y., Hu, J., Wu, J., Zhu, C., Hui, Y., Han, Y., et al. (2012). a7 nicotinic acetylcholine receptor-mediated neuroprotection against dopaminergic neuron loss in an MPTP mouse model via inhibition of astrocyte activation. J. Neuroinflammation 9:98.

López-Hernández, G. Y., Ananth, M., Jiang, L., Ballinger, E. C., Talmage, D. A., and Role, L. W. (2017). Electrophysiological properties of basal forebrain cholinergic neurons identified by genetic and optogenetic tagging. J. Neurochem. 142, 103-110. doi: 10.1111/jnc.14073

Loram, L. C., Harrison, J. A., Chao, L., Taylor, F. R., Reddy, A., Travis, C. L., et al. (2010). Intrathecal injection of an $\alpha 7$ nicotinic acetylcholine receptor agonist attenuates gp120-induced mechanical allodynia and spinal pro-inflammatory cytokine profiles in rats. Brain Behav. Immun. 24, 959-967. doi: 10.1016/j.bbi. 2010.03.008

Lu, X., Hong, Z., Tan, Z., Sui, M., Zhuang, Z., Liu, H., et al. (2017). Nicotinic acetylcholine receptor $\alpha 7$ subunit mediates vagus nerve stimulationinduced neuroprotection in acute permanent cerebral ischemia by
a7nAchR/JAK2 pathway. Med. Sci. Monit. 23, 6072-6081. doi: 10.12659/msm. 907628

Lue, L. F., Kuo, Y. M., Beach, T., and Walker, D. G. (2010). Microglia activation and anti-inflammatory regulation in alzheimer's disease. Mol. Neurobiol. 41, 115-128. doi: 10.1007/s12035-010-8106-8

Magnus, T., Chan, A., Linker, R. A., Toyka, K. V., and Gold, R. (2002). Astrocytes are less efficient in the removal of apoptotic lymphocytes than microglia cells: implications for the role of glial cells in the inflamed central nervous system. J. Neuropathol. Exp. Neurol. 61, 760-766. doi: 10.1093/jnen/61.9.760

Mahncke, H. W., Bronstone, A., and Merzenich, M. M. (2006). Chapter 6 Brain plasticity and functional losses in the aged: scientific bases for a novel intervention. Prog. Brain Res. 157, 81-109. doi: 10.1016/s0079-6123(06) 57006-2

Malfliet, A., Coppieters, I., Van Wilgen, P., Kregel, J., De Pauw, R., Dolphens, M., et al. (2017). Brain changes associated with cognitive and emotional factors in chronic pain: a systematic review. Eur. J. Pain 21, 769-786. doi: 10.1002/ ejp.1003

Mangold, C. A., Masser, D. R., Stanford, D. R., Bixler, G. V., Pisupati, A., Giles, C. B., et al. (2017). CNS-wide sexually dimorphic induction of the major histocompatibility complex 1 pathway with aging. J. Gerontol. A Biol. Sci. Med. Sci. 72, 16-29. doi: 10.1093/gerona/glv232

Martelli, D., McKinley, M. J., and McAllen, R. M. (2014). The cholinergic anti-inflammatory pathway: a critical review. Auton. Neurosci. Basic Clin. 182, 65-69. doi: 10.1016/j.autneu.2013.12.007

Martín, A., Szczupak, B., Gómez-Vallejo, V., Domercq, M., Cano, A., Padro, D., et al. (2015). In vivo PET imaging of the $\alpha 4 \beta 2$ nicotinic acetylcholine receptor as a marker for brain inflammation after cerebral ischemia. J. Neurosci. 35, 5998-6009. doi: 10.1523/JNEUROSCI.3670-14.2015

Massey, K. A., Zago, W. M., and Berg, D. K. (2006). BDNF up-regulates $\alpha 7$ nicotinic acetylcholine receptor levels on subpopulations of hippocampal interneurons. Mol. Cell. Neurosci. 33, 381-388. doi: 10.1016/j.mcn.2006.08.011

Matyash, V., and Kettenmann, H. (2010). Heterogeneity in astrocyte morphology and physiology. Brain Res. Rev. 63, 2-10. doi: 10.1016/j.brainresrev.2009. 12.001

Maurer, S. V., and Williams, C. L. (2017). The cholinergic system modulates memory and hippocampal plasticity via its interactions with non-neuronal cells. Front. Immunol. 8:1489. doi: 10.3389/fimmu.2017.01489

Mckeith, I., Del Ser, T., Spano, P., Emre, M., Wesnes, K., Anand, R., et al. (2000). Efficacy of rivastigmine in dementia with Lewy bodies: a randomised double-blind, placebo-controlled international study. Lancet 356, 2031-2036. doi: 10.1016/S0140-6736(00)03399-7

McKinney, M. (2005). Brain cholinergic vulnerability: relevance to behavior and disease. Biochem. Pharmacol. 70, 1115-1124. doi: 10.1016/j.bcp.2005.05.019

McMurtray, A. M., Licht, E., Yeo, T., Krisztal, E., Saul, R. E., and Mendez, M. F. (2008). Positron emission tomography facilitates diagnosis of early-onset alzheimer's disease. Eur. Neurol. 59, 31-37. doi: 10.1159/0001 09258

Medeiros, R., Castello, N. A., Cheng, D., Kitazawa, M., Baglietto-Vargas, D., Green, K. N., et al. (2014). $\alpha 7$ nicotinic receptor agonist enhances cognition in aged $3 \times \mathrm{Tg}-\mathrm{AD}$ mice with robust plaques and tangles. Am. J. Pathol. 184, 520-529.

Mena-Segovia, J. (2016). Structural and functional considerations of the cholinergic brainstem. J. Neural Transm. 123, 731-736. doi: 10.1007/s00702016-1530-9

Meneses, G., Bautista, M., Florentino, A., Díaz, G., Acero, G., Besedovsky, H., et al. (2016). Electric stimulation of the vagus nerve reduced mouse neuroinflammation induced by lipopolysaccharide. J. Inflamm. 13:33. doi: 10.1186/s12950-016-0140-5

Messi, M. L., Renganathan, M., Grigorenko, E., and Delbono, O. (1997). Activation of $\alpha 7$ nicotinic acetylcholine receptor promotes survival of spinal cord motoneurons. FEBS Lett. 411, 32-38.

Mills Ko, E., Ma, J. H., Guo, F., Miers, L., Lee, E., Bannerman, P., et al. (2014). Deletion of astroglial CXCL10 delays clinical onset but does not affect progressive axon loss in a murine autoimmune multiple sclerosis model. J. Neuroinflammation 11:105. doi: 10.1186/1742-2094-11-105

Milner, T. A. (1991). Cholinergic neurons in the rat septal complex: ultrastructural characterization and synaptic relations with catecholaminergic terminals J. Comp. Neurol. 314, 37-54. doi: 10.1002/cne.903140105 
Minghetti, L., and Levi, G. (1995). Induction of prostanoid biosynthesis by bacterial lipopolysaccharide and isoproterenol in rat microglial cultures. J. Neurochem. 65, 2690-2698. doi: 10.1046/j.1471-4159.1995.65062690.x

Mitsis, E. M., Cosgrove, K. P., Staley, J. K., Frohlich, E. B., Bois, F., Tamagnan, G. D., et al. (2007). ${ }^{[123]}$ 5-IA-85380 SPECT imaging of $\beta 2$-nicotinic acetylcholine receptor availability in the aging human brain. Ann. N Y Acad. Sci. 1097, 168-170. doi: 10.1196/annals.1379.015

Moestrup, S. K., and Møller, H. J. (2004). CD163: a regulated hemoglobin scavenger receptor with a role in the anti-inflammatory response. Ann. Med. 36, 347-354. doi: 10.1080/07853890410033171

Mooradian, A. D. (1988). Effect of aging on the blood-brain barrier. Neurobiol. Aging 9, 31-39. doi: 10.1016/s0197-4580(88)80013-7

Mooradian, A. D., Morin, A. M., Cipp, L. J., and Haspel, H. C. (1991). Glucose transport is reduced in the blood-brain barrier of aged rats. Brain Res. 551, 145-149. doi: 10.1016/0006-8993(91)90926-m

Morioka, N., Hisaoka-Nakashima, K., and Nakata, Y. (2018). "Regulation by nicotinic acetylcholine receptors of microglial glutamate transporters: role of microglia in neuroprotection," in Nicotinic Acetylcholine Receptor Signaling in Neuroprotection, eds A. Akaike, S. Shimohama and Y. Misu (Singapore: Springer), 73-88. doi: 10.1007/978-981-10-8488-1_5

Morioka, N., Tokuhara, M., Nakamura, Y., Idenoshita, Y., Harano, S., Zhang, F. F., et al. (2014). Primary cultures of rat cortical microglia treated with nicotine increases in the expression of excitatory amino acid transporter 1 (GLAST) via the activation of the $\alpha 7$ nicotinic acetylcholine receptor. Neuroscience 258, 374-384. doi: 10.1016/j.neuroscience.2013.11.044

Mosconi, L. (2005). Brain glucose metabolism in the early and specific diagnosis of Alzheimer's disease: FDG-PET studies in MCI and AD. Eur. J. Nucl. Med. Mol. Imaging 32, 486-510. doi: 10.1007/s00259-005-1762-7

Mota, B., and Herculano-Houzel, S. (2014). All brains are made of this: a fundamental building block of brain matter with matching neuronal and glial masses. Front. Neuroanat. 8:127. doi: 10.3389/fnana.2014.00127

Nair, A. T., Ramachandran, V., Joghee, N. M., Antony, S., and Ramalingam, G. (2018). Gut microbiota dysfunction as reliable non-invasive early diagnostic biomarkers in the pathophysiology of Parkinson's disease: a critical review. J. Neurogastroenterol. Motil. 24, 30-42. doi: 10.5056/jnm17105

Nava Catorce, M., and Gevorkian, G. (2016). LPS-induced murine neuroinflammation model: main features and suitability for pre-clinical assessment of nutraceuticals. Curr. Neuropharmacol. 14, 155-164. doi: $10.2174 / 1570159 \times 14666151204122017$

Newman, E. L., Gupta, K., Climer, J. R., Monaghan, C. K., and Hasselmo, M. E. (2012). Cholinergic modulation of cognitive processing: insights drawn from computational models. Front. Behav. Neurosci. 6:24. doi: 10.3389/fnbeh.2012. 00024

Nimmerjahn, A., Kirchhoff, F., and Helmchen, F. (2005). Neuroscience: Resting microglial cells are highly dynamic surveillants of brain parenchyma in vivo. Science 308, 1314-1318. doi: 10.1126/science. 1110647

Niranjan, R., Nath, C., and Shukla, R. (2012). Melatonin attenuated mediators of neuroinflammation and $\alpha-7$ nicotinic acetylcholine receptor mRNA expression in lipopolysaccharide (LPS) stimulated rat astrocytoma cells, C6. Free Radic. Res. 46, 1167-1177. doi: 10.3109/10715762.2012.697626

Niraula, A., Sheridan, J. F., and Godbout, J. P. (2017). Microglia priming with aging and stress. Neuropsychopharmacology 42, 318-333. doi: 10.1038/npp.2016.185

Nishimura, J. I., Endo, Y., and Kimura, F. (1992). Increases in cerebral blood flow in rat hippocampus after medial septal injection of naloxone. Stroke 23, 1325-1329. doi: 10.1161/01.str.23.9.1325

Nolan, Y., Maher, F. O., Martin, D. S., Clarke, R. M., Brady, M. T., Bolton, A. E., et al. (2005). Role of interleukin-4 in regulation of age-related inflammatory changes in the hippocampus. J. Biol. Chem. 280, 9354-9362. doi: 10.1074/jbc. $\mathrm{m} 412170200$

Norden, D. M., and Godbout, J. P. (2013). Review: microglia of the aged brain: primed to be activated and resistant to regulation. Neuropathol. Appl. Neurobiol. 39, 19-34. doi: 10.1111/j.1365-2990.2012.01306.x

O’Callaghan, J. P., Kelly, K. A., VanGilder, R. L., Sofroniew, M. V., and Miller, D. B. (2014). Early activation of STAT3 regulates reactive astrogliosis induced by diverse forms of neurotoxicity. PLoS One 9:e102003. doi: 10.1371/journal.pone. 0102003

O’Neill, M. J., Murray, T. K., Lakics, V., Visanji, N. P., and Duty, S. (2002). The role of neuronal nicotinic acetylcholine receptors in acute and chronic neurodegeneration. Curr. Drug Targets CNS Neurol. Disord. 1, 399-411. doi: 10.2174/1568007023339166

Oliveira, J. F., Riedel, T., Leichsenring, A., Heine, C., Franke, H., Krügel, U., et al. (2011). Rodent cortical astroglia express in situ functional P2X 7 receptors sensing pathologically high ATP concentrations. Cereb. Cortex 21, 806-820. doi: $10.1093 /$ cercor/bhq154

Oria, M., Figueira, R. L., Scorletti, F., Sbragia, L., Owens, K., Li, Z., et al. (2018). CD200-CD200R imbalance correlates with microglia and pro-inflammatory activation in rat spinal cords exposed to amniotic fluid in retinoic acid-induced spina bifida. Sci. Rep. 8:10638. doi: 10.1038/s41598-01828829-5

Pabst, M., Braganza, O., Dannenberg, H., Hu, W., Pothmann, L., Rosen, J., et al. (2016). Astrocyte intermediaries of septal cholinergic modulation in the hippocampus. Neuron 90, 853-865. doi: 10.1016/j.neuron.2016.04.003

Pannell, M., Meier, M. A., Szulzewsky, F., Matyash, V., Endres, M., Kronenberg, G., et al. (2016). The subpopulation of microglia expressing functional muscarinic acetylcholine receptors expands in stroke and Alzheimer's disease. Brain Struct. Funct. 221, 1157-1172. doi: 10.1007/s00429014-0962-y

Parada, E., Egea, J., Buendia, I., Negredo, P., Cunha, A. C., Cardoso, S., et al. (2013). The microglial $\alpha 7$-acetylcholine nicotinic receptor is a key element in promoting neuroprotection by inducing heme oxygenase-1 via nuclear factor erythroid-2-related factor 2. Antioxidants Redox Signal. 19, 1135-1148. doi: $10.1093 / \mathrm{med} / 9780199794591.003 .0008$

Parhizkar, S., Arzberger, T., Brendel, M., Kleinberger, G., Deussing, M., Focke, C., et al. (2019). Loss of TREM2 function increases amyloid seeding but reduces plaque-associated ApoE. Nat. Neurosci. 22, 191-204. doi: 10.1038/s41593-0180296-9

Parisi, C., Napoli, G., Pelegrin, P., and Volonté, C. (2016). M1 and M2 functional imprinting of primary microglia: role of $\mathrm{P} 2 \mathrm{X} 7$ activation and miR-125b. Mediators Inflamm. 2016:2989548. doi: 10.1155/2016/2989548

Parkhurst, C. N., Yang, G., Ninan, I., Savas, J. N., Yates, J. R., Lafaille, J. J., et al. (2013). Microglia promote learning-dependent synapse formation through brain-derived neurotrophic factor. Cell 155, 1596-1609. doi: 10.1016/j.cell. 2013.11.030

Parpura, V., Basarsky, T. A., Liu, F., Jeftinija, K., Jeftinija, S., and Haydon, P. G. (1994). Glutamate-mediated astrocyte-neuron signalling. Nature 369, 744-747. doi: $10.1038 / 369744 \mathrm{a} 0$

Parvizi, J., Van Hoesen, G. W., and Damasio, A. (2001). The selective vulnerability of brainstem nuclei to Alzheimer's disease. Ann. Neurol. 49, 53-66. doi: 10.1002/1531-8249(200101)49:1<53::aid-ana30>3.0.co;2-q

Patel, H., McIntire, J., Ryan, S., Dunah, A., and Loring, R. (2017). Antiinflammatory effects of astroglial $\alpha 7$ nicotinic acetylcholine receptors are mediated by inhibition of the NF- $\mathrm{B}$ pathway and activation of the Nrf2 pathway. J. Neuroinflammation 14:192. doi: 10.1186/s12974-0170967-6

Patti, L., Raiteri, L., Grilli, M., Parodi, M., Raiteri, M., and Marchi, M. (2006). P2X7 receptors exert a permissive role on the activation of release-enhancing presynaptic $\alpha 7$ nicotinic receptors co-existing on rat neocortex glutamatergic terminals. Neuropharmacology 50, 705-713. doi: 10.1016/j.neuropharm.2005. 11.016

Pelvig, D. P., Pakkenberg, H., Stark, A. K., and Pakkenberg, B. (2008). Neocortical glial cell numbers in human brains. Neurobiol. Aging 29, 1754-1762. doi: 10.1016/j.neurobiolaging.2007.04.013

Perea, G., and Araque, A. (2005). Glial calcium signaling and neuron-glia communication. Cell Calcium 38, 375-382. doi: 10.1016/j.ceca.2005.06.015

Perosa, V., Priester, A., Ziegler, G., Cardenas-Blanco, A., Dobisch, L., Spallazzi, M., et al. (2020). Hippocampal vascular reserve associated with cognitive performance and hippocampal volume. Brain 143, 622-634. doi: 10.1093/brain/awz383

Perry, V. H., and Holmes, C. (2014). Microglial priming in neurodegenerative disease. Nat. Rev. Neurol. 10, 217-224. doi: 10.1038/nrneurol.2014.38

Phillips, R. J., and Powley, T. L. (2001). As the gut ages: timetables for aging of innervation vary by organ in the Fischer 344 rat. J. Comp. Neurol. 434, 358-377. doi: $10.1002 / \mathrm{cne} .1182$

Phillips, R. J., Walter, G. C., and Powley, T. L. (2010). Age-related changes in vagal afferents innervating the gastrointestinal tract. Auton. Neurosci. 153, 90-98. doi: 10.1016/j.autneu.2009.07.009 
Picciotto, M. R., and Zoli, M. (2002). Nicotinic receptors in aging and dementia. J. Neurobiol. 53, 641-655. doi: 10.1002/neu.10102

Pirttimaki, T. M., Codadu, N. K., Awni, A., Pratik, P., Nagel, D. A., Hill, E. J., et al. (2013). $\alpha 7$ nicotinic receptor-mediated astrocytic gliotransmitter release: $\mathrm{A} \beta$ effects in a preclinical Alzheimer's mouse model. PLoS One 8:e81828. doi: 10.1371 /journal.pone.0081828

Prado, V. F., Janickova, H., Al-Onaizi, M. A., and Prado, M. A. M. (2017). Cholinergic circuits in cognitive flexibility. Neuroscience 345, 130-141. doi: $10.1016 /$ j.neuroscience.2016.09.013

Pym, L., Kemp, M., Raymond-Delpech, V., Buckingham, S., Boyd, C. A. R., and Sattelle, D. (2005). Subtype-specific actions of $\beta$-amyloid peptides on recombinant human neuronal nicotinic acetylcholine receptors $(\alpha 7, \alpha 4 \beta 2$, a334) expressed in Xenopus laevis oocytes. Br. J. Pharmacol. 146, 964-971. doi: 10.1038/sj.bjp.0706403

Ransohoff, R. M. (2016). A polarizing question: do M1 and M2 microglia exist. Nat. Neurosci. 19, 987-991. doi: 10.1038/nn.4338

Ransohoff, R. M., and Cardona, A. E. (2010). The myeloid cells of the central nervous system parenchyma. Nature 468, 253-262. doi: 10.1038/nature 09615

Ransohoff, R. M., and El Khoury, J. (2016). Microglia in health and disease. Cold Spring Harb. Perspect. Biol. 8, 1-15. doi: 10.1101/cshperspect.a020560

Reid, R. T., Sabbagh, M. N., CoreyBloom, J., Tiraboschi, P., and Thal, L. J. (2000). Nicotinic receptor losses in dementia with Lewy bodies: comparisons with Alzheimer's disease. Neurobiol. Aging 21, 741-746. doi: 10.1016/s01974580(00)00168-8

Rinne, J. O., Myllykylä, T., Lönnberg, P., and Marjamäki, P. (1991). A postmortem study of brain nicotinic receptors in Parkinson's and Alzheimer's disease. Brain Res. 547, 167-170. doi: 10.1016/0006-8993(91)90588-m

Rocha, S. M., Cristovão, A. C., Campos, F. L., Fonseca, C. P., and Baltazar, G. (2012). Astrocyte-derived GDNF is a potent inhibitor of microglial activation. Neurobiol. Dis. 47, 407-415. doi: 10.1016/j.nbd.2012.04.014

Rock, R. B., Gekker, G., Aravalli, R. N., Hu, S., Sheng, W. S., and Peterson, P. K. (2008). Potentiation of HIV-1 expression in microglial cells by nicotine: involvement of transforming growth factor- $\beta 1$. J. Neuroimmune Pharmacol. 3 , 143-149. doi: 10.1007/s11481-007-9098-7

Rosczyk, H. A., Sparkman, N. L., and Johnson, R. W. (2008). Neuroinflammation and cognitive function in aged mice following minor surgery. Exp. Gerontol. 43, 840-846. doi: 10.1016/j.exger.2008.06.004

Rothhammer, V., Borucki, D. M., Tjon, E. C., Takenaka, M. C., Chao, C. C., Ardura-Fabregat, A., et al. (2018). Microglial control of astrocytes in response to microbial metabolites. Nature 557, 724-728. doi: 10.1038/s41586-018$0119-\mathrm{x}$

Ryan, R. E., Ross, S. A., Drago, J., and Loiacono, R. E. (2001). Dose-related neuroprotective effects of chronic nicotine in 6-hydroxydopamine treated rats and loss of neuroprotection in $\alpha 4$ nicotinic receptor subunit knockout mice. $B r$. J. Pharmacol. 132, 1650-1656. doi: 10.1038/sj.bjp.0703989

Sarlus, H., and Heneka, M. T. (2017). Microglia in Alzheimer's disease. J. Clin. Invest. 127, 3240-3249. doi: 10.1083/jcb.201709069

Sarter, M., and Bruno, J. P. (2004). Developmental origins of the age-related decline in cortical cholinergic function and associated cognitive abilities. Neurobiol. Aging 25, 1127-1139. doi: 10.1016/j.neurobiolaging.2003.11.011

Sato, A., and Sato, Y. (1995). Cholinergic neural regulation of regional cerebral blood flow. Alzheimer Dis. Assoc. Disord. 9, 28-38. doi: 10.1097/00002093199505000-00007

Sato, A., Sato, Y., and Uchida, S. (2004). Activation of the intracerebral cholinergic nerve fibers originating in the basal forebrain increases regional cerebral blood flow in the rat's cortex and hippocampus. Neurosci. Lett. 361, 90-93. doi: 10.1016/j.neulet.2004.01.004

Schliebs, R., and Arendt, T. (2011). The cholinergic system in aging and neuronal degeneration. Behav. Brain Res. 221, 555-563. doi: 10.1016/j.bbr.2010.11.058

Schmitz, T. W., Mur, M., Aghourian, M., Bedard, M. A., and Spreng, R. N. (2018). Longitudinal Alzheimer's degeneration reflects the spatial topography of cholinergic basal forebrain projections. Cell Rep. 24, 38-46. doi: 10.1016/j. celrep.2018.06.001

Schmitz, T. W., and Nathan Spreng, R. (2016). Basal forebrain degeneration precedes and predicts the cortical spread of Alzheimer's pathology. Nat. Commun. 7:13249. doi: 10.1038/ncomms13249
Schmitz, T. W., Soreq, H., Poirier, J., and Spreng, R. N. (2020). Longitudinal basal forebrain degeneration interacts with TREM2/C3 biomarkers of inflammation in presymptomatic Alzheimer's disease. J. Neurosci. 40, 1931-1942. doi: 10.1523/jneurosci.1184-19.2019

Schuitemaker, A., van der Doef, T. F., Boellaard, R., van der Flier, W. M., Yaqub, M., Windhorst, A. D., et al. (2012). Microglial activation in healthy aging. Neurobiol. Aging 33, 1067-1072. doi: 10.1016/j.neurobiolaging.2010. 09.016

Seigneur, J., Kroeger, D., Nita, D. A., and Amzica, F. (2006). Cholinergic action on cortical glial cells in vivo. Cereb. Cortex 16, 655-668. doi: 10.1093/cercor/bhj011

Sfera, A., Gradini, R., Cummings, M., Diaz, E., Price, A. I., and Osorio, C. (2018). Rusty microglia: trainers of innate immunity in Alzheimer's disease. Front. Neurol. 9:1062. doi: 10.3389/fneur.2018.01062

Shah, G. N., and Mooradian, A. D. (1997). Age-related changes in the blood-brain barrier. Exp. Gerontol. 32, 501-519.

Shaw, S., Bencherif, M., and Marrero, M. B. (2002). Janus kinase 2, an early target of $\alpha 7$ nicotinic acetylcholine receptor-mediated neuroprotection against $A \beta$ (1-42) amyloid. J. Biol. Chem. 277, 44920-44924. doi: 10.1074/jbc.M204610200

Shen, J. X., and Yakel, J. L. (2009). Nicotinic acetylcholine receptor-mediated calcium signaling in the nervous system. Acta Pharmacol. Sin. 30, 673-680. doi: 10.1038/aps.2009.64

Shinozaki, Y., Shibata, K., Yoshida, K., Shigetomi, E., Gachet, C., Ikenaka, K., et al. (2017). Transformation of astrocytes to a neuroprotective phenotype by microglia via p2y1 receptor downregulation. Cell Rep. 19, 1151-1164. doi: 10.1016/j.celrep.2017.04.047

Shrivastava, K., Gonzalez, P., and Acarin, L. (2012). The immune inhibitory complex CD200/CD200R is developmentally regulated in the mouse brain J. Comp. Neurol. 520, 2657-2675. doi: 10.1002/cne.23062

Shytle, R. D., Mori, T., Townsend, K., Vendrame, M., Sun, N., Zeng, J., et al. (2004). Cholinergic modulation of microglial activation by $\alpha 7$ nicotinic receptors. J. Neurochem. 89, 337-343. doi: 10.1046/j.1471-4159.2004.02347.x

Sidoryk-Wegrzynowicz, M., Wegrzynowicz, M., Lee, E., Bowman, A. B., and Aschner, M. (2011). Role of astrocytes in brain function and disease. Toxicol. Pathol. 39, 115-123. doi: 10.1177/0192623310385254

Sierra, A., Gottfried-Blackmore, A. C., Mcewen, B. S., and Bulloch, K. (2007). Microglia derived from aging mice exhibit an altered inflammatory profile. Glia 55, 412-424. doi: 10.1002/glia.20468

Sobrado-Calvo, P., Vidal-Sanz, M., and Villegas-Pérez, M. P. (2007). Rat retinal microglial cells under normal conditions, after optic nerve section and after optic nerve section and intravitreal injection of trophic factors or macrophage inhibitory factor. J. Comp. Neurol. 501, 866-878. doi: 10.1002/cne. 21279

Sochocka, M., Diniz, B. S., and Leszek, J. (2017). Inflammatory response in the CNS: friend or foe? Mol. Neurobiol. 54, 8071-8089. doi: 10.1007/s12035-0160297-1

Sofroniew, M. V. (2009). Molecular dissection of reactive astrogliosis and glial scar formation. Trends Neurosci. 32, 638-647. doi: 10.1016/j.tins.2009.08.002

Sofroniew, M. V. (2015). Astrogliosis. Cold Spring Harb. Perspect. Biol. 7:a020420. doi: $10.1101 /$ cshperspect.a020420

Solari, N., and Hangya, B. (2018). Cholinergic modulation of spatial learning, memory and navigation. Eur. J. Neurosci. 48, 2199-2230. doi: 10.1111/ejn. 14089

Soleimannejad, E., Naghdi, N., Semnanian, S., Fathollahi, Y., and Kazemnejad, A. (2007). Antinociceptive effect of intra-hippocampal CA1 and dentate gyrus injection of MK801 and AP5 in the formalin test in adult male rats. Eur. J. Pharmacol. 562, 39-46. doi: 10.1016/j.ejphar.2006.11.051

Sorensen, E. W., Lian, J., Ozga, A. J., Miyabe, Y., Ji, S. W., Bromley, S. K., et al. (2018). CXCL10 stabilizes T cell-brain endothelial cell adhesion leading to the induction of cerebral malaria. JCI Insight 3:e98911. doi: 10.1172/jci.insight. 98911

Streit, W. J., Sammons, N. W., Kuhns, A. J., and Sparks, D. L. (2004). Dystrophic microglia in the aging human brain. Glia 45, 208-212. doi: 10.1002/glia. 10319

Suarez, A. N., Hsu, T. M., Liu, C. M., Noble, E. E., Cortella, A. M., Nakamoto, E. M., et al. (2018). Gut vagal sensory signaling regulates hippocampus function through multi-order pathways. Nat. Commun. 9:2181. doi: 10.1038/s41467018-04639-1 
Surendranathan, A., Su, L., Mak, E., Passamonti, L., Hong, Y. T., Arnold, R., et al. (2018). Early microglial activation and peripheral inflammation in dementia with Lewy bodies. Brain 141, 3415-3427. doi: 10.1093/brain/awy265

Suzuki, T., Hide, I., Ido, K., Kohsaka, S., Inoue, K., and Nakata, Y. (2004). Production and release of neuroprotective tumor necrosis factor by P2X 7 receptor-activated microglia. J. Neurosci. 24, 1-7. doi: 10.1523/jneurosci. 3792-03.2004

Suzuki, T., Hide, I., Matsubara, A., Hama, C., Harada, K., Miyano, K., et al. (2006). Microglial $\alpha 7$ nicotinic acetylcholine receptors drive a phospholipase C/IP3 pathway and modulate the cell activation toward a neuroprotective role. J. Neurosci. Res. 83, 1461-1470. doi: 10.1002/jnr.20850

Szutowicz, A., Bielarczyk, H., Jankowska-Kulawy, A., Paweczyk, T., and Ronowska, A. (2013). Acetyl-CoA the key factor for survival or death of cholinergic neurons in course of neurodegenerative diseases. Neurochem. Res. 38, 1523-1542. doi: 10.1007/s11064-013-1060-x

Takács, V. T., Cserép, C., Schlingloff, D., Pósfai, B., Szönyi, A., Sos, K. E., et al. (2018). Co-transmission of acetylcholine and GABA regulates hippocampal states. Nat. Commun. 9:2848. doi: 10.1038/s41467-018-05136-1

Takata, K., Amamiya, T., Mizoguchi, H., Kawanishi, S., Kuroda, E., Kitamura, R., et al. (2018). $\alpha 7$ nicotinic acetylcholine receptor-specific agonist DMXBA (GTS-21) attenuates $A \beta$ accumulation through suppression of neuronal $\gamma$-secretase activity and promotion of microglial amyloid- $\beta$ phagocytosis and ameliorates cognitive impairment in a mouse mode. Neurobiol. Aging 62, 197-209. doi: 10.1016/j.neurobiolaging.2017.10.021

Takata, K., Kitamura, Y., Saeki, M., Terada, M., Kagitani, S., Kitamura, R., et al. (2010). Galantamine-induced amyloid- $\beta$ clearance mediated via stimulation of microglial nicotinic acetylcholine receptors. J. Biol. Chem. 285, 40180-40191. doi: $10.1074 /$ jbc.M110.142356

Takeda, S., Sato, N., and Morishita, R. (2014). Systemic inflammation, blood-brain barrier vulnerability and cognitive/non-cognitive symptoms in Alzheimer disease: relevance to pathogenesis and therapy. Front. Aging Neurosci. 6:171. doi: 10.3389/fnagi.2014.00171

Talantova, M., Sanz-Blasco, S., Zhang, X., Xia, P., Akhtar, M. W., Okamoto, S. I., et al. (2013). A $\beta$ induces astrocytic glutamate release, extrasynaptic NMDA receptor activation, and synaptic loss. Proc. Natl. Acad. Sci. U S A 110, E2518-E2527. doi: 10.1073/pnas.1306832110

Tan, Y. L., Yuan, Y., and Tian, L. (2020). Microglial regional heterogeneity and its role in the brain. Mol. Psychiatry 25, 351-367. doi: 10.1038/s41380-019-0609-8

Tanaka, S., Ide, M., Shibutani, T., Ohtaki, H., Numazawa, S., Shioda, S., et al. (2006). Lipopolysaccharide-induced microglial activation induces learning and memory deficits without neuronal cell deathin rats. J. Neurosci. Res. 83, 557-566. doi: 10.1002/jnr.20752

Tanuma, N., Sakuma, H., Sasaki, A., and Matsumoto, Y. (2006). Chemokine expression by astrocytes plays a role in microglia/macrophage activation and subsequent neurodegeneration in secondary progressive multiple sclerosis. Acta Neuropathol. 112, 195-204. doi: 10.1007/s00401-006-0083-7

Teaktong, T., Graham, A. J., Court, J. A., Perry, R. H., Jaros, E., Johnson, M., et al. (2004). Nicotinic acetylcholine receptor immunohistochemistry in Alzheimer's disease and dementia with Lewy bodies: differential neuronal and astroglial pathology. J. Neurol. Sci. 225, 39-49. doi: 10.1016/j.jns.2004.06.015

Teaktong, T., Graham, A., Court, J., Perry, R., Jaros, E., Johnson, M., et al. (2003). Alzheimer's disease is associated with a selective increase in $\alpha 7$ nicotinic acetylcholine receptor immunoreactivity in astrocytes. Glia 41, 207-211. doi: $10.1002 /$ glia. 10132

Thayer, J. F., and Sternberg, E. M. (2010). Neural aspects of immunomodulation: focus on the vagus nerve. Brain Behav. Immun. 24, 1223-1228. doi: 10.1016/j. bbi.2010.07.247

Tiraboschi, P., Hansen, L. A., Alford, M., Merdes, A., Masliah, E., Thal, L. J., et al. (2002). Early and widespread cholinergic losses differentiate dementia with Lewy bodies from Alzheimer disease. Arch. Gen. Psychiatry 59, 946-951. doi: $10.1001 /$ archpsyc.59.10.946

Togo, T., Iseki, E., Marui, W., Akiyama, H., Uéda, K., and Kosaka, K. (2001). Glial involvement in the degeneration process of Lewy body-bearing neurons and the degradation process of Lewy bodies in brains of dementia with Lewy bodies. J. Neurol. Sci. 184, 71-75. doi: 10.1016/s0022-510x(00)00498-6

Tohgi, H., Utsugisawa, K., Yoshimura, M., Nagane, Y., and Mihara, M. (1998). Age-related changes in nicotinic acetylcholine receptor subunits $\alpha 4$ and $\beta 2$ messenger RNA expression in postmortem human frontal cortex and hippocampus. Neurosci. Lett. 245, 139-142. doi: 10.1016/s0304-3940(98) 00205-5

Tohidpour, A., Morgun, A. V., Boitsova, E. B., Malinovskaya, N. A., Martynova, G. P., Khilazheva, E. D., et al. (2017). Neuroinflammation and infection: molecular mechanisms associated with dysfunction of neurovascular unit. Front. Cell. Infect. Microbiol. 7:276. doi: 10.3389/fcimb.2017. 00276

Turnbull, M. T., and Coulson, E. J. (2017). Cholinergic basal forebrain lesion decreases neurotrophin signaling without affecting tau hyperphosphorylation in genetically susceptible mice. J. Alzheimers Dis. 55, 1141-1154. doi: 10.3233/ jad- 160805

Utkin, Y. N. (2019). Aging affects nicotinic acetylcholine receptors in brain. Cent. Nerv. Syst. Agents Med. Chem. 19, 119-124. doi: 10.2174/ 1871524919666190320102834

Vainchtein, I. D., and Molofsky, A. V. (2020). Astrocytes and microglia: in sickness and in health. Trends Neurosci. 49, 73-95. doi: 10.1016/j.tins.2020.01.003

Valenstein, E. S. (2002). The discovery of chemical neurotransmitters. Brain Cogn. 49, 73-95. doi: 10.1006/brcg.2001.1487

Van Beek, A. H. E. A., and Claassen, J. A. H. R. (2011). The cerebrovascular role of the cholinergic neural system in Alzheimer's disease. Behav. Brain Res. 221 , 537-542. doi: 10.1016/j.bbr.2009.12.047

Van Rossum, D., and Hanisch, U. K. (2004). Microglia. Metab. Brain Dis. 19, 393-411. doi: 10.1023/b:mebr.0000043984.73063.d8

VanGuilder, H. D., Bixler, G. V., Brucklacher, R. M., Farley, J. A., Yan, H., Warrington, J. P., et al. (2011). Concurrent hippocampal induction of MHC II pathway components and glial activation with advanced aging is not correlated with cognitive impairment. J. Neuroinflammation 8:138. doi: 10.1186/17422094-8-138

Verkhratsky, A. (2006). Glial calcium signaling in physiology and pathophysiology. Acta Pharmacol. Sin. 27, 773-780. doi: 10.1111/j.17457254.2006.00396.x

Verkhratsky, A., and Kettenmann, H. (1996). Calcium signalling in glial cells. Trends Neurosci. 19, 346-352. doi: 10.1016/0166-2236(96)10048-5

Veroni, C., Gabriele, L., Canini, I., Castiello, L., Coccia, E., Remoli, M. E., et al. (2010). Activation of TNF receptor 2 in microglia promotes induction of anti-inflammatory pathways. Mol. Cell. Neurosci. 45, 234-244. doi: 10.1016/j. men.2010.06.014

Volterra, A., and Meldolesi, J. (2005). Astrocytes, from brain glue to communication elements: the revolution continues. Nat. Rev. Neurosci. 6, 626-640. doi: 10.1038/nrn1722

Wagner, K. R., Sharp, F. R., Ardizzone, T. D., Lu, A., and Clark, J. F. (2003). Heme and iron metabolism: role in cerebral hemorrhage. J. Cereb. Blood Flow Metab. 23, 629-652. doi: 10.1097/01.wcb.0000073905.87928.6d

Walker, J. A., Low, K. A., Fletcher, M. A., Cohen, N. J., Gratton, G., and Fabiani, M. (2017). Hippocampal structure predicts cortical indices of reactivation of related items. Neuropsychologia 95, 182-192. doi: 10.1016/j.neuropsychologia. 2016.12.005

Walter, U., Tsiberidou, P., Kersten, M., Storch, A., and Löhle, M. (2018). Atrophy of the vagus nerve in Parkinson's disease revealed by high-resolution ultrasonography. Front. Neurol. 9:805. doi: 10.3389/fneur.2018.00805

Wenk, G. L., McGann, K., Mencarelli, A., Hauss-Wegrzyniak, B., Del Soldato, P., and Fiorucci, S. (2000). Mechanisms to prevent the toxicity of chronic neuroinflammation on forebrain cholinergic neurons. Eur. J. Pharmacol. 402, 77-85. doi: 10.1016/s0014-2999(00)00523-9

Wes, P. D., Holtman, I. R., Boddeke, E. W. G. M., Möller, T., and Eggen, B. J. L. (2016). Next generation transcriptomics and genomics elucidate biological complexity of microglia in health and disease. Glia 64, 197-213. doi: 10.1002/glia.22866

West, C. L., Amin, J. Y., Farhin, S., Stanisz, A. M., Mao, Y.-K., and Kunze, W. A. (2019). Colonic motility and jejunal vagal afferent firing rates are decreased in aged adult male mice and can be restored by an aminosterol. Front. Neurosci. 13:955. doi: 10.3389/fnins.2019.00955

Wolf, S. A., Boddeke, H. W. G. M., and Kettenmann, H. (2017). Microglia in physiology and disease. Annu. Rev. Physiol. 79, 619-643. doi: 10.1146/annurevphysiol-022516-034406

Wolfe, C. M., Fitz, N. F., Nam, K. N., Lefterov, I., and Koldamova, R. (2019). The role of APOE and TREM2 in Alzheimer's disease-current understanding and perspectives. Int. J. Mol. Sci. 20:81. doi: 10.3390/ijms20010081 
Wong, W. T. (2013). Microglial aging in the healthy CNS: phenotypes, drivers, and rejuvenation. Front. Cell. Neurosci. 7:22. doi: 10.3389/fncel.2013. 00022

Woolf, N. J., Jacobs, R. W., and Butcher, L. L. (1989). The pontomesencephalotegmental cholinergic system does not degenerate in Alzheimer's disease. Neurosci. Lett. 96, 277-282. doi: 10.1016/0304-3940(89) 90391-1

Wu, H., Williams, J., and Nathans, J. (2014). Complete morphologies of basal forebrain cholinergic neurons in the mouse. eLife 3:e02444. doi: 10.7554/eLife. 02444

Wu, L., Zhang, K., Hu, G., Yang, H., Xie, C., and Wu, X. (2014). Inflammatory response and neuronal necrosis in rats with cerebral ischemia. Neural Regen. Res. 9, 1753-1762. doi: 10.4103/1673-5374.143419

Wurtman, R. J. (1992). Choline metabolism as a basis for the selective vulnerability of cholinergic neurons. Trends Neurosci. 15, 117-122. doi: 10.1016/01662236(92)90351-8

Xie, Z., Morgan, T. E., Rozovsky, I., and Finch, C. E. (2003). Aging and glial responses to lipopolysaccharide in vitro: Greater induction of IL-1 and IL-6, but smaller induction of neurotoxicity. Exp. Neurol. 182, 135-141. doi: 10.1016/s0014-4886(03)00057-8

Xiu, J., Nordberg, A., Zhang, J. T., and Guan, Z. Z. (2005). Expression of nicotinic receptors on primary cultures of rat astrocytes and up-regulation of the $\alpha 7, \alpha 4$ and $\beta 2$ subunits in response to nanomolar concentrations of the $\beta$ amyloid peptide1-42. Neurochem. Int. 47, 281-290. doi: 10.1016/j.neuint.2005. 04.023

Yang, T., Xiao, T., Sun, Q., and Wang, K. (2017). The current agonists and positive allosteric modulators of $\alpha 7 \mathrm{nAChR}$ for CNS indications in clinical trials. Acta Pharm. Sin. B 7, 611-622. doi: 10.1016/j.apsb.2017. 09.001

Ye, S. M., and Johnson, R. W. (2001). An age-related decline in interleukin-10 may contribute to the increased expression of interleukin-6 in brain of aged mice. Neuroimmunomodulation 9, 183-192. doi: 10.1159/0000 49025

You, P., Fu, S., Yu, K., Xia, Y., Wu, H., Yang, Y., et al. (2018). Scutellarin suppresses neuroinflammation via the inhibition of the AKT/NF-kB and p38/JNK pathway in LPS-induced BV-2 microglial cells. Naunyn. Schmiedebergs. Arch. Pharmacol. 391, 743-751. doi: 10.1007/s00210-018-1503-7

Zaborszky, L., van den Pol, A., and Gyengesi, E. (2012). "Chapter 28 - The basal forebrain cholinergic projection system in mice," in The Mouse Nervous System. eds C. Watson, G. Paxinos, and L. Puelles (USA: Academic Press), 684-718 doi: 10.1016/B978-0-12-369497-3.10028-7
Zamanian, J. L., Xu, L., Foo, L. C., Nouri, N., Zhou, L., Giffard, R. G., et al. (2012). Genomic analysis of reactive astrogliosis. J. Neurosci. 32, 6391-6410. doi: 10.1523/JNEUROSCI.6221-11.2012

Zhang, D., Hu, X., Qian, L., O'Callaghan, J. P., and Hong, J. S. (2010). Astrogliosis in CNS pathologies: is there a role for microglia? Mol. Neurobiol. 41, 232-241. doi: 10.1007/s12035-010-8098-4

Zhang, D., Hu, X., Qian, L., Wilson, B., Lee, C., Flood, P., et al. (2009). Prostaglandin E2 released from activated microglia enhances astrocyte proliferation in vitro. Toxicol. Appl. Pharmacol. 238, 64-70. doi: 10.1016/j.taap. 2009.04.015

Zhang, J., and Rivest, S. (2001). Anti-inflammatory effects of prostaglandin E2 in the central nervous system in response to brain injury and circulating lipopolysaccharide. J. Neurochem. 76, 855-864. doi: 10.1046/j.1471-4159.2001. 00080.x

Zhai, Q., Lai, D., Cui, P., Zhou, R., Chen, Q., Hou, J., et al. (2017). Selective activation of basal forebrain cholinergic neurons attenuates polymicrobial sepsis-induced inflammation via the cholinergic anti-inflammatory pathway. Crit. Care Med. 45, e1075-e1082. doi: 10.1097/ccm.0000000000002646

Zhao, Y. W., Pan, Y. Q., Tang, M. M., and Lin, W. J. (2018). Blocking p38 signaling reduces the activation of pro-inflammatory cytokines and the phosphorylation of p38 in the habenula and reverses depressive-like behaviors induced by neuroinflammation. Front. Pharmacol. 9:511. doi: 10.3389/fphar. 2018.00511

Zila, I., Mokra, D., Kopincova, J., Kolomaznik, M., Javorka, M., and Calkovska, A. (2017). Vagal-immune interactions involved in cholinergic anti-inflammatory pathway. Physiol. Res. 66, S139-S145. doi: 10.33549/physiolres.933671

Zoli, M., Picciotto, M. R., Ferrari, R., Cocchi, D., and Changeux, J. P. (1999). Increased neurodegeneration during ageing in mice lacking high-affinity nicotine receptors. EMBO J. 18, 1235-1244. doi: 10.1093/emboj/18.5.1235

Conflict of Interest: The authors declare that the research was conducted in the absence of any commercial or financial relationships that could be construed as a potential conflict of interest.

Copyright (c) 2020 Gamage, Wagnon, Rossetti, Childs, Niedermayer, Chesworth and Gyengesi. This is an open-access article distributed under the terms of the Creative Commons Attribution License (CC BY). The use, distribution or reproduction in other forums is permitted, provided the original author(s) and the copyright owner(s) are credited and that the original publication in this journal is cited, in accordance with accepted academic practice. No use, distribution or reproduction is permitted which does not comply with these terms. 